\title{
Health Resource Availability, State Policy, and Cardiovascular Health in U.S. Adults
}

\author{
Courtney S. Pilkerton
}

Follow this and additional works at: https://researchrepository.wvu.edu/etd

\section{Recommended Citation}

Pilkerton, Courtney S., "Health Resource Availability, State Policy, and Cardiovascular Health in U.S. Adults" (2015). Graduate Theses, Dissertations, and Problem Reports. 6421.

https://researchrepository.wvu.edu/etd/6421

This Dissertation is protected by copyright and/or related rights. It has been brought to you by the The Research Repository @ WVU with permission from the rights-holder(s). You are free to use this Dissertation in any way that is permitted by the copyright and related rights legislation that applies to your use. For other uses you must obtain permission from the rights-holder(s) directly, unless additional rights are indicated by a Creative Commons license in the record and/ or on the work itself. This Dissertation has been accepted for inclusion in WVU Graduate Theses, Dissertations, and Problem Reports collection by an authorized administrator of The Research Repository @ WVU.

For more information, please contact researchrepository@mail.wvu.edu. 
Health Resource Availability, State Policy, and Cardiovascular Health in U.S. Adults

Courtney S. Pilkerton, BA

Dissertation submitted

to the School of Public Health

at West Virginia University

in partial fulfillment of the requirements for the degree of

Doctor of Philosophy in

Public Health Sciences, Epidemiology

Stephanie J. Frisbee PhD, Co-Chair

Thomas K. Bias PhD, Co-Chair

Matthew J. Gurka PhD

Motao Zhu MD PhD

Thomas Hulsey M.S.P.H., Sc.D

Peter R. Giacobbi PhD

Donald M. Lloyd-Jones MD, ScM

Department of Epidemiology

Morgantown, West Virginia

2015

Keywords: cardiovascular health, health policy, Life's Simple 7, health resources

Copyright 2015 Courtney S. Pilkerton, BA 


\section{ABSTRACT \\ Health Resource Availability, State Policy, and Cardiovascular Health in U.S. Adults \\ Courtney S. Pilkerton}

Introduction: Despite advances in treatment and decreases in risk factors, more than 80 million Americans are living with cardiovascular disease and it remains the cause of 1 in 3 deaths in the United States. A thorough understanding of health determinants requires inclusion of factors at multiple levels of proximity to individuals. The overall objective of this project is to determine the associations between cardiovascular health and socioeconomic and demographic factors, health resource availability, and state health resource policies. The central hypothesis of this project is that higher cardiovascular health is associated with having evidence-based policies that promote the availability of health care resources, particularly those that support preventive and primary care.

Methods: 2011 Behavioral Risk Factor Surveillance System survey data were used to calculate American Heart Association's cardiovascular health index (CVHI) for individuals. County variables were abstracted from Area Health Resource File. Poisson regression was used to determine the association between individual/county/state characteristics and $\mathrm{CVHI}$.

Results: County population attainment of Healthy People 2010 objectives of cardiovascular health components was very low. CVHI was poorest in the Southeast and Appalachian regions. $\mathrm{CVHI}$ decreased from $3.73 \pm 0.01$ in 2003 to $3.45 \pm 0.01$ in 2011 . The majority of states experienced decreases in mean $\mathrm{CVHI}$ and an increase in the prevalence of poor $\mathrm{CVHI}$ in their population between 2003 and 2009. Educational attainment, whether at the individual level or county level, had a comparatively large influence on $\mathrm{CVHI}$ when compared with other factors. While individual factors had the greatest impact on individual CVHI, community characteristics were able to modify the relationship between individual characteristics and $\mathrm{CVHI}$. The poorest individuals benefited from living in higher income areas while higher income individuals benefited when in lower income areas. Higher density of an individual's race/ethnicity in their community was associated with higher CVHI. Primary care physician and physician assistant supply were positively associated with $\mathrm{CVHI}$ in both community and individual-level analysis. Those individuals deriving the largest marginal benefit from increased primary care provider supply were middle aged, non-Hispanic other race/ethnicity, female, lived in a non-urban community, had a household income less than $\$ 25,000$ per year, and lived in a community with low insurance coverage. Policies with the potential to increase the autonomy of primary care physicians and nurse practitioners or decrease barriers in their ability to practice were associated with higher $\mathrm{CVHI}$ even after controlling for provider supply.

Conclusions: This project adds to the understanding of the determinants of individual cardiovascular health by examining factors at the organizational, community, and policy levels. Interactions suggest feedback loops that create differential advantage to certain populations and may potentially increase disparities over time. These contributions are significant because they allow policymakers and public health officials to make more informed decisions about the environments and types of policies that when in place may improve cardiovascular health. 


\section{Dedication}

To my husband and family who have always supported my goals and kept me grounded, I could not have been successful without you. I love you and thank you for always being there.

\section{Acknowledgements}

I want to thank my mentors, Dr. Stephanie J. Frisbee and Dr. Thomas K. Bias, for all the many hours of time and effort they dedicated to me, my committee members, Dr. Matthew J. Gurka, Dr. Motao Zhu, Dr. Thomas Hulsey, and Dr. Peter R. Giacobbi, for providing technical help and mentoring throughout this process, and Dr. Donald Lloyd-Jones for his advice and encouragement along the way. I also want to thank Kayla Briggs and Dr. Greg Elmes for all their assistance as I tried to learn the often frustrating ins and outs of the GIS world and the Center for Cardiovascular and Respiratory Sciences and the Health Research Center for their support in space, equipment, and funding.

To the students in the School of Public Health and the MDPhD program, I will always appreciate the honest feedback and unconditional support as we navigated through our time together at WVU. To the faculty and staff in the School of Public Health and School of Medicine, I thank the many who always had an open door for questions and a friendly face when circumstances were beyond all of our control. 


\section{Table of Contents}

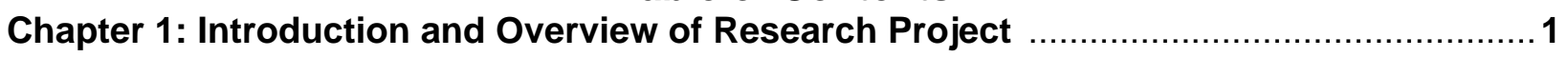

1.1 Cardiovascular Disease Burden in the United States .................................................. 1

1.2 Traditional Measurement of Cardiovascular Disease .............................................. 1

1.3 American Heart Association Cardiovascular Health Index ....................................... 2

1.4 Determinants of Cardiovascular Health and Gaps in the Literature .................................. 4

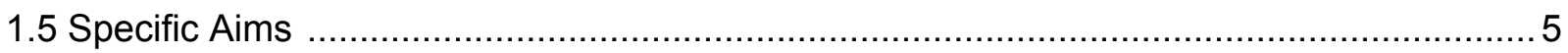

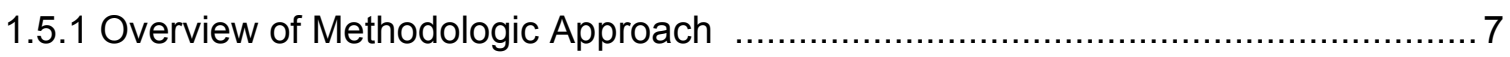

1.5.2 Aim 1: State trends, sociodemographic factors, and cardiovascular health ........... 9

1.5.3 Aim 2: Health care resource supply and cardiovascular health .......................... 9

1.5.4 Aim 3: State health care resource policy and cardiovascular health ....................11

Chapter 2: (Manuscript 1 - Pre-Proposal Aim) Cardiovascular Health in U.S. Counties: Community Sociodemographic Predictors of County-Level Cardiovascular Health ........12

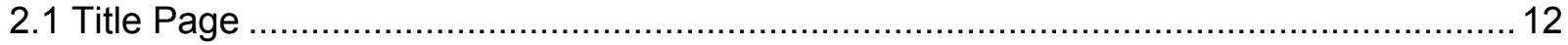

2.2 Abstract

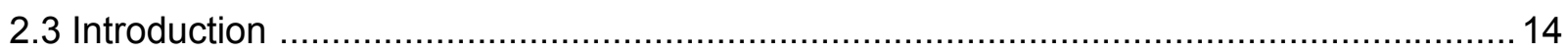

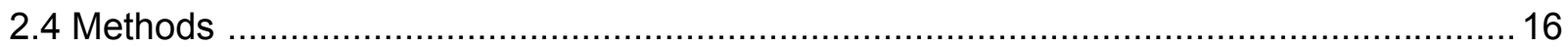

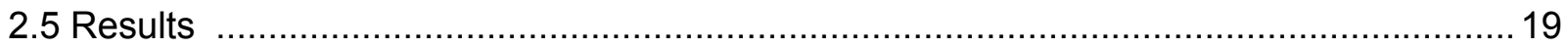

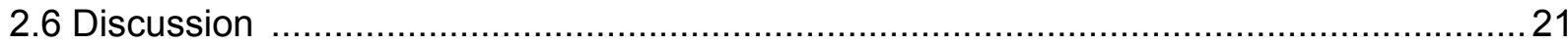

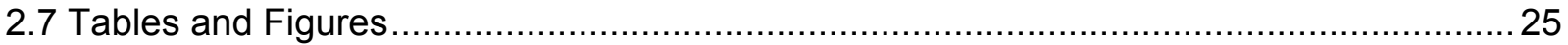

Chapter 3: (Manuscript 2 - Aim 1: Objective 1) Influence of individual and community socioeconomic factors on cardiovascular health in the United States .............................32

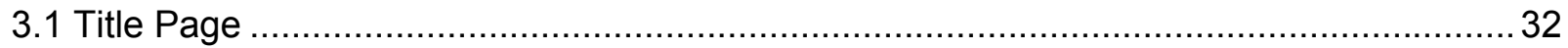

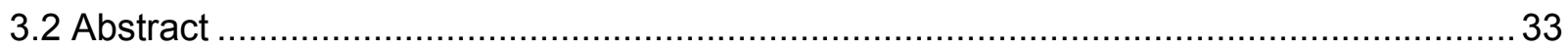

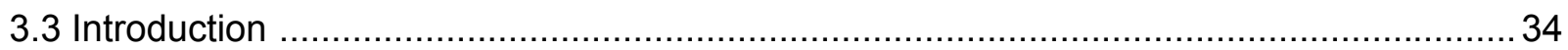

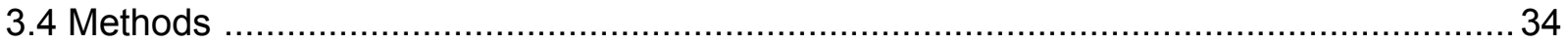

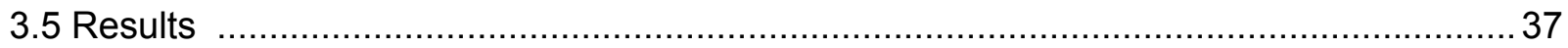

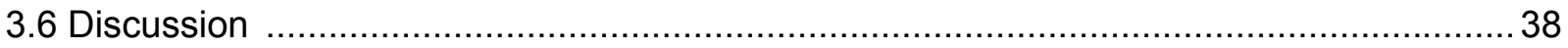

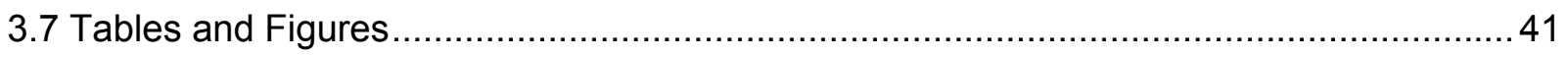

Chapter 4: (Manuscript 3 - Aim 1: Objective 2) Changes in Cardiovascular Health in the

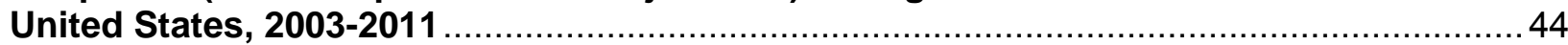

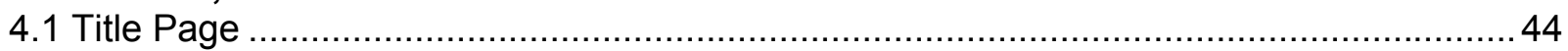

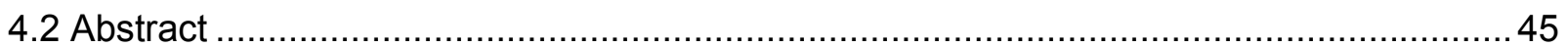

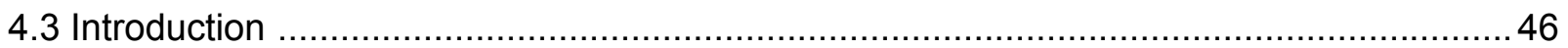

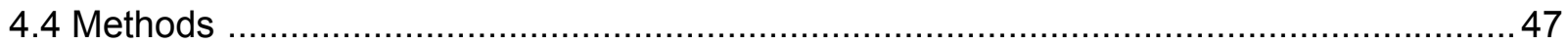




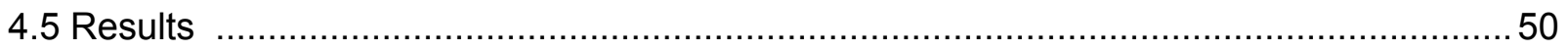

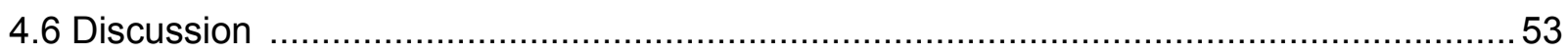

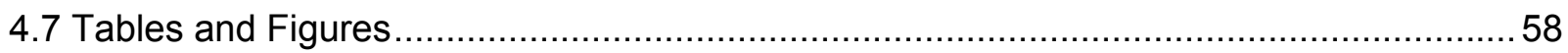

Chapter 5: (Manuscript 4 - Aim 2) Health care resource availability and cardiovascular

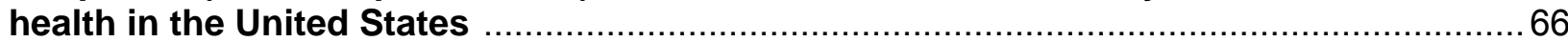

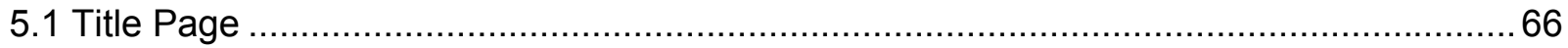

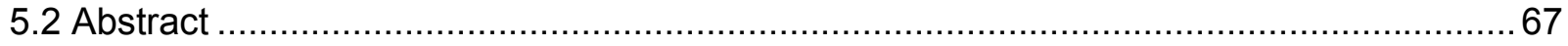

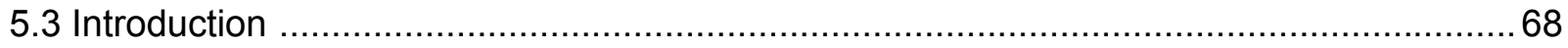

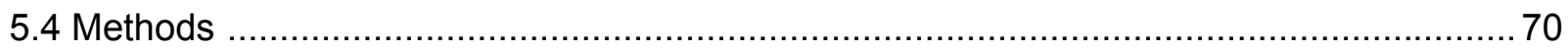

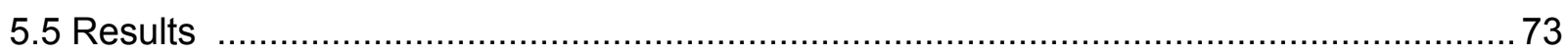

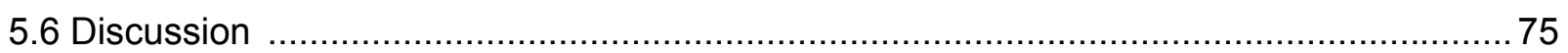

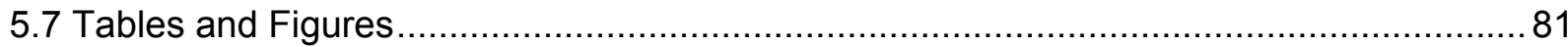

Chapter 6: (Manuscript 5 - Aim 3) Health care resource policy and cardiovascular health

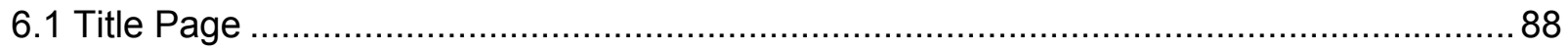

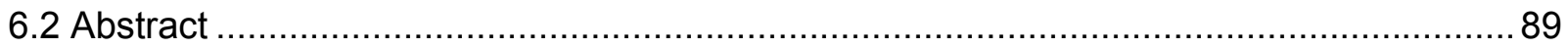

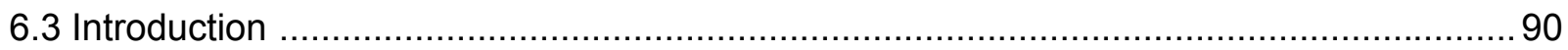

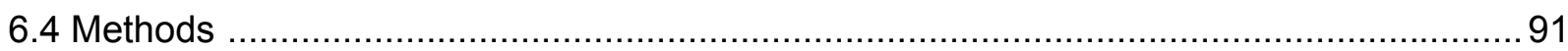

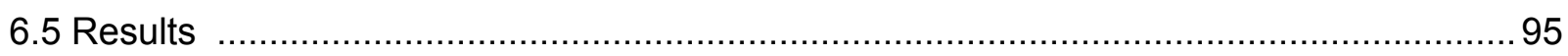

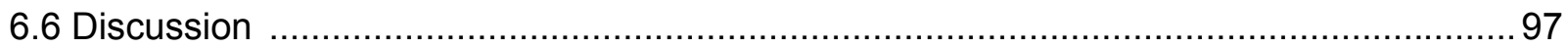

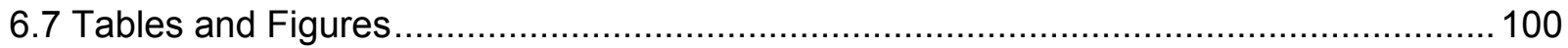

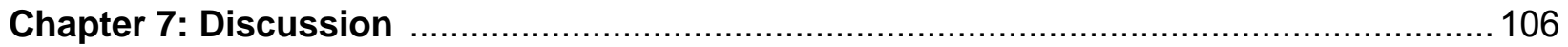

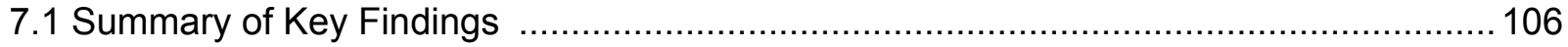

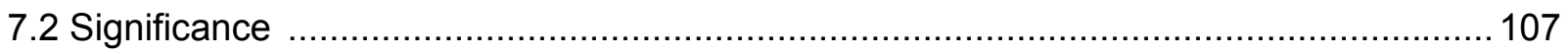

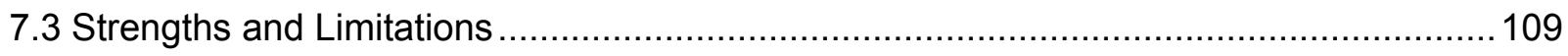

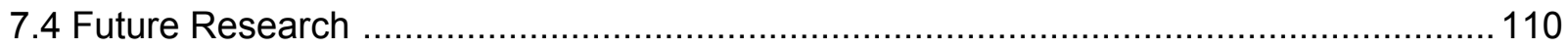

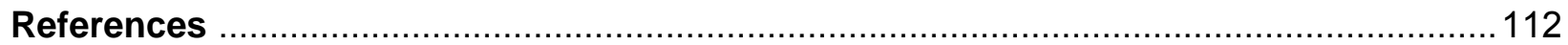




\section{Chapter 1}

\section{Introduction and Overview of Research Project}

\subsection{Cardiovascular Disease Burden in the United States}

As of 2011, the mortality rate attributed to cardiovascular disease was 229.6 per 100,000 people; the cause of 1 in 3 deaths in the United States (U.S.) $)^{2}$. Although deaths attributable to cardiovascular disease have been declining since the 1960s, cardiovascular disease remains the leading killer of men and women in the U.S. ${ }^{3,4}$. Decreases have been largely credited to advances in treatment, improvements in blood pressure and cholesterol control, and decreases in the prevalence of smoking 5 . More recently, concerns have been raised as the declining cardiovascular disease specific mortality rate has begun to slow, even plateau for some groups as of the 1990's. This has been attributed to increasing trends in obesity, hypertension, and diabetes with little change in cholesterol ${ }^{6,7}$. By 2030, it is expected the prevalence of cardiovascular disease will increase by $10 \%$ and direct medical costs will triple ${ }^{8}$.

\subsection{Traditional Measurement of Cardiovascular Disease}

Traditional measures of cardiovascular disease include mortality in addition to incidence and prevalence of disease events and risk factors. Researchers have historically used these measures to determine the status of cardiovascular health. Traditional measures count only those experiencing disease or who have died from disease. They limit the pertinence of information to mainly older age groups and, by the nature of their definition, focus research efforts on risks for disease or death. This focus on disease also concentrates public health efforts on primary and secondary prevention. Primary prevention focuses on reducing or controlling risk factors in those who have already developed some risk, while secondary prevention focuses on postponing symptoms in those with early disease. While primary and 
secondary prevention are clearly important and necessary, studies have demonstrated that the mere development of a risk factor results in an increased risk for lifetime disease development ${ }^{9}$ and fewer years disease free ${ }^{10}$. Thus, primordial prevention, defined as the prevention of risk factor development, has been identified as a critical priority and essential both for reducing disease incidence and the advancement of population health ${ }^{3}$. Primordial cardiovascular prevention, then, is synonymous with the advancement of cardiovascular health. And therefore, public health activities should be focused on efforts that advance the understanding of factors, environments, and actions that drive and foster cardiovascular health, both in individuals and populations. Fundamental to the ultimate improvement in cardiovascular health is the ability to measure health and not only disease. To this end, and with deliberate intent to support and advance Healthy People 2020 objectives to improve cardiovascular health in the U.S. ${ }^{11}$, the American Heart Association (AHA) developed a comprehensive measure of cardiovascular health that can be measured in both individuals and populations ${ }^{12}$.

\subsection{American Heart Association Cardiovascular Health Index}

In 2010, a special report published in Circulation, the AHA published the definition of a cardiovascular health index (CVHI) which includes both health factors (total cholesterol, blood pressure, body mass index, and fasting plasma glucose) as well as health behaviors (smoking, physical activity, and diet) ${ }^{12}$. In the metric's most simple form, each factor can be categorized as ideal or not ideal with one point awarded for each component that is ideal. To determine overall cardiovascular health, the points for components are summed and result in a score that ranges from 0 (worst) to 7 (best) or a categorization of ideal (6 or 7 points), intermediate (3-5), or poor (0-2). During index development the AHA considered the need to balance a rigorous score with feasibility. This included the ability to use existing national public health databases and ease of use in both patient populations and the general public ${ }^{12}$. 
Prevalence of cardiovascular health status has been examined in various populations globally including China ${ }^{13-16}$, Korea $^{17}$, Ecuador ${ }^{18}$, Finland ${ }^{19}$, Norway ${ }^{20}$, Ireland ${ }^{21}$, India ${ }^{22}$, the Mediterranean ${ }^{23}$, and the Republic of Srpska ${ }^{24}$. In the U.S., cardiovascular health has been examined in adults ${ }^{25-27}$, adolescents ${ }^{19,28,29}$ and various subpopulations including American Indians $^{30}$, African Americans ${ }^{31,32}$, rural populations ${ }^{33}$, foreign-born citizens ${ }^{34}$, and individual states $^{35}$. Less than $2 \%$ of adults in the U.S. meet ideal criteria in all seven cardiovascular health components $^{25,36}$. Smoking behavior is the component with the highest prevalence of ideal and diet is the component with the lowest prevalence of ideal ${ }^{25}$. Among states, ideal cardiovascular health ranged from a low of $1.2 \%$ of the total population in Oklahoma to a high of $5.5 \%$ of the population in Vermont ${ }^{35}$. Two studies have examined temporal changes in the cardiovascular health and its components in the U.S. ${ }^{35,37}$. Both reported improvement in smoking behavior, declines in ideal body mass index (BMI) and blood glucose levels, and no change in ideal cholesterol, blood pressure, or physical activity. Whereas one study reported no changes in ideal diet, another reported a slight improvement in diet in men but not women.

Additionally, validation studies have demonstrated that having higher cardiovascular health was associated with decreased cardiovascular disease, as measured by cardiovascular disease mortality and prevalence and incidence of cardiovascular events ${ }^{13,20,26,36,38}$. Decreased allcause mortality ${ }^{36}$ and decrease prevalence and progression of unhealthy vasculature changes ${ }^{19}$, 39-42 were also observed. Longitudinal studies have demonstrated that ideal cardiovascular health during childhood is associated with higher levels of ideal blood pressure, total cholesterol, and glucose in adults ${ }^{43}$ and less atherosclerosis in middle age ${ }^{44}$. Low cardiovascular disease risk profiles in middle age, which include many of the AHA cardiovascular health components, have also been associated with better quality of life ${ }^{45}$ and decreased Medicare costs later in life ${ }^{46}$. Further, studies have found higher cardiovascular health to be associated with fewer symptoms of depression ${ }^{47}$, higher cognitive functioning ${ }^{48}$, and 
decreased incident cancer ${ }^{49}$. Although having ideal cardiovascular health is associated with decreases in cardiovascular disease, the public health imperative for efforts to improve cardiovascular health is highlighted by the report that less than $5 \%$ of U.S adults have ideal cardiovascular health 50 .

\subsection{Determinants of Cardiovascular Health and Gaps in the Literature}

A thorough understanding of health determinants requires inclusion of factors at multiple levels of proximity to individuals (Figure 1). As the CVHI was only developed in 2010, descriptive studies have characterized cardiovascular health at the national and state levels, but few have begun to examine the determinants of cardiovascular health observed within and between population sub-groups or to identify factors and environments that promote and foster cardiovascular health. Of those studies examining determinants, most have focused on the importance of individual socioeconomic and demographic characteristics in determining cardiovascular health. An individual's $\operatorname{sex}^{34}$, race/ethnicity ${ }^{34}$, age ${ }^{25}$, and education level $24,34,51,52$ have all been found to be associated with both cardiovascular disease and cardiovascular health.

One study has examined neighborhood characteristics associated with cardiovascular health, finding associations between physical activity, food resources, and community socioeconomic status $^{53}$. Other community social factors have not been as thoroughly examined ${ }^{4,54}$. Understanding the influences of variables at levels more distal to an individual are important as they are thought to impact health through an individual's stress, values, and locus of control ${ }^{55}$. 


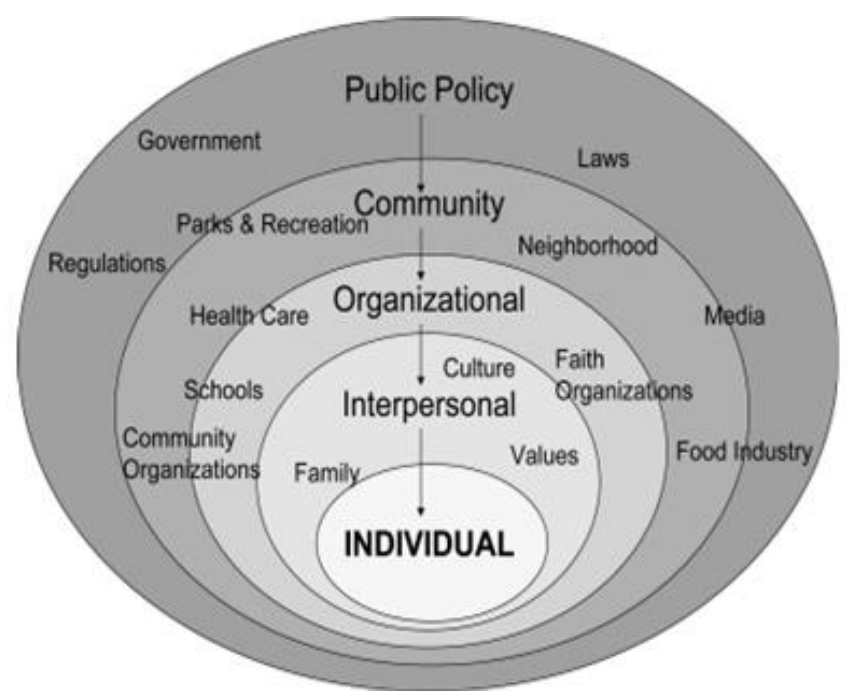

Figure 1.1 Social ecological model picturing influences on the individual and emphasizing the importance of the context in which an individual lives ${ }^{1}$.

\subsection{Specific Aims}

The overall objective of this project was to determine the associations between cardiovascular health and socioeconomic and demographic factors, health care resource availability, and state health care resource policies. The central hypothesis of this project was that higher cardiovascular health would be associated with having evidence-based policies that promote the availability of health care resources, particularly those that support preventive and primary care. Figure 1.2 presents the conceptual model explored and depicts the hypothesized relationships. 


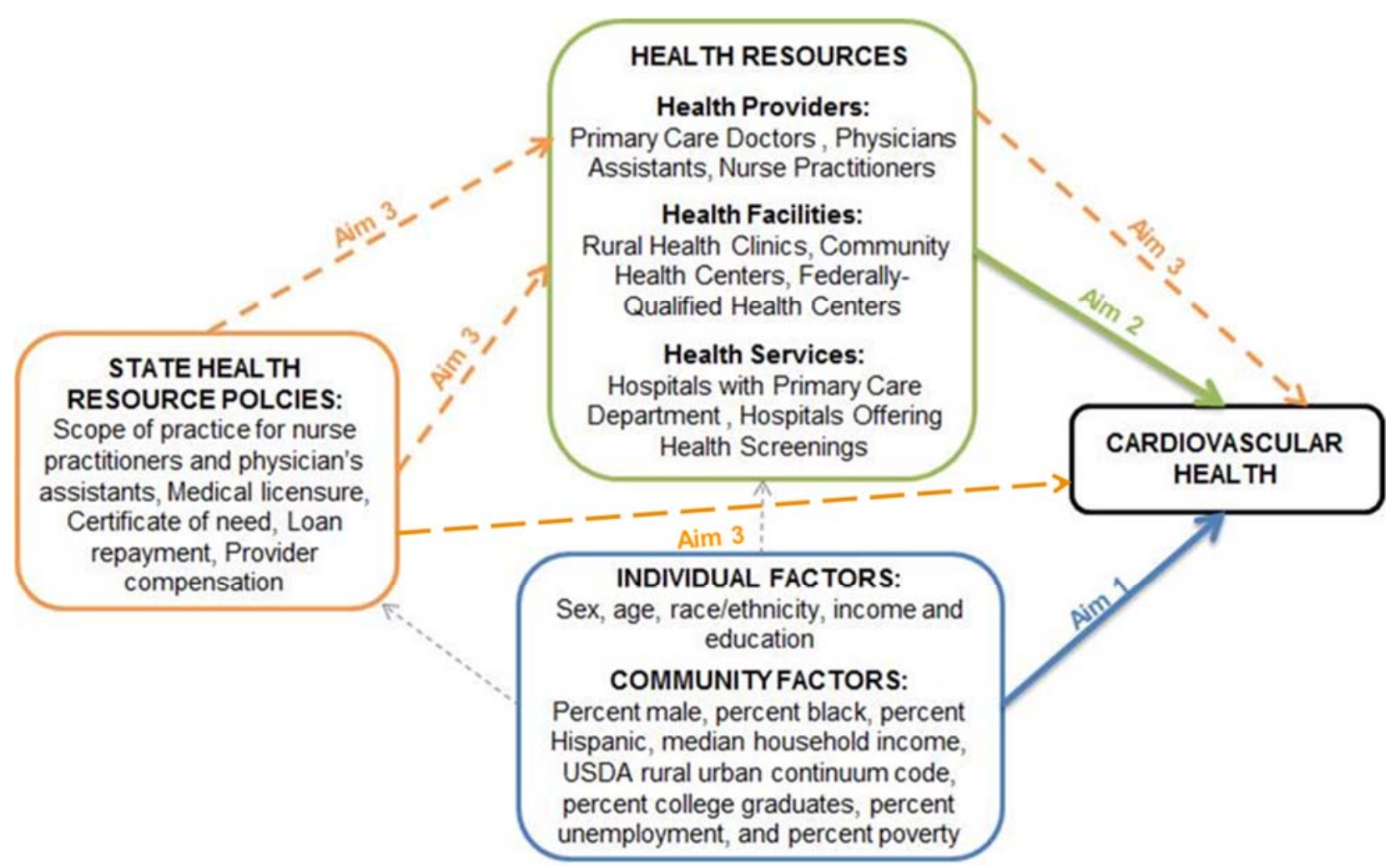

Figure 1.2. Conceptual model explored in this project.

\section{Aim 1: Examine changes in cardiovascular health in the U.S and the relationship between cardiovascular health and traditional socioeconomic and demographic factors.}

Objective 1.1: Determine the association between the cardiovascular health index and individual and community level traditional socioeconomic and demographic factors.

Working Hypotheses: Southeast and Appalachian regions will have lower cardiovascular health index scores. Individual and community levels of education, gender, race/ethnicity, and income are associated with cardiovascular health index.

Objective 1.2: Determine the trend of the state level cardiovascular health index between 2003 and 2009.

Working Hypothesis: State cardiovascular health index has decreased over time. 


\section{Aim 2: Determine the association between the cardiovascular health index and health care resource (providers, services, and facilities) availability.}

Working Hypotheses: Higher cardiovascular health index is associated with higher numbers of health providers, services, and facilities in particular those with a preventive or primary care focus.

\section{Aim 3: Determine the direct and indirect associations between the cardiovascular health index and state health care resource policy. Working Hypotheses: States with a health resource environment supporting higher availability of primary care resources will have higher cardiovascular health. Health care resource policy will mainly impact cardiovascular health through increased health care resource availability.}

\subsubsection{Overview of Methodologic Approach}

This study utilized Behavioral Risk Factor Surveillance System (BRFSS) data to determine individual CVHI. BRFSS is an annually administered national telephone survey collecting information in each U.S. state and the District of Columbia on health risk behaviors, chronic health conditions, and use of preventive services since $1984^{56}$. State health departments, with support from the Center for Disease Control and Prevention, use random digit dialing to interview adults 18 years old and older who are part of the civilian, non-institutionalized population. The BRFSS survey includes a core component which is used by all states, and optional modules, which each state can choose to include or not. For this project, only questions in the core component were used to ensure consistency across the United States. BRFSS also alternates questions in the core component between even and odd years with only odd years including questions for all CVHI components. Due to the availability of BRFSS 
questions needed to calculate all CVHI components and the release of geographic county identification codes, our analyses was limited to years 2003, 2005, 2007, 2009, and 2011.

Selection of covariates was guided by our conceptual model, as outlined in Figure 1.2, and existing literature. Individual level socioeconomic and demographic variables were abstracted from the BRFSS. For each county, community-level socioeconomic and demographic variables were abstracted from the Area Health Resource Files (AHRF $)^{57}$. The AHRF is an annual collection of health resources and socioeconomic data collected from over 50 sources (e.g., Census, Medicare, etc.) by the Health Research and Services Administration. Data elements included in the AHRF are information on health facilities, health professions, resource scarcity measures, health status, economic activity, health training programs, and socioeconomic and demographic indicators at the county, state, and national levels.

SAS 9.3 was used for data management. Data for individuals, communities, and state policies was match-merged using Federal Information Processing Codes (FIPS). Descriptive summaries and prevalence estimates were assessed using frequencies, proportions, means, and standard deviation. Tests for differences with categorical variables were examined using Rao-Scott chi-square test of independence. Poisson regression models were utilized to assess the influence of individual and community sociodemographic characteristics, health care resources, and state health care resource policy on CVHI. Where appropriate, models were adjusted for multiple community and individual-level socioeconomic and demographic covariates. 


\subsubsection{Aim 1: Examine changes in cardiovascular health in the U.S and the relationship between cardiovascular health and traditional socioeconomic and demographic factors.}

The main goal of specific aim 1 was to measure $\mathrm{CVHI}$ in individuals and determine associations between $\mathrm{CVHI}$ and traditional socioeconomic and demographic characteristics. We tested the working hypotheses that (1) Southeast and Appalachian regions would have lower CVHI, (2) individual and community levels of education, gender, race/ethnicity, and income would be associated with $\mathrm{CVHI}$, and (3) state $\mathrm{CVHI}$ had decreased over time.

As discussed above, descriptive studies have characterized $\mathrm{CVHI}$ at the national and state level and the cardiovascular health index has been validated through studies demonstrating that a higher cardiovascular health index is associated with decreased cardiovascular disease. However, as such a new metric, studies have not begun to examine the differences in cardiovascular health observed at population levels smaller than the state, to identify the characteristics of community environments that promote and foster cardiovascular health, or to understand the variation in $\mathrm{CVHI}$ trends by state. The availability of such information to public health and government agencies would greatly assist in developing priorities and in evaluating the effectiveness of policies and programs promoting population health ${ }^{58,59}$. Successful completion of this specific aim will help assist in providing this information to public health officials and policy makers. Additionally, completion of this specific aim will provide information on the characteristics of environments that have higher cardiovascular health.

\subsubsection{Aim 2: Determine the association between the cardiovascular health index and health care resource (providers, services, and facilities) availability.}

The main goal of this specific aim was to determine the associations between $\mathrm{CVHI}$ and health care resources. We tested the working hypothesis that higher CVHI would be associated with 
higher numbers of health providers, services, and facilities; in particular those with a preventive or primary care focus.

Available health care resources, particularly a medical home, are key to maintaining and improving health. A medical home, defined as a regular place and/or provider of care, has been associated with better health status ${ }^{60}$, more equitable care ${ }^{61}$, and increased use of preventive services $^{62-64}$. Two essential aspects of medical homes are the provider supply and the physical facility ${ }^{65}$. Increased physician supply has been found to be associated with better outcomes across a wide variety of medical conditions and procedures ${ }^{66}$ and increases in total provider supply were associated with improved health outcomes ${ }^{67}$. As there is a documented shortage of health care providers it has been proposed that increasing the availably of primary care providers by increasing physician assistant and nurse practitioner numbers could make up for the deficit in physicians ${ }^{68}$. Studies suggest physician assistants and nurse practitioners provide a similar quality of services to primary care physicians ${ }^{69}$.

Community health centers, such as Rural Health Centers and Federally Qualified Health Centers funded by the Health Research and Services Administration, aim to provide the desired centralized, stable source of care to underserved communities and vulnerable populations ${ }^{70,71 .}$ Studies indicate community health centers provide more equitable care and increased number of services for vulnerable populations when compared with other primary care $\operatorname{sites}^{72,73}$.

Successful completion of this specific aim will provide information on which health care resources are associated with higher cardiovascular health and whether certain health resources have different impacts depending on the characteristics of the area. Completion of this aim will also provide evidence for the relative impacts of health care resources versus traditional socioeconomic and demographic factors on cardiovascular health. 


\subsubsection{Aim 3: Determine the direct and indirect associations between the cardiovascular health index and state health care resource policy.}

The main goal of this specific aim was to determine the indirect and direct relationships between cardiovascular health and health resource policy. We tested the working hypotheses that (1) states with a health resource environment supporting higher availability of primary care resources will have higher cardiovascular health and (2) health care resource policy will mainly impact cardiovascular health through increased health care resource availability.

Health policy has proven itself effective in achieving many of the past successes in public health $^{74,75}$. Further, Frieden's health impact model proposes that it is the policies that address issues on a societal or population level that have the most potential for improving population health as they require less effort on the part of the individual ${ }^{76}$. In a panel discussion of the challenges in tackling chronic diseases it was highlighted that a key challenge related to policy interventions is the need to determine which policies work best and how best to implement these policies ${ }^{77}$. Successful completion of this specific aim will provide insight into how policies and policy environments may be associated with cardiovascular health. 


\section{Chapter 2}

FULL TITLE: Cardiovascular Health in U.S. Counties: Community Sociodemographic Predictors of County-Level Cardiovascular Health

SHORT TITLE: Cardiovascular Health in U.S. Counties

AUTHORS \& AFFILIATIONS: Courtney Pilkerton, BA ${ }^{1,2,3}$, Thomas K. Bias, $\mathrm{PhD}^{3,4}$, and

Stephanie J. Frisbee, $\mathrm{PhD}^{3,4}$

${ }^{1}$ West Virginia University School of Medicine

${ }^{2}$ West Virginia University School of Public Health, Department of Epidemiology

${ }^{3}$ West Virginia University Robert C. Byrd Health Sciences Center, Center for Cardiovascular and

Respiratory Sciences

${ }^{4}$ West Virginia University School of Public Health, Department of Health Policy, Management \& Leadership

CORRESPONDING AUTHOR:

Stephanie J. Frisbee, PhD

West Virginia University

Robert C. Byrd Health Sciences Center

Center for Cardiovascular \& Respiratory Sciences

1 Medical Center Drive - PO Box 1905

Morgantown WV 26505-1905

304-293-6552 / sfrisbee@hsc.wvu.edu 


\section{ABSTRACT}

Background: Cardiovascular disease is the cause of death for 1 in 3 adults in the United States (U.S.), making improving cardiovascular health a key population health goal. As part of public health efforts to achieve this, the American Heart Association recently developed a comprehensive cardiovascular health index $(\mathrm{CVHI})$ that incorporates smoking, body mass index, physical activity, diet, cholesterol, blood pressure, and blood glucose. The objectives of the current study were to determine $\mathrm{CVHI}$ in all U.S. counties and identify key sociodemographic determinants of county-level CVHI.

Methods and Results: Data from the 2009 Behavioral Risk Factor Surveillance System were used to calculate age-standardized CVHI for each county; $63 \%$ (2051 of 3143) of U.S. counties were included. County $\mathrm{CVHI}$ ranged from 2.11 to 4.80 with an average of $3.50 \pm 0.35$. CVHI was poorer in the Southeast and Appalachian regions. Less than $3 \%$ of counties met the Healthy People objective for any component of CVHI except smoking behavior for which the objective was met in a quarter of counties. Of all sociodemographic determinants assessed, the proportion of a county's population who were college graduates had the largest impact on CVHI.

Conclusions: Overall, cardiovascular health is low in U.S counties, and there are substantial disparities in its distribution. While sociodemographic characteristics, particularly educational attainment, are important in determining cardiovascular health, substantial variation in cardiovascular health remains unexplained. Further studies are needed to identify key factors affecting population cardiovascular health, information that can subsequently be used to guide population strategies that would be most effective in improving overall cardiovascular health.

Key Words: cardiovascular health, epidemiology, counties, social determinants, 2020 Strategic Impact Goals 


\section{INTRODUCTION}

Although mortality attributable to cardiovascular disease (CVD) has declined since the $1960 \mathrm{~s}^{4}$, CVD remains the cause of $30 \%$ of deaths for adults in the U.S. ${ }^{78}$. It has been projected that, by 2030, more than $40 \%$ of the U.S. population will have CVD, the associated direct medical costs will triple, and the indirect costs of CVD will increase by $61 \%$ (both from 2010 levels) ${ }^{8}$. To reduce the enormous societal burdens imposed by such increases in CVD prevalence, greater focus on effective population-based primordial prevention strategies is urgently needed ${ }^{8,79}$. The efficacy of such population-based approaches has been underscored by recent reports demonstrating that even small shifts in the risk patterns and exposures in populations can have significant impacts on overall population health and subsequent societal outcomes ${ }^{80-82}$.

Primordial prevention, as described by the American Heart Association ${ }^{79}$, is synonymous with a lifecourse approach to the promotion of population-level cardiovascular health. This terminology emphasizes a transition from the traditional public health approach, specifically an evolution towards three concepts. The first is the measurement of population health rather than disease prevalence or event rates, as the latter necessarily focuses research and public health efforts on primary and secondary prevention in older age groups. Second is the identification of factors that affect population-level (vs. individual) health including the absolute and relative distribution of these factors between and within populations. Third is the identification of tools, such as public policy and environmental change, that can improve the health of entire populations ${ }^{12}$.

The need for the prioritization of population health and primordial prevention has been supported by two leading public health authorities in the U.S.; the Department of Health and Human Services via their Healthy People 2020 Roadmap for the developmental objective (HDS1) of increasing cardiovascular health in the U.S. population ${ }^{11}$; and the American Heart Association's recently established 2020 Strategic Impact Goal to improve by $20 \%$ the cardiovascular health of Americans by $2020^{12}$. To support and advance these priorities, the 
American Heart Association recently developed a comprehensive cardiovascular health index, a metric that includes both health factors (total cholesterol, blood pressure, body mass index, and fasting plasma glucose) as well as health behaviors (smoking, physical activity, and diet), which allows for the measurement of cardiovascular health in both individuals and populations ${ }^{12}$. Previous studies have reported the prevalence of ideal, intermediate, and poor CVHI in various populations globally ${ }^{14,15,17,18}$ and within the U.S. ${ }^{25,26,28,34,83,84} 25,36$. Among U.S. states, ideal $\mathrm{CVHI}$ has been reported to range from a low of $1.2 \%$ of the total population in Oklahoma to a high of $5.5 \%$ of the population in Vermont ${ }^{35}$. Studies investigating the temporal trends in $\mathrm{CVHI}$ have reported that, while smoking prevalence continues to decline, this is likely offset by increases in obesity and dysglycemia and unclear trends for the prevalence of hypertension, hypercholesterolemia, diet and physical activity ${ }^{37,85}$. Ideal cardiovascular health remains very low in the U.S. population, and subsequent concern for the ability to meet the stated public health goals ${ }^{37,85,86}$ underscores the need for population-based approaches to meet these goals.

Such approaches will require an understanding of cardiovascular health in communities, community-level factors affecting cardiovascular health, and the tools, namely appropriate public policies ${ }^{79,87}$, that can improve aggregate cardiovascular health. Further, the smallest geographic unit for which community-level health data are systematically and uniformly available nation-wide is the county. In the U.S., counties represent key geopolitical units that can influence community-level factors, in part through the adoption of appropriate public policies that directly or indirectly affect the cardiovascular health of their constituents.

While previous studies have reported on cardiovascular health in states and nation-wide, the purpose of the present study was to determine: 1) the cardiovascular health of counties in the United States, and 2) the association and impact of traditional sociodemographic factors on cardiovascular health in counties. Our primary hypothesis is that cardiovascular health will vary substantially between counties within states. We further hypothesize that traditional 
sociodemographic and regional factors will only partially explain the observed variations in cardiovascular health.

\section{METHODS}

$\mathrm{CVHI}$ and its individual components were examined in counties in the United States. To examine the association of traditional social determinants of health and $\mathrm{CVHI}$, regression was performed with multiple county socioeconomic and sociodemographic covariates.

Data Source: The Behavioral Risk Factor Surveillance System (BRFSS), which began in 1984, is an annually administered national telephone survey in each U.S. state and the District of Columbia and collects information on health risk behaviors, chronic health conditions, and use of preventive services ${ }^{56}$. State health departments with support from the Center for Disease Control and Prevention use random digit dialing to interview adults at least 18 years of age who are part of the civilian, non-institutionalized population. Detailed descriptions of BRFSS study design and methods are described elsewhere ${ }^{56}$. The survey includes a core component which is used by all states, and optional modules, which each state can choose to administer or not. For this study, only questions in the core component were used to ensure consistency across all counties. Due to question availability for all AHA cardiovascular health metric components, only an odd year of BRFSS was used in this study.

Study Population: All participants of the 2009 BRFSS survey were examined to determine eligibility $(n=432,607)$. Participants were excluded if they were missing any question required to determine one of the seven CHVI components $(n=114,266)$ or if missing a county Federal Information Processing Standards (FIPS) code $(n=42,043)$. Females were also ineligible if pregnant at the time of survey $(n=3,247)$. The final population of individuals eligible was 287,493 . Additionally, counties were excluded from analysis if there were fewer than 15 
respondents from that county $(n=184)$ or if county FIPS code was censored in BRFSS $(n=$ 913). The final analysis included 2,051 counties (65.2\%).

Cardiovascular Health: At the individual level, BRFSS questions and definitions used to determine ideal for each $\mathrm{CVHI}$ component were defined using previous work by Fang et al ${ }^{35}$. The criteria and classification process for each of the individual components of the $\mathrm{CVHI}$ is summarized in Table 1. For individuals, $\mathrm{CVHI}$ was calculated as a count of components meeting 'ideal' criteria, and so could range from 0 to 7 . Overall individual cardiovascular health was considered 'ideal' if a participant had 6 or 7 components classified as 'ideal', 'intermediate' if they had 3 to 5 components were classified as 'ideal', and 'poor' if they had 2 or less components classified as 'ideal'. For counties, CVHI was calculated as the age-standardized mean of all eligible BRFSS participants in the same FIPS code. For each component, a county was considered to 'meet objective' if the prevalence of individuals classified as 'ideal' for a specific component met the goals established by Healthy People 201088. Healthy People 2010 goals were used as this study utilized BRFSS data from 2009.

Covariates (Sociodemographic Determinants of Health): Sociodemographic characteristics of each county were obtained from the Area Health Resource File (AHRF) ${ }^{89}$. The AHRF is an annual compilation of health resources and socioeconomic data collected from over 50 sources (e.g., Census, Medicare, etc.) by the Health Research and Services Administration. Sociodemographic covariates included were gender (proportion of the population male), percent non-Hispanic black, percent Hispanic, median household income, percent college graduates, percent without health insurance, and percent poverty. AHRF data was from 2010 and 2011 depending on availability of covariate.

Additionally, measures of population density and income disparity for each county were also included. Population density was defined as metropolitan, non-metropolitan, or rural based upon the U.S. Department of Agriculture 2013 urban rural continuum code, which is a 
categorical variable that ranges from 1 to $8^{90}$. Metropolitan status is as defined by the Office of Management and Budget, non-metropolitan is defined as counties with no metropolitan designation and a population of more than or equal to 20,000 , and rural is defined as counties with a population of less than 20,000 . Gini coefficients, a measure of income disparity, for each county were abstracted from the 2010 American Community Survey, a yearly survey by the U.S. Census Bureau ${ }^{71}$. The Gini coefficient ranges from zero to one, with zero indicating perfect equality (all households have the same income) and one indicating perfect inequality (one household has all the income $)^{91}$.

Statistical Analysis: For each eligible county, age-standardized mean CVHI and the prevalence of ideal for each component were determined using 2000 U.S. projected population (distribution $8)^{92}$ and using survey procedures to account for BRFSS survey weights and design. The standard population distribution uses age groups 18-24 years, 25-44 years, 45-64 years and 65 years and older. A map of mean CVHI by county was made using ArcGIS 10.1 (ESRI 2012. ArcGIS Desktop: Release 10.1. Redlands, CA: Environmental Systems Research Institute). Univariate and adjusted linear regression analysis was used to determine the association of county sociodemographic variables to county $\mathrm{CVHI}$. Interactions between covariates and median household income and rural-urban designation were assessed. All statistical analyses were performed with Stata 13 (StataCorp. 2013. Stata Statistical Software: Release 13. College Station, TX: StataCorp LP). Due to the significant proportion of individuals and counties missing, a sensitivity analysis was performed imputing values for cholesterol and physical activity as these were the two CVHI components most likely to be missing. The sensitivity analysis resulted in no additional counties being included and results from the regression analysis were identical to analysis with no imputed values, therefore only analysis with no imputation is presented. 


\section{RESULTS}

Sociodemographic characteristics of included and excluded counties are presented in Table 2. The average included county had a population that was $49.7 \%$ male, $9.6 \%$ African American/black, and $7.6 \%$ Hispanic. In the average included county, $17.0 \%$ of the population was classified as living in poverty and $20.5 \%$ of adults over 25 years of age were college graduates. Additionally, the average included county had a median household income of $\$ 44,824$, a Gini coefficient of 0.43 , and $49 \%$ of included counties were metropolitan. Approximately $37 \%$ of counties were excluded from analysis. Compared to included counties, excluded counties were more likely to have a smaller non-Hispanic black population $(7.2 \%$ vs $9.6 \%, p<0.0001)$, a larger Hispanic population (9.6\% vs $7.6 \%, p<0.0001)$, a smaller median household income $(\$ 39,989$ vs $\$ 44,824, p<0.0001)$, have a smaller population proportion of college graduates $(16.2 \%$ vs $20.5 \%, p<0.0001)$, a slightly larger population living in poverty (17.7\% vs $17.7 \%, p=0.002)$, and to have a slightly larger male population $(50.6 \%$ vs $49.7 \%, p$ $<0.0001)$. Additionally, excluded counties were substantially more rural than included counties (84.3\% to $36.6 \%)$ and from the geographic central part of the U.S. (Figure 1).

Attainment of Healthy People 2010 (HP2010) objectives was very low, with less than $1 \%$ of counties achieving the HP2010 objective for blood pressure, cholesterol, BMI, diet, or physical activity and less than 3\% of counties achieved the HP2010 objective for diabetes (Table 3). Counties were most likely to achieve the HP2010 objective for smoking, with slightly more than quarter of counties achieving the objective. There were significant differences in meeting objectives across population density categories. Rural counties, when compared to metropolitan or non-metropolitan counties, were statistically significantly more likely to meet HP2010 objectives for cholesterol, diabetes, and BMI. Non-metropolitan counties were least likely to meet the HP2010 objective for smoking. There were significant differences in meeting 
the smoking objective across median household income quartiles. Those in the highest income quartile were more likely to have meet the smoking objective than other income quartiles.

The geographical distribution of age-standardized mean $\mathrm{CVHI}$ is shown in the county map in Figure 1. Visual inspection suggests $\mathrm{CVHI}$ is poorer in the Southeast and Appalachian regions. As shown in Figure 2, age-standardized mean $\mathrm{CVHI}$ ranged from 2.11 to 4.80 with an average of $3.50 \pm 0.35$ (Figure $2 \mathrm{~A}$ ). Mean $\mathrm{CVHI}$ was poorest in rural and the least wealthy counties (Figure 2C). Averaged across all included counties, the average prevalence of poor cardiovascular health was $21.6 \% \pm 0.22$ (Figure $2 \mathrm{~B}$ ). Additionally, more than a quarter of the population in the lowest income counties have poor cardiovascular health and there is a dose response pattern as income increases (Figure $2 \mathrm{C}$ ).

Results from regression analysis assessing the association between cardiovascular health and sociodemographic characteristics are shown in Tables 4 and 5. Table 4 presents the overall univariate and adjusted analysis. In univariate analyses, all sociodemographic characteristics were significantly associated with $\mathrm{CVHI}$ except the Gini coefficient. In fully adjusted regression models, a county's age-standardized CVHI was higher in counties with higher population proportions of males, Hispanics, and college graduates, and lower population proportion of uninsured and living in poverty. Standardized coefficients were examined to assess the comparative impact of these traditional sociodemographic factors on cardiovascular health. The proportion of a county's population with a college education was substantially more important than all other sociodemographic factors examined, including race, income, and insurance status; one standard deviation increase in the proportion of county who were college graduates was associated with a 0.16 point increase in age-standardized mean CVHI.

We observed statistically significant interactions between a county's population density and median household income $(p=0.045)$, percent college graduates ( $p$ value $<0.0001)$, and percent poverty $(p=0.03)$. Thus, we performed stratified regression analysis, the results of 
which are shown in Table 5. In all stratifications, college education was significantly associated with a county's CVHI. Percent poverty was only associated with $\mathrm{CVHI}$ in metropolitan counties and the proportion of a population that was male was only associated with $\mathrm{CVHI}$ in rural and non-metropolitan counties. Population density is only associated with cardiovascular health in the lowest and highest quartile of income.

\section{DISCUSSION}

This is the first study to examine cardiovascular health, as defined by the AHA, at the county level and to assess the social determinants of county cardiovascular health. Understanding health at the population level is important, as shifting the distribution of risk factors in the population even a small amount can substantially decrease prevalence of disease beyond substantial increases in treatment levels ${ }^{93,94}$.

Multiple studies have reported the importance of maintaining cardiovascular health. Individuals who are successful in not developing cardiovascular risk factors have decreased prevalence of poor health later in life ${ }^{43}$ and have decreased risk of cardiovascular disease, cardiovascular disease specific mortality, and all-cause mortality ${ }^{9,36}$. In populations with a higher prevalence of ideal cardiovascular health, it is reasonable to expect this to correspond to reduced health care costs and decreased years of lives lost. Unfortunately, our results suggest cardiovascular health is low in most counties in the United States, as is the number of counties meeting national benchmarks for the individual $\mathrm{CVHI}$ components.

The low prevalence of ideal cardiovascular health $(3.9 \% \pm 0.05$, Figure $2 \mathrm{C})$ reported in this study is consistent with results from other studies that have used the AHA metric ${ }^{25,35,85}$. The estimate of mean cardiovascular health in this study, $3.50 \pm 0.35$, is slightly lower than previous studies. As reported in Fang et al, mean $\mathrm{CVHI}$ for states was 4.34 and ranged from 4.0 to $4.7^{35}$. It is expected that analysis aggregated at the state-level, as in Fang et al, would require fewer 
exclusions due, in particular, to too few residents and or absence of a county FIPS code. Thus, our county-level results, while accurate for included counties, may slightly under-estimate cardiovascular health determined using different levels of geographic aggregation.

Consistent with Fang et al, we found cardiovascular health to be lowest in the Southern and Appalachian geographical regions. There was also, as we hypothesized, considerable variation in $\mathrm{CVHI}$ within states. For example, in Colorado, the fifth ranked state in Fang et al, counties ranged from an age-standardized mean $\mathrm{CVHI}$ of 3.41 to 4.80 . Also, in Oklahoma, the worst ranked state by Fang et al, counties ranged from an age-standardized mean CVHI of 2.53 to 4.45. In working to improve overall cardiovascular heath, it is important to have an understanding of the disparities in health to dually determine causes of those disparities and to target services and policies appropriately and where most needed.

Sociodemographic characteristics, particularly education, have been shown to be associated with health outcomes and mortality 51, 52, 95-97. Consistent with previous studies, we observed that educational attainment was the most important of the traditional sociodemographic factors evaluated. The mechanisms through which education may impact health is as a protective factor that influences lifestyle behaviors and choices, values, time preference, and ability to understand, navigate, and access resources among many others ${ }^{51,98,99}$. Interestingly, overall income was not significantly associated with cardiovascular health, although within quartiles of income different sociodemographic factors were significantly associated with CVHI. Further, the ability of sociodemographic factors to explain linear variation in cardiovascular health was markedly different depending on income quartile. Sociodemographic factors explained more of the variation in high income populations $\left(R^{2}=0.26\right)$ than in other income quartiles $\left(R^{2}=0.09\right)$.

While sociodemographic factors are significantly associated with cardiovascular health, particularly education, the overall adjusted model only explained a quarter of the linear variance in county cardiovascular health $\left(R^{2}=0.25\right)$. Thus there remains other factors that have a 
significant impact on county cardiovascular health that are not captured in the models we examined in the current study. Such factors, which will be important to examine in future studies, undoubtedly include environment factors including but not limited to the built environment and the accessibility and availability of healthcare services.

The strength of this study is the large sample available from BRFSS that connects individuals to FIPS codes allowing for data to be examined at the county level. One limitation of this study is that BRFSS is a self-reported survey, which may overestimate ideal health. In particular, selfreport of height and weight are known to be biased ${ }^{100}$. The nature of BRFSS questions for blood pressure, cholesterol, and diabetes also requires that a participant has seen a healthcare provider. There is also possible bias in the study population as a significant number of counties had no or insufficient participants with data. In particular, $84.3 \%$ of the counties excluded are rural and this analysis may not be generalizable to those populations.

In conclusion, this study provides an assessment of the distribution and disparities in countylevel cardiovascular health as well as the sociodemographic determinants of cardiovascular health in counties. This information can be used to inform population health strategies that would be most effective in improving overall cardiovascular health of counties. Further research is needed to identify other factors that are important determinants of cardiovascular health in counties. 


\section{Acknowledgements:}

The authors wish to thank Dr. Matthew J. Gurka from the West Virginia University School of Public Health for his very helpful technical (statistical) advice during this study.

\section{Funding Sources:}

Board. Research reported in this study was supported, in part, by the West Virginia Clinical and Translational Research Institute (WV-CTSI), which is supported by the National Institute of General Medical Sciences of the National Institute of Health under award U54GM104942. The content is solely the responsibility of the authors and does not necessarily represent the official views of the National Institutes of Health.

\section{Disclosures:}

This study was approved as non-human subjects research by the West Virginia University Institutional Review 


\section{Tables and Figures}

Table 1. Summary of how ideal/meeting objective is defined in this study for cardiovascular health index components at the individual and county levels.

\begin{tabular}{|c|c|c|c|}
\hline & $\begin{array}{l}\text { American Heart Association } \\
\text { Definition of Ideal for and Individual }{ }^{12}\end{array}$ & $\begin{array}{l}\text { Adaptation of Ideal to be Used for } \\
\text { Individuals }{ }^{35}\end{array}$ & $\begin{array}{c}\text { Definition of Meeting Objective for } \\
\text { Counties adapted from Healthy } \\
\text { People } 2010 \text { Goals }^{88}\end{array}$ \\
\hline Cholesterol & $<200 \mathrm{mg} / \mathrm{dL}$ untreated & $\begin{array}{l}\text { Previously screened and never been told } \\
\text { had high cholesterol }\end{array}$ & $\begin{array}{l}83 \% \text { of the population meets adapted } \\
\text { AHA goal (defined in column 2) }\end{array}$ \\
\hline Blood Pressure & $<120 /<80 \mathrm{~mm} \mathrm{Hg}$ untreated & Never been told had high blood pressure & $\begin{array}{l}86 \% \text { of population meets adapted AHA } \\
\text { goal (defined in column } 2 \text { ) }\end{array}$ \\
\hline BMI & $<25 \mathrm{~kg} / \mathrm{m} 2$ & Between 18.5 and 24.9 & $\begin{array}{l}60 \% \text { of the population meets adapted } \\
\text { AHA goal }\end{array}$ \\
\hline Smoking & Never or quit $>=12$ months ago & $\begin{array}{l}\text { Had not smoked at least } 100 \text { cigarettes } \\
\text { in their lifetime or reported smoking } 100 \\
\text { cigarettes in their lifetime but not } \\
\text { currently smoking }\end{array}$ & $\begin{array}{l}88 \% \text { of the population meets adapted } \\
\text { AHA goal (defined in column 2) }\end{array}$ \\
\hline Blood Sugar & $<100 \mathrm{mg} / \mathrm{dL}$ untreated & Never been told had diabetes & $\begin{array}{l}97.5 \% \text { of the population meets adaptec } \\
\text { AHA goal (defined in column } 2 \text { ) }\end{array}$ \\
\hline Diet & $\begin{array}{l}\text { 4-5 diet components meeting national } \\
\text { standards (Fruits and vegetables, Fish, } \\
\text { Fiber-rich whole grains, Sodium, Sugar- } \\
\text { sweetened beverages) }\end{array}$ & $\begin{array}{l}\geq 5 \text { servings of fruits and vegetables per } \\
\text { day }\end{array}$ & $\begin{array}{l}50 \% \text { of the population meets adapted } \\
\text { AHA goal (defined in column } 2 \text { ) }\end{array}$ \\
\hline Physical Activity & $\begin{array}{l}\geq 150 \mathrm{~min} / \mathrm{wk} \text { moderate intensity } \mathrm{OR} \geq \\
75 \mathrm{~min} / \mathrm{wk} \text { vigorous intensity OR } \\
\text { combination }\end{array}$ & $\begin{array}{l}\geq 150 \mathrm{~min} / \mathrm{wk} \text { moderate intensity OR } \geq \\
75 \mathrm{~min} / \mathrm{wk} \text { vigorous intensity OR } \\
\text { combination }\end{array}$ & $\begin{array}{l}50 \% \text { of the population meets adapted } \\
\text { AHA goal (defined in column } 2 \text { ) }\end{array}$ \\
\hline
\end{tabular}


Table 2. Socioeconomic and demographic characteristics of United States counties (mean \pm SD).

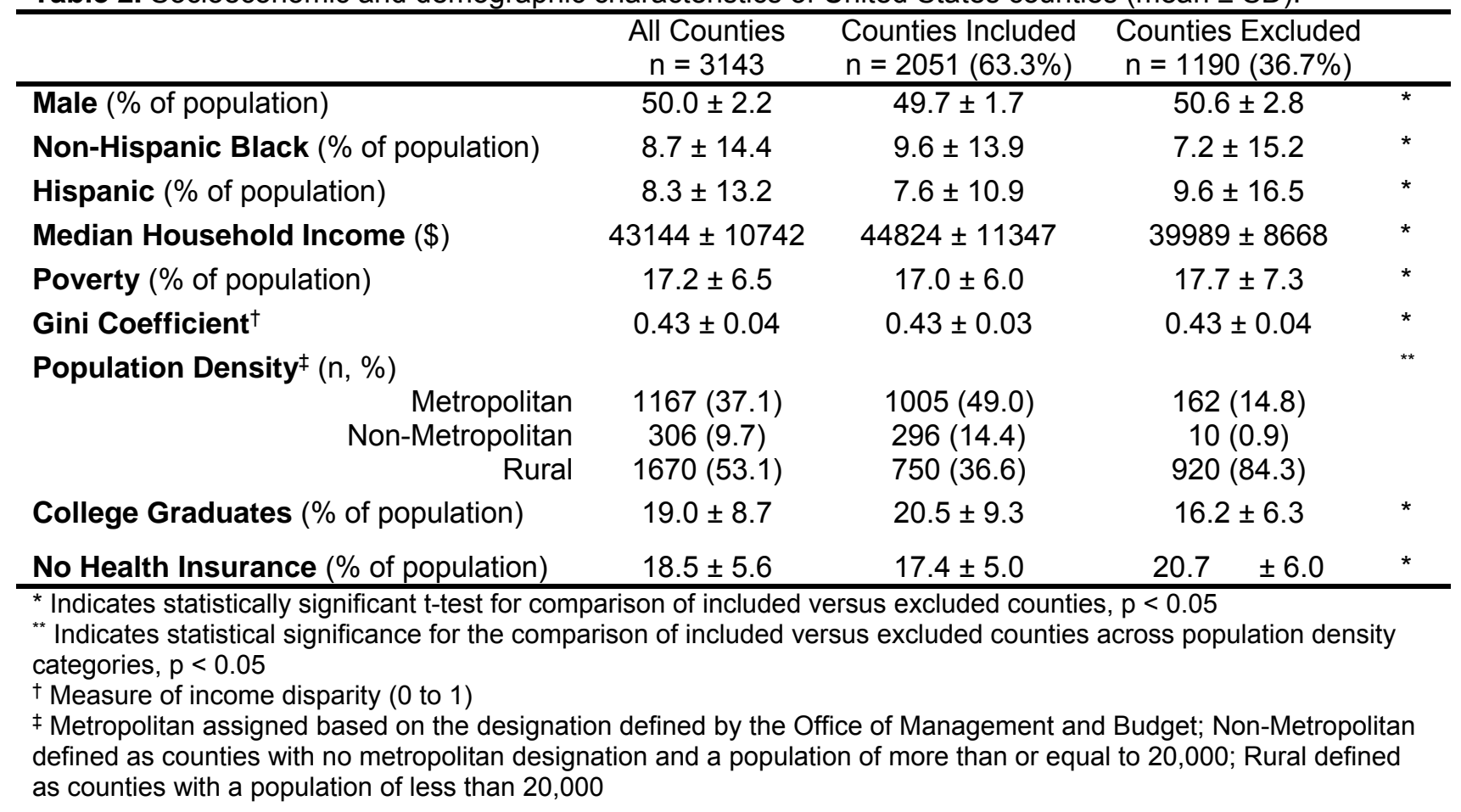


Table 3. Counties meeting Healthy People 2010 objectives for cardiovascular health index components.

\begin{tabular}{|c|c|c|c|c|c|c|c|c|c|c|}
\hline & \multirow[b]{2}{*}{$\begin{array}{l}\text { Overall } \\
\mathrm{n},(\%)\end{array}$} & \multicolumn{3}{|c|}{ Population Density ${ }^{\ddagger} \mathrm{n},(\%)$} & & \multicolumn{5}{|c|}{ County Median Household Income ${ }^{\star \star} \mathrm{n},(\%)$} \\
\hline & & $\begin{array}{l}\text { Metropolitan } \\
(n=1005)\end{array}$ & $\begin{array}{c}\text { Non- } \\
\text { Metropolitan } \\
(\mathrm{n}=296) \\
\end{array}$ & $\begin{array}{c}\text { Rural } \\
(n=750)\end{array}$ & & Quartile 1 & Quartile 2 & Quartile 3 & Quartile 4 & \\
\hline $\begin{array}{l}\text { Met Blood Pressure Objective } \\
(86 \% \text { of population ideal })^{\dagger}\end{array}$ & $16(0.8)$ & $6(0.6)$ & $2(0.7)$ & $8(1.1)$ & & $1(0.3)$ & $3(0.6)$ & $6(1.2)$ & $6(1.0)$ & \\
\hline $\begin{array}{l}\text { Met Cholesterol Objective } \\
(83 \% \text { of population ideal })^{\dagger}\end{array}$ & $44(2.2)$ & $10(1.0)$ & $6(2.0)$ & $28(3.7)$ & * & $11(2.7)$ & $14(2.8)$ & $9(1.7)$ & $10(1.6)$ & \\
\hline $\begin{array}{l}\text { Met Diabetes Objective } \\
(97.5 \% \text { of population ideal })^{\dagger}\end{array}$ & $92(4.5)$ & $28(2.8)$ & $10(3.4)$ & $54(7.2)$ & * & $17(4.2)$ & $15(3.0)$ & $23(4.4)$ & $37(6.0)$ & \\
\hline $\begin{array}{l}\text { Met BMI Objective } \\
(60 \% \text { of population ideal })^{\dagger}\end{array}$ & $37(1.8)$ & $9(0.9)$ & $9(3.0)$ & $19(2.5)$ & * & $10(2.5)$ & $8(1.6)$ & $11(2.1)$ & $8(1.3)$ & \\
\hline $\begin{array}{l}\text { Met Smoking Objective } \\
(88 \% \text { of population ideal })^{\dagger}\end{array}$ & $556(27.0)$ & $274(27.3)$ & $64(21.6)$ & $218(29.1)$ & * & $90(22.1)$ & $126(25.1)$ & $131(25.2)$ & $209(33.7)$ & * \\
\hline 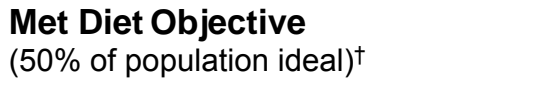 & $14(0.7)$ & $5(0.5)$ & $3(1.0)$ & $6(0.8)$ & & $3(0.7)$ & $4(0.8)$ & $5(1.0)$ & $2(0.3)$ & \\
\hline $\begin{array}{l}\text { Met Physical Activity Objective } \\
(50 \% \text { of population ideal })^{\dagger}\end{array}$ & $10(0.5)$ & $3(0.3)$ & $0(0.0)$ & $7(0.9)$ & & $3(0.7)$ & $4(0.8)$ & $2(0.4)$ & $1(0.2)$ & \\
\hline
\end{tabular}

Total number of counties included $=2051$

† Determined using Healthy People 2010 goals

* Significant at the 0.05 level

¥ Metropolitan is based on the designation defined by the Office of Management and Budget, Non-Metropolitan is defined as counties with no metropolitan designation and a population of more than or equal to 20,000, Rural is defined as counties with a population of less than 20,000

** Income Quartile $1(<\$ 36,129)$, Quartile $2(\$ 36,129$ - $\$ 41,256)$, Quartile $3(\$ 41,256$ - $\$ 47,724)$, Quartile $4(>\$ 47,724)$ 
Table 4. Univariate, adjusted, and standardized linear regression analysis assessing associations between county sociodemographic characteristics and mean age-standardized $\mathrm{CVHI}$, adjusted $\mathrm{R}^{2}=0.25$, coefficient (95\% confidence interval)

\begin{tabular}{|c|c|c|c|c|c|c|c|c|c|}
\hline $\begin{array}{l}\text { Sociodemographic } \\
\text { Covariates }\end{array}$ & & Univariate & & & Adjusted & & $\begin{array}{l}\text { Adjusted and } \\
\text { Standardized }\end{array}$ & $\begin{array}{l}\text { Standard } \\
\text { Deviation }\end{array}$ & \\
\hline Intercept & & & & 2.72 & & & & & \\
\hline$\%$ Male & 0.006 & $(-0.002,0.01)$ & & 0.02 & $(0.009,0.03)$ & ** & 0.03 & 1.7 & ** \\
\hline \% Non-Hispanic Black & -0.003 & $(-0.004,-0.002)$ & ** & -0.0001 & $(-0.001,0.001)$ & & -0.002 & 13.9 & \\
\hline$\%$ Hispanic & 0.005 & $(0.003,0.006)$ & ** & 0.004 & $(0.003,0.006)$ & ** & 0.05 & 10.9 & ** \\
\hline Median Household Income & 0.00001 & $(0.00001,0.000013)$ & ** & -0.0000002 & $(-0.000004,0.000001)$ & & -0.02 & 11000 & \\
\hline$\%$ Poverty & -0.017 & $(-0.02,-0.015)$ & ** & -0.006 & $(-0.01,-0.002)$ & ** & -0.04 & 6.0 & ** \\
\hline $\begin{array}{l}\text { Gini Coefficient } \\
\text { Population Density }\end{array}$ & -0.33 & $(-0.8,0.1)$ & & -0.32 & $(-0.92,0.27)$ & & -0.01 & 0.03 & \\
\hline Non-Metro vs Metro & -0.04 & $(-0.08,0.007)$ & & 0.05 & $(0.005,0.09)$ & * & 0.02 & 0.35 & * \\
\hline Rural vs Metro & -0.14 & $(-0.17,-0.1)$ & ** & 0.02 & $(-0.02,0.05)$ & & 0.009 & 0.48 & \\
\hline$\%$ College Graduates & 0.017 & $(0.016,0.019)$ & ** & 0.017 & $(0.014,0.019)$ & ** & 0.16 & 9.3 & ** \\
\hline$\%$ With No Insurance & -0.01 & $(-0.02,-0.01)$ & ** & -0.004 & $(-0.008,-0.0005)$ & * & -0.02 & 5.0 & * \\
\hline
\end{tabular}

${ }^{*} p<0.05$

$* * p<0.01$ 
Table 5. Linear regression analysis assessing associations between county sociodemographic characteristics and mean age-standardized CVHI stratified by median household income quartile, coefficient ( $95 \%$ confidence interval).

\begin{tabular}{|c|c|c|c|c|c|c|c|c|c|c|c|c|}
\hline \multirow[b]{2}{*}{$\begin{array}{l}\text { Sociodemographic } \\
\text { Covariates }\end{array}$} & \multicolumn{12}{|c|}{ Median Household Income } \\
\hline & \multicolumn{3}{|c|}{$\begin{array}{c}\text { Quartile 1 } \\
\text { (Less than } \$ 36,129) \\
\text { adjusted } R^{2}=0.11\end{array}$} & \multicolumn{3}{|c|}{$\begin{array}{c}\text { Quartile 2 } \\
(\$ 36,129-\$ 41,256) \\
\text { adjusted } R^{2}=0.09\end{array}$} & \multicolumn{3}{|c|}{$\begin{array}{c}\text { Quartile 3 } \\
\text { (\$41,256 }-\$ 47,724) \\
\text { adjusted } \mathrm{R}^{2}=0.08\end{array}$} & \multicolumn{3}{|c|}{$\begin{array}{c}\text { Quartile 4 } \\
\text { (Greater than } \$ 47,724) \\
\text { adjusted } \mathrm{R}^{2}=0.26\end{array}$} \\
\hline Intercept & 2.25 & & & 2.44 & & & 2.29 & & & 3.11 & & \\
\hline$\%$ Male & 0.02 & $(0.005,0.04)$ & ** & 0.02 & $(0.001,0.03)$ & * & 0.02 & $(-0.004,0.03)$ & & 0.004 & $(-0.01,0.02)$ & \\
\hline$\%$ Non-Hispanic Black & 0.001 & $(-0.001,0.003)$ & & -0.0006 & $(-0.003,0.002)$ & & -0.002 & $(-0.005,0.001)$ & & -0.003 & $(-0.005,-0.0001)$ & * \\
\hline$\%$ Hispanic & 0.004 & $(0.0008,0.008)$ & * & 0.004 & $(0.001,0.008)$ & ** & 0.002 & $(-0.006,0.006)$ & & 0.003 & $(0.0004,0.006)$ & * \\
\hline$\%$ Poverty & -0.0009 & $(-0.01,0.008)$ & & -0.001 & $(-0.01,0.008)$ & & -0.004 & $(-0.02,0.008)$ & & 0.0002 & $(-0.008,0.008)$ & \\
\hline Gini Coefficient & -1.45 & $(-3.0,0.11)$ & & 0.11 & $(-1.3,1.5)$ & & 1.0 & $(-0.46,2.4)$ & & -0.14 & $(-0.91,0.63)$ & \\
\hline Population Density ${ }^{\dagger}$ & & & & & & & & & & & & \\
\hline Non-Metro vs Metro & 0.17 & $(0.04,0.31)$ & * & 0.06 & $(-0.01,0.14)$ & & -0.02 & $(-0.1,0.06)$ & & 0.05 & $(-0.03,0.13)$ & \\
\hline Rural vs Metro & 0.1 & $(0.001,0.21)$ & * & 0.03 & $(-0.04,0.09)$ & & -0.01 & $(-0.08,0.06)$ & & 0.08 & $(0.02,0.15)$ & * \\
\hline$\%$ College Graduates & 0.02 & $(0.01,0.03)$ & ** & 0.01 & $(0.009,0.02)$ & ** & 0.01 & $(0.006,0.02)$ & ** & 0.015 & $(0.012,0.017)$ & \\
\hline$\%$ With No Insurance & -0.001 & $(-0.01,0.01)$ & & -0.005 & $(-0.01,0.003)$ & & -0.006 & $(-0.01,0.002)$ & & -0.002 & $(-0.008,0.003)$ & \\
\hline
\end{tabular}

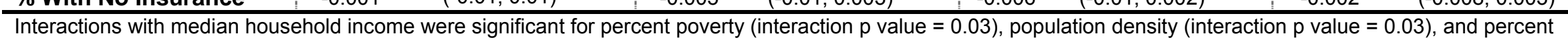
college graduates (interaction $p$ value $<0.0001$ ). Significant interactions indicated in table by shading.

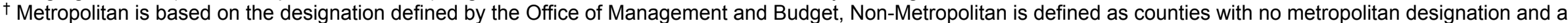
population of more than or equal to 20,000 , Rural is defined as counties with a population of less than 20,000

${ }^{*} p<0.05$

$* * p<0.01$ 


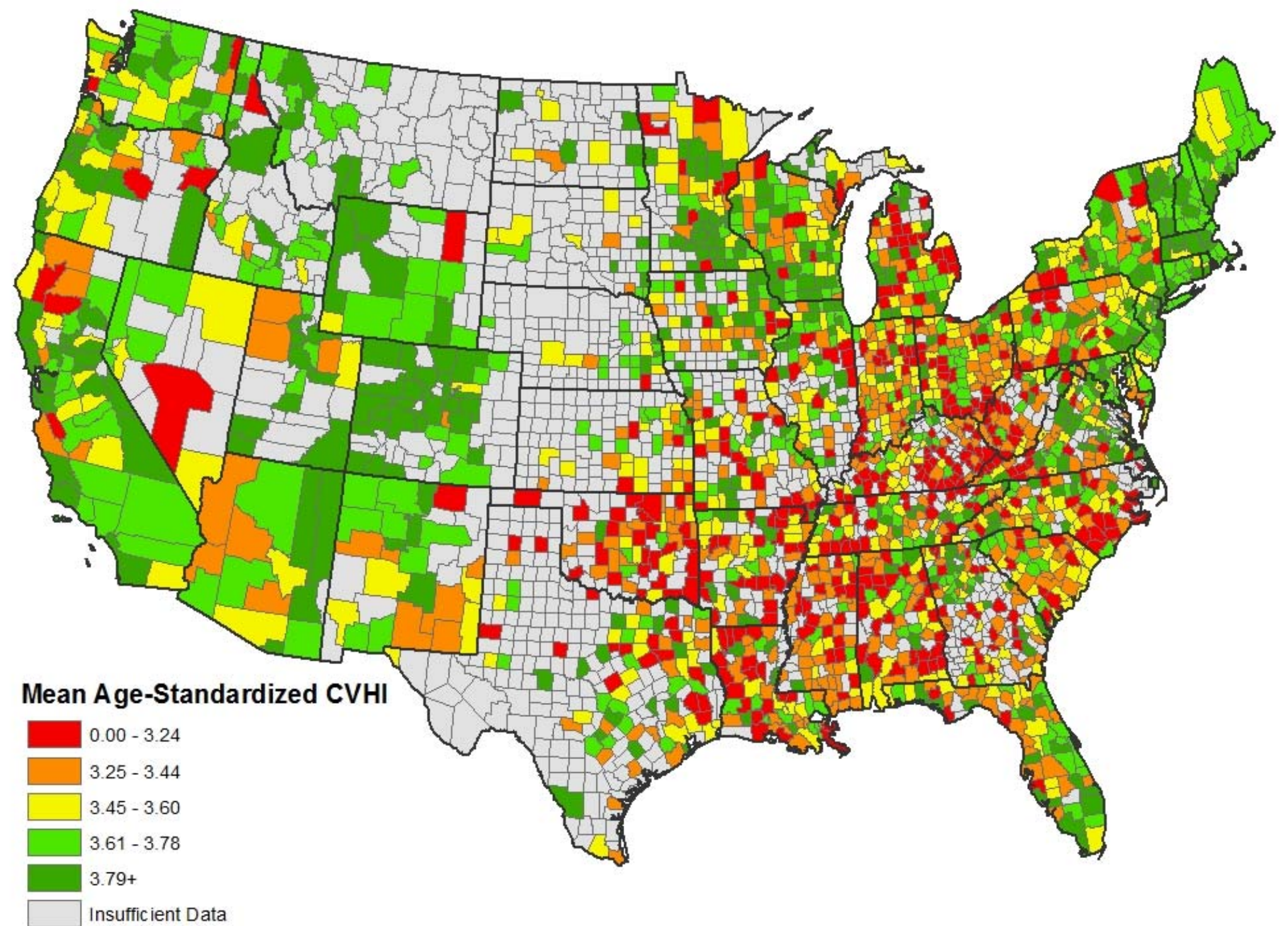

Figure 1. Mean age-standardized cardiovascular health index by quintile for each United States county using 2009 Behavioral Risk Factor Surveillance Study (BFRSS). 


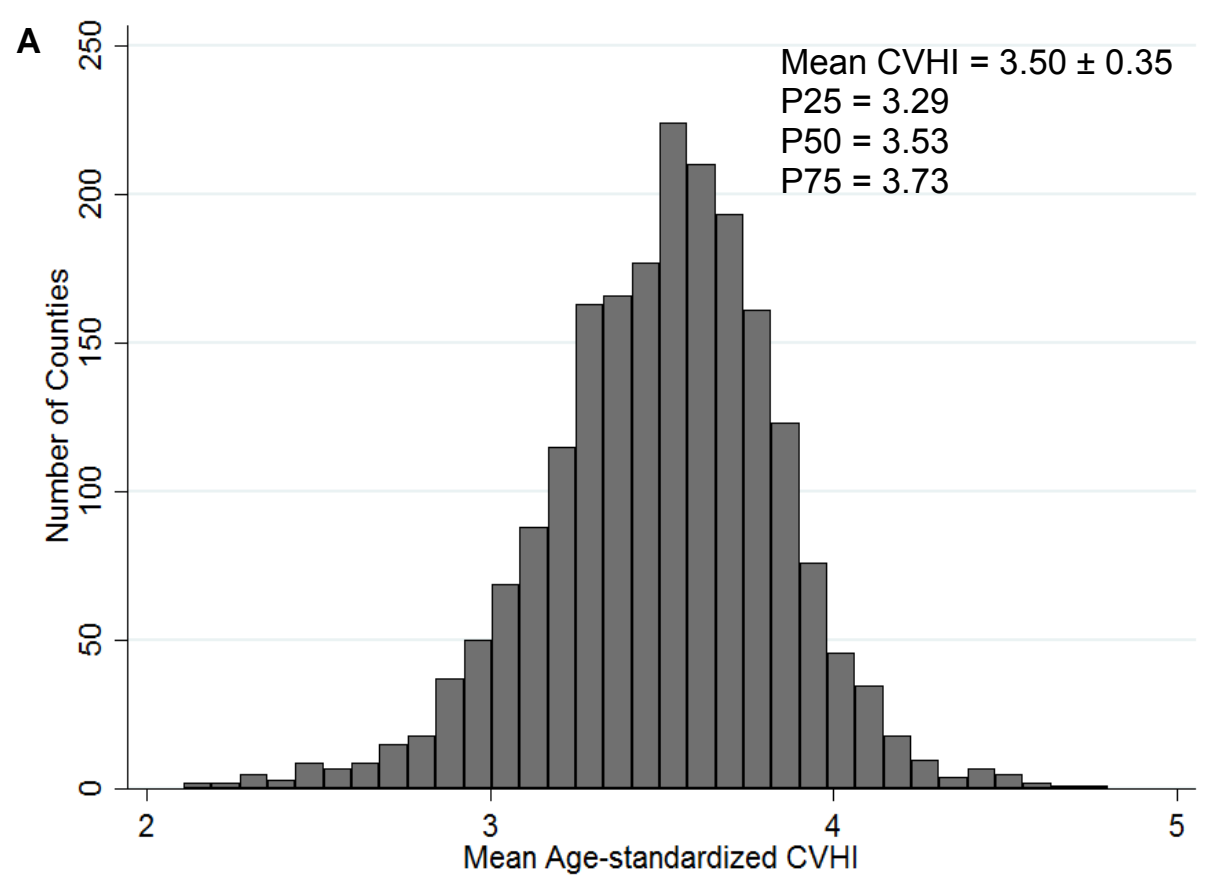

B

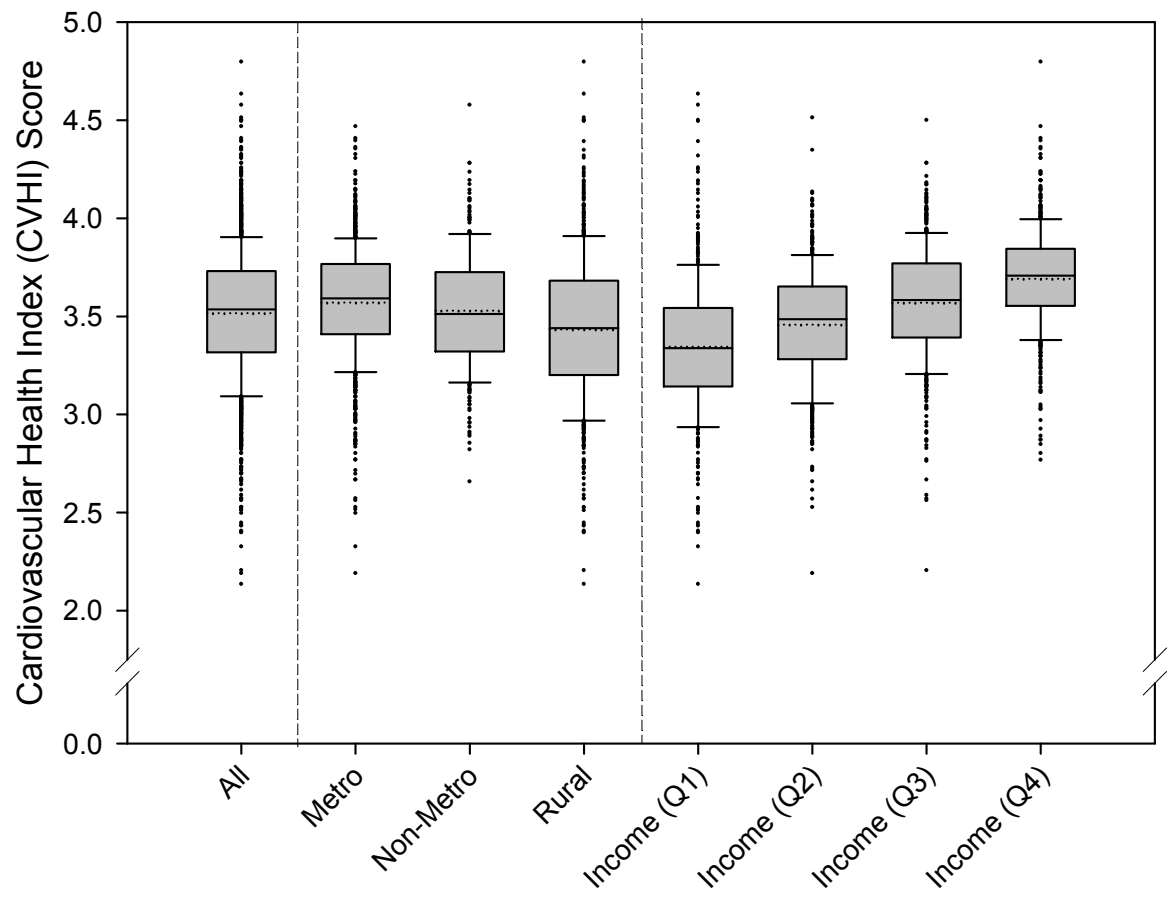

C
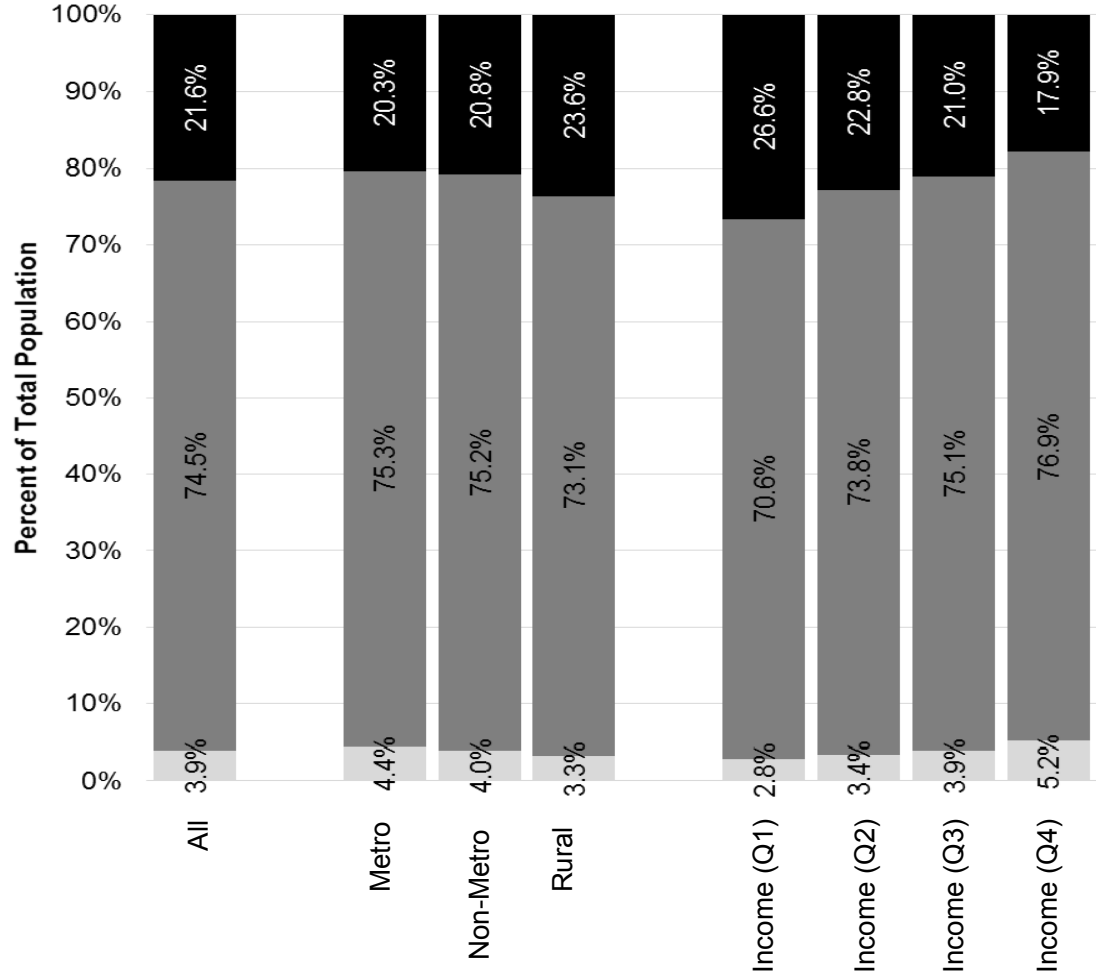

Percent Poor

Percent Intermediate

Figure 2. Distribution of age-standardized mean $\mathrm{CVHI}$ for all counties and stratified by population density and median household income. Panel $A$ is the frequency distribution of United States counties by their mean CVHI. Panel B is a box plot of $\mathrm{CVHI}$ for all counties and stratifications. Panel $\mathrm{C}$ is the distribution of the categories of CVHI, ideal, intermediate, and poor, for all counties and stratifications. 


\section{Chapter 3}

FULL TITLE: Influence of individual and community socioeconomic factors on cardiovascular health in the United States

AUTHORS \& AFFILIATIONS: Courtney S. Pilkerton, B.A. ${ }^{1,2,3}$, Sarah S. Singh, M.D. ${ }^{2,3}$, Thomas

K. Bias, $\mathrm{PhD}^{3,4}$, Adam D. Christian, B.S. ${ }^{1}$, and Stephanie J. Frisbee, $\mathrm{PhD}^{3,4}$

${ }^{1}$ West Virginia University School of Medicine, Morgantown, WV

${ }^{2}$ West Virginia University School of Public Health, Department of Epidemiology, Morgantown, WV

${ }^{3}$ West Virginia University Robert C. Byrd Health Sciences Center, Center for Cardiovascular and Respiratory Sciences, Morgantown, WV

${ }^{4}$ West Virginia University School of Public Health, Department of Health Policy, Management \& Leadership, Morgantown, WV

\section{CORRESPONDING AUTHOR:}

Stephanie J. Frisbee, PhD

West Virginia University

Robert C. Byrd Health Sciences Center

Center for Cardiovascular \& Respiratory Sciences

1 Medical Center Drive - PO Box 1905

Morgantown WV 26505-1905

304-293-6552 / sfrisbee@hsc.wvu.edu

WORD COUNT: Total Words (1472), Number of Pages (15), Tables (2), Figures (1)

\section{CONFLICTS OF INTEREST:}

Courtney S. Pilkerton has no conflicts of interest.

Sarah S. Singh has no conflicts of interest.

Thomas K. Bias has no conflicts of interest.

Stephanie J. Frisbee has no conflicts of interest.

Adam D. Christian has no conflicts of interest.

\section{FINANCIAL DISCLOSURES:}

Courtney S. Pilkerton has no financial disclosures.

Sarah S. Singh has no financial disclosures.

Thomas K. Bias has no financial disclosures.

Stephanie J. Frisbee has no financial disclosures.

Adam D. Christian has no financial disclosures. 


\section{ABSTRACT}

Introduction: Despite advances in treatment and decreases in risk factors, cardiovascular disease remains the cause of 1 in 3 deaths in the United States. A thorough understanding of health determinants requires inclusion of factors at multiple levels of proximity to individuals. The objective of this study was to identify the characteristics of individuals and the areas in which they live that promote cardiovascular health.

Methods: 2011 Behavioral Risk Factor Surveillance System survey data were used to calculate American Heart Association's cardiovascular health index (CVHI) for individuals. County variables were abstracted from Area Health Resource File. Poisson regression was used to determine the association between individual/county characteristics and $\mathrm{CVHI}$.

Results: Females had a $12.0 \%(12.0,13.0)$ higher CVHI than males. Individuals identifying as non-Hispanic black had a 7.0\% $(6.0,8.0)$ higher CVHI than non-Hispanic whites. An individual's education and income had a dose response association with $\mathrm{CVHI}$. A 10\% increase in the number of college graduates in a county was associated with 4.0\% $(4.0,4.0)$ higher CVHI. There was a significant interaction $(p<0.01)$ between an individual's income level and the median household income of the county lived in and $(p<0.01)$ between an individual's race/ethnicity and the ethnic density of the county in which they live.

Conclusion: Both individual and county demographic characteristics were associated with individual-level $\mathrm{CVHI}$ and county demographic characteristics can modify the relationship between individual factors and CVHI. This information can assist public health and government agencies in developing priorities and evaluating the potential effectiveness of policies and programs. 


\section{INTRODUCTION}

Cardiovascular disease is the cause of 1 in 3 deaths in the U.S. ${ }^{2}$. It is expected the prevalence of cardiovascular disease will increase by $10 \%$ and direct medical costs will triple by $2030^{8}$. Many studies have identified the importance of individual socioeconomic and demographic characteristics in determining cardiovascular health. An individual's sex ${ }^{34}$, race/ethnicity ${ }^{34}$, $\operatorname{age}^{25}$, and education level $24,34,51,52$ have all been found to be associated with both cardiovascular disease and cardiovascular health. Although some social or group level

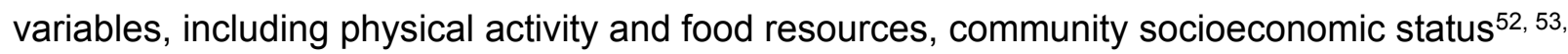
95, 97, 101-103, and racial composition ${ }^{97}$, have also been found to impact cardiovascular disease their relationship and those of other community factors have not been as thoroughly examined. Understanding the influences of variables at levels more distal to an individual are important as they are thought to influence health through impacting an individual's stress, values, and locus of control ${ }^{55}$. The objective of this study was to identify the socioeconomic and demographic characteristics of individuals and the areas in which they live that promote cardiovascular health and how the relationships between individual and group level variables can modify each other.

\section{METHODS}

\section{Data Sources}

The Behavioral Risk Factor Surveillance System (BRFSS) is an annually administered national telephone survey in each U.S. state and the District of Columbia. Detailed description of BRFSS study design and methods are described elsewhere ${ }^{56}$. BRFSS data from 2011 was abstracted for cardiovascular health index (CVHI) component questions and individual socioeconomic and demographic characteristics. Socioeconomic and demographic characteristics of each county were abstracted from the Area Health Resource File (AHRF) ${ }^{89}$. 
AHRF is an annual compilation of health care resources and socioeconomic data collected from over 50 sources (e.g., Census, Medicare, etc.) by the Health Resources and Services Administration.

\section{Study Population}

All participants of the 2011 BRFSS survey were examined to determine eligibility $(n=507,402)$. Participants were excluded if they were missing any question required to determine one of the seven CVHI components $(n=157,908)$ or if missing a county Federal Information Processing Standards (FIPS) code $(n=37,163)$. Females were also ineligible if pregnant or pregnancy status unknown at the time of survey $(n=3,693)$. The final population of eligible individuals was 308,895 .

\section{Cardiovascular Health}

BRFSS questions used to determine ideal for each of the American Heart Association's CVHI ${ }^{12}$ components were defined using previous work by Fang et al ${ }^{35}$. Cholesterol, blood pressure, and blood glucose were considered ideal if they had never been told by a health provider they had high cholesterol, high blood pressure, or diabetes. Body mass index for an individual was considered ideal between 18.5 and 24.9. Smoking behavior was considered ideal if individual had not smoked at least 100 cigarettes in their lifetime or not currently smoking. Diet was considered ideal if the individual had $\geq$ to 5 servings of fruits and vegetables per day. Physical activity was considered ideal if the individual participated in $\geq 150 \mathrm{~min} /$ week moderate intensity $\mathrm{OR} \geq 75 \mathrm{~min} /$ week vigorous intensity OR equivalent combination. $\mathrm{CVHI}$ was calculated as a sum of components meeting ideal criteria, ranging from 0 to 7 . 


\section{Covariates}

Individual socioeconomic and demographic characteristics included age, sex, race/ethnicity (non-Hispanic white, non-Hispanic black, Hispanic, and other), education level (less than high school, high school, some college), and income (under $\$ 25,000, \$ 25,000$ - \$49,999, \$50,000 $\$ 74,999, \$ 75,000$ or more). County socioeconomic and demographic covariates included sex (percent of the population male), percent non-Hispanic black, percent Hispanic, median household income, percent four-year college graduates, percent without health insurance, percent unemployment, percent of the population over 65 years old, and percent poverty.

\section{Statistical Analysis}

Study population characteristics were estimated using weighted means and percentages of each covariate. Univariate and adjusted Poisson regression analysis was performed to determine the association between individual and county socioeconomic and demographic characteristics and individual-level CVHI. Poisson regression coefficients are interpreted as mean ratios; the mean $\mathrm{CVHI}$ of a group over the mean $\mathrm{CVHI}$ of the referent group. Interactions between county-level factors and individual-level factors were assessed. For significant interactions, the margins command was used to determine predicted individual-level CVHI by county-level factors for individual group levels. All statistical analyses were performed with Stata 13 (StataCorp. 2013. Stata Statistical Software: Release 13. College Station, TX: StataCorp LP) and accounting for survey weights. 


\section{RESULTS}

Socioeconomic and demographic characteristics of the study population are presented in Table

1. Counties in which study participants lived had an average population that was $49.2 \%$ male, $12.1 \%$ Non-Hispanic black, and $15.3 \%$ Hispanic. On average, $15.8 \%$ of a county's population was classified as living in poverty, $13.2 \%$ were age 65 or older, $17.3 \%$ had no health insurance, and $27.8 \%$ of adults over 25 years of age were four-year college graduates. Additionally, the average county had a median household income of $\$ 52,260$. The average individual was 51 years old. The study population was $52.2 \%$ female, $72.2 \%$ Non-Hispanic white, $59.5 \%$ had some college, and $31.6 \%$ had an annual household income of $\$ 75,000$ or more. The average CVHI was $3.31 \pm 0.005$, with $2.6 \% \pm 0.001$ of the population having ideal $\mathrm{CVHI}$ (6 or 7 ideal components) and $26.6 \% \pm 0.002$ having poor CVHI (0-2 ideal components).

Analysis from the Poisson regression for the association between individual and county socioeconomic and demographic factors and individual CVHI are presented in Table 2. Both individual and county factors were significantly associated with CVHI, except county percent Non-Hispanic black and county percent living at or below the poverty line. Females had $12 \%$ higher $\mathrm{CVHI}$ than males. Individuals identifying as non-Hispanic black had 7\% lower $\mathrm{CVHI}$ than Non-Hispanic whites and those identifying as other race/ethnicity had $2 \%$ higher CVHI. There was a dose response effect for both education and income with increasing education and income associated with higher $\mathrm{CVHI}$. Higher percent of a county unemployed, male, and college graduates was associated with $4 \%$ higher CVHI. Higher percent of a county with no health insurance was associated with $2 \%$ lower $\mathrm{CVHI}$.

Predicted CVHI analysis for significant interactions between individual and community factors are presented in Figure 1. Individuals with a household income of less than $\$ 25,000$ had higher CVHI as county median household income went up while all other household income groups had lower CVHI (Figure 1A). Males had lower CVHI as county median household income went 
up while there was no significant change in females (Figure 1B). CVHI was higher for all age and race/ethnicity groups as county population with a college education went up (Figure 1C and 1D). Steeper slope in CVHI were seen for younger individuals, Non-Hispanic white, and other race/ethnicity. Non-Hispanic whites have lower CVHI as county percent Non-Hispanic black went up (Figure 1E). Non-Hispanic-blacks have higher $\mathrm{CVHI}$ as county percent Non-Hispanic black went up.

\section{DISCUSSION}

To our knowledge, this is the first study to assess the relationships, including interactions, between both individual and county demographic characteristics and CVHI. Results show cardiovascular health is low in the United States and that both individual characteristics and county demographics are associated with cardiovascular health. These findings are consistent with the growing body of literature documenting the association between individual characteristics and both cardiovascular disease and health ${ }^{25}$. In addition to the community socioeconomic status variables ${ }^{53}$, these findings suggest previously unstudied community factors are associated with CVHI. Counties with larger percentages of seniors, males, insured, and college graduates are all associated with individual-level CVHI.

A growing body of literature supports an "ethnic density" effect in which the higher the density of an individual's race/ethnicity in their community the better the health outcomes ${ }^{104,105}$. It has been suggested that social cohesion and connection this density provides decreased stress leading to improved health ${ }^{106}$. Many studies have examined the association between health outcomes and income inequality, but none to our knowledge have examined how community income may modify the relationship between an individual's income or gender and health. It has been suggested there is marginal benefit to individuals who have high social status relative 
to those around them ${ }^{107}$. The poorest individuals benefit from living in higher income areas possibly due to increased services while higher income individuals benefit when in lower income areas.

\section{Limitations}

The self-report nature of BRFSS questions as well as questions for cholesterol, blood pressure, and diabetes that require participants to have seen a health provider may lead to an overestimation of ideal health. There is also possible bias as there was a significant percentage of participants with missing data for at least one CVHI component. As a cross-sectional study, no causal inferences can be made, but our findings add to the literature supporting the association between individual and community characteristics and cardiovascular health.

\section{Conclusions}

In conclusion, this study provides an assessment of the relationships and interactions between individual and county socioeconomic and demographic characteristics and cardiovascular health. Future studies should evaluate not only if policies and programs can improve overall health, but if they can modify the interactions between individual and community factors to possibly decrease or eliminate disparities. 


\section{Acknowledgements:}

The authors wish to thank Dr. Matthew J. Gurka from the West Virginia University School of Public Health for his very helpful technical (statistical) advice during this study.

\section{Funding Sources:}

Board. Research reported in this study was supported, in part, by the West Virginia Clinical and Translational Research Institute (WV-CTSI), which is supported by the National Institute of General Medical Sciences of the National Institute of Health under award U54GM104942. The content is solely the responsibility of the authors and does not necessarily represent the official views of the National Institutes of Health.

\section{Disclosures:}

This study was approved as non-human subjects research by the West Virginia University Institutional Review 
Table 1. Characteristics of study population, BRFSS 2011.

\section{County Demographic Characteristics}

Percent 65 Years and Older

$13.2 \pm 0.01$

Percent Male

$49.2 \pm 0.004$

Percent Non-Hispanic Black

$12.1 \pm 0.04$

Percent Hispanic

$15.3 \pm 0.06$

Percent College Graduates

$27.8 \pm 0.03$

Median Household Income (\$)

$52260 \pm 46$

Percent Poverty

$15.8 \pm 0.02$

Percent Unemployment

$9.1 \pm 0.01$

Percent No Health Insurance

$17.3 \pm 0.02$

\section{Individual Demographic Characteristics}

Age (years)

Sex

Race/Ethnicity

$\begin{array}{rr}\text { Female } & 193,473(52.2 \%) \\ \text { Male } & 123,283(47.8 \%)\end{array}$

Non-Hispanic White $\quad 254,944(72.2 \%)$

Non-Hispanic Black $\quad 26,450(11.3 \%)$

Hispanic $\quad 16,243(11.1 \%)$

Other $\quad 10,744(5.4 \%)$

Education

$$
\begin{array}{rr}
\text { Less than High School } & 24,026(12.3 \%) \\
\text { High School } & 88,975(28.2 \%) \\
\text { Some College } & 203,272(59.5 \%)
\end{array}
$$

Income

$\begin{array}{rr}\text { Under } \$ 25,000 & 77,144(26.7 \%) \\ \$ 25,000-\$ 49,999 & 74,078(25.3 \%) \\ \$ 50,000-\$ 74,999 & 45,967(16.4 \%) \\ \$ 75,000 \text { or More } & 82,058(31.6 \%)\end{array}$

Cardiovascular Health

Mean Individual Cardiovascular Health Index

$3.31 \pm 0.005$

Percent with Poor Cardiovascular Health Index

$26.6 \pm 0.002$

Percent with Intermediate Cardiovascular Health Index

$70.8 \pm 0.002$

Percent with Ideal Cardiovascular Health Index

$2.6 \pm 0.001$

BRFSS - Behavioral Risk Factor Surveillance System

Mean \pm standard deviation is presented for continuous variables and $\mathrm{n}$ (weighted frequency) is presented for categorical variables. 
Table 2. Poisson regression analysis for the association between individual and county socioeconomic and demographic factors and individual cardiovascular health index (CVHI).

\begin{tabular}{|c|c|c|c|}
\hline Covariate & Univariate $^{\S}$ & Semi-Adjusted $^{\S}$ & Fully Adjusted $^{\S}$ \\
\hline \multicolumn{4}{|l|}{ County Demographic Characteristics } \\
\hline Percent Non-Hispanic Black ${ }^{\dagger}$ & $0.99(0.99-0.99)^{*}$ & $1.00(0.99-1.00)^{*}$ & $1.00(1.00-1.00)$ \\
\hline Percent Hispanic ${ }^{\dagger}$ & $1.01(1.01-1.01)^{*}$ & $1.01(1.01-1.02)^{*}$ & $1.01(1.01-1.02)^{*}$ \\
\hline Percent Unemployment ${ }^{\dagger}$ & $0.94(0.93-0.96)^{*}$ & $1.04(1.03-1.06)^{*}$ & $1.04(1.03-1.06)^{*}$ \\
\hline Percent 65 Years and Older ${ }^{\dagger}$ & $0.94(0.93-0.94)^{*}$ & $0.99(0.98-1.00)^{*}$ & $1.02(1.01-1.03)^{*}$ \\
\hline Percent Male $^{\dagger}$ & $0.98(0.96-1.00)^{*} \ddagger$ & $1.04(1.01-1.06)^{*}$ & $1.04(1.02-1.07)^{*}$ \\
\hline Percent Poverty ${ }^{\dagger}$ & $0.95(0.94-0.95)^{*}$ & $0.97(0.96-0.98)^{*}$ & $0.99(0.98-1.00)$ \\
\hline Percent College Graduates ${ }^{\dagger}$ & $1.05(1.05-1.06)^{*}$ & $1.05(1.05-1.06)^{*}$ & $1.04(1.04-1.04)^{*}$ \\
\hline Median Household Income (per \$5000) & $1.02(1.02-1.02)^{*}$ & $1.00(0.99-1.00)^{*} \ddagger$ & $1.00(1.00-1.00)^{*} \ddagger$ \\
\hline Percent No Health Insurance ${ }^{\dagger}$ & $0.97(0.97-0.98)^{*}$ & $0.98(0.97-0.99)^{*}$ & $0.98(0.97-0.99)^{*}$ \\
\hline \multicolumn{4}{|l|}{ Individual Demographic Characteristics } \\
\hline Age (per 5 years) & $0.97(0.97-0.97)^{*}$ & $0.97(0.97-0.97)^{*}$ & $0.99(0.99-0.99)^{*}$ \\
\hline \multicolumn{4}{|l|}{ Sex } \\
\hline Male & 1.00 & 1.00 & 1.00 \\
\hline Female & $1.10(1.09-1.10)^{*}$ & $1.12(1.11-1.13)^{*}$ & $1.12(1.12-1.13)$ \\
\hline \multicolumn{4}{|l|}{ Race/Ethnicity } \\
\hline Non-Hispanic White & 1.00 & 1.00 & 1.00 \\
\hline Non-Hispanic Black & $0.92(0.91-0.93)^{*}$ & $0.93(0.92-0.94)^{*}$ & $0.93(0.92-0.94)$ \\
\hline Hispanic & $1.01(1.00-1.02)^{\ddagger}$ & $1.02(1.01-1.03)^{*}$ & $1.00(0.98-1.01)$ \\
\hline Other & $1.09(1.07-1.10)^{*}$ & $1.03(1.02-1.05)^{*}$ & $1.02(1.00-1.03)^{*}$ \\
\hline \multicolumn{4}{|l|}{ Education } \\
\hline Less than High School & 1.00 & 1.00 & 1.00 \\
\hline High School & $1.10(1.09-1.12)^{*}$ & $1.05(1.04-1.07)^{*}$ & $1.05(1.04-1.06)^{*}$ \\
\hline Some College & $1.26(1.24-1.27)^{*}$ & $1.13(1.11-1.14)^{*}$ & $1.11(1.10-1.13)^{*}$ \\
\hline \multicolumn{4}{|l|}{ Income } \\
\hline Under $\$ 25,000$ & 1.00 & 1.00 & 1.00 \\
\hline$\$ 25,000-\$ 49,999$ & $1.10(1.09-1.11)^{*}$ & $1.08(1.07-1.09)^{*}$ & $1.08(1.07-1.09)^{*}$ \\
\hline$\$ 50,000-\$ 74,999$ & $1.16(1.15-1.17)^{*}$ & $1.11(1.10-1.12)^{*}$ & $1.11(1.10-1.12)$ \\
\hline$\$ 75,000$ or More & $1.26(1.25-1.27)^{*}$ & $1.18(1.17-1.19)^{*}$ & $1.16(1.16-1.17)$ \\
\hline
\end{tabular}

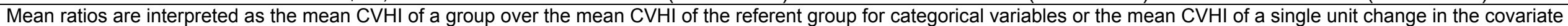
over the mean $\mathrm{CVHI}$ of the base level of the covariate for continuous variables.

* Indicates significance at the alpha 0.05 level.

$\dagger$ Coefficients are presented as a 10 unit change in the covariate.

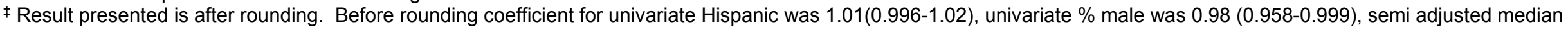
household income was 0.9999992(0.9999987, 0.9999997), fully adjusted median household income was 0.999999(0.9999985, 0.9999995)

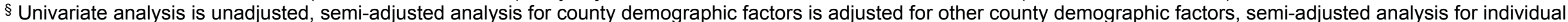
demographic factors is adjusted for other individual demographic factors, and fully adjusted analysis is adjusted for both county and individual demographic factors. 

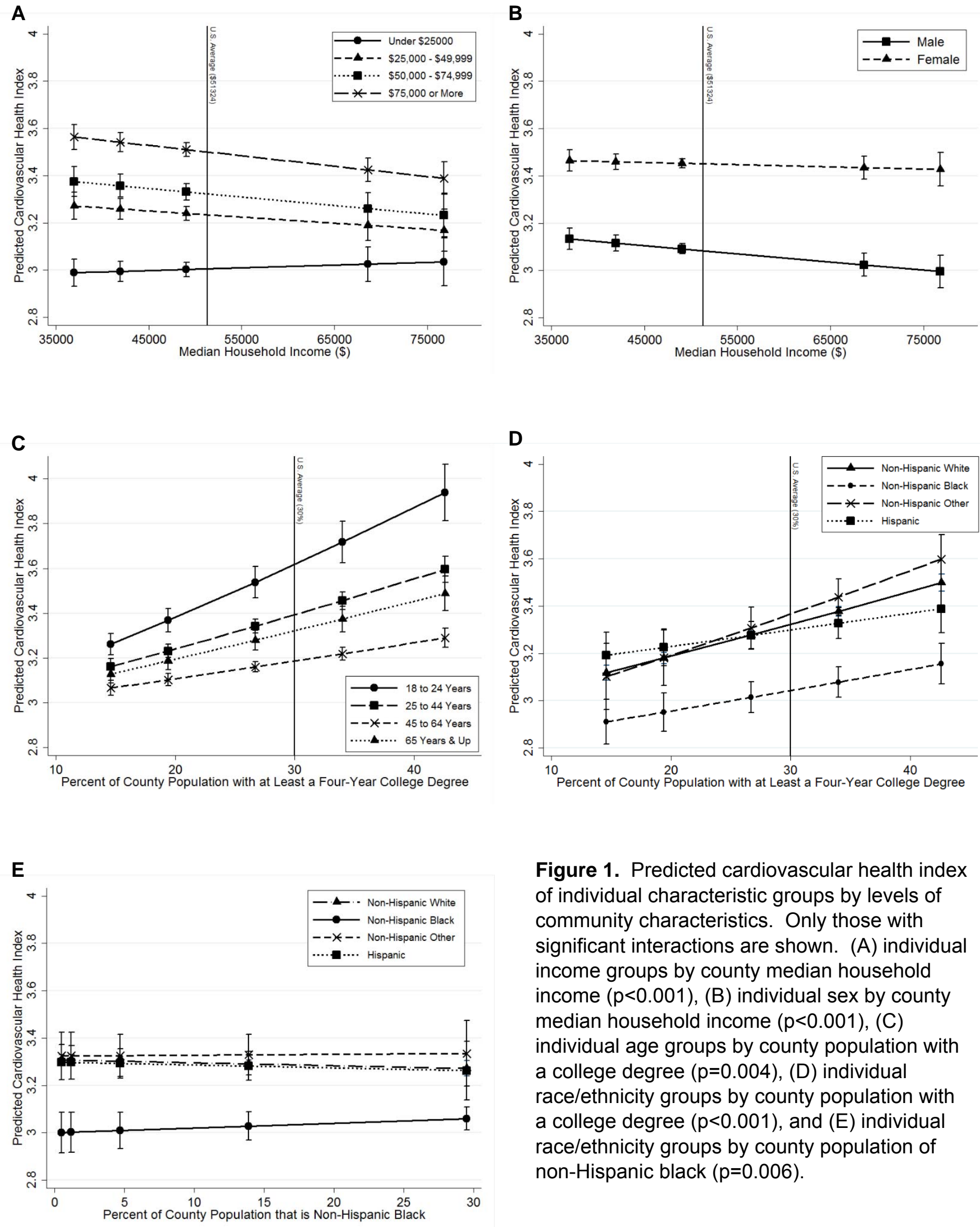

Figure 1. Predicted cardiovascular health index of individual characteristic groups by levels of community characteristics. Only those with significant interactions are shown. (A) individual income groups by county median household income $(p<0.001),(B)$ individual sex by county median household income $(p<0.001),(C)$ individual age groups by county population with a college degree $(p=0.004),(D)$ individual race/ethnicity groups by county population with a college degree $(p<0.001)$, and $(E)$ individual race/ethnicity groups by county population of non-Hispanic black $(p=0.006)$. 


\title{
Chapter 4
}

Full Title: Changes in Cardiovascular Health in the United States, 2003-2011

Short Title: Trends in CVHI, 2003-2011

Authors and Affiliations: Courtney S. Pilkerton, BA ${ }^{1,2,3}$, Sarah S. Singh, MD, $\mathrm{MPH}^{2,3}$, Thomas K. Bias, $\mathrm{PhD}^{2,4,5}$, and Stephanie J. Frisbee, $\mathrm{PhD}^{2,3,4}$

${ }^{1}$ School of Medicine, West Virginia University, Morgantown, WV

${ }^{2}$ School of Public Health, West Virginia University, Morgantown, WV

${ }^{3}$ Center for Cardiovascular and Respiratory Sciences, West Virginia University Robert C. Byrd Health Sciences Center, Morgantown, WV

${ }^{4}$ West Virginia Clinical and Translational Science Institute (WV-CTSI), West Virginia University, Morgantown, WV

${ }^{5}$ Health Research Center, West Virginia University Robert C. Byrd Health Sciences Center, Morgantown, WV

\author{
Corresponding Author: \\ Stephanie J. Frisbee, PhD \\ West Virginia University \\ Robert C. Byrd Health Sciences Center \\ Center for Cardiovascular \& Respiratory Sciences \\ 1 Medical Center Drive - PO Box 1905 \\ Morgantown WV 26505-1905 \\ 304-293-6552 / sfrisbee@hsc.wvu.edu
}

Journal Subject Codes: $8,112,113,121,135,190$

\section{Acknowledgements:}

The authors wish to thank Drs. Matthew J. Gurka and D. Leeann Long, both from the West Virginia University School of Public Health, for their very helpful technical (statistical) advice during this study.

\section{Disclosures:}

This study was approved as non-human subjects research by the West Virginia University Institutional Review Board. Research reported in this study was supported, in part, by the West Virginia Clinical and Translational Research Institute (WV-CTSI), which is supported by the National Institute of General Medical Sciences of the National Institute of Health under award U54GM104942. The content is solely the responsibility of the authors and does not necessarily represent the official views of the National Institutes of Health. 


\section{ABSTRACT}

Background: Cardiovascular disease is the leading cause of death in the United States, making improving cardiovascular health a key population health goal. As part of efforts to achieve this, the American Heart Association has developed the first comprehensive cardiovascular health index (CVHI). Our objective was to investigate the changes in $\mathrm{CVHI}$ in U.S. states from 2003-2011.

Methods and Results: CVHI was examined using Behavioral Risk Factor Surveillance data between 2003 and 2011 (odd-numbered years). Total CVHI decreased from 3.73 00.01 in 2003 to $3.45 \pm 0.01$ in 2011 . The majority of states (88\%) experienced a decline in $\mathrm{CVHI}$ and an increase in the prevalence of "poor" CVHI between 2003 and 2009. Among CVHI components, the highest prevalence of "ideal" was observed for blood glucose followed by smoking, whereas the lowest prevalence of "ideal" was observed for physical activity and diet. Between 2003 and 2009, prevalence of "ideal" smoking and diet status increased, while ideal prevalence of blood pressure, cholesterol, blood glucose, and physical activity status decreased. We observed statistically significant differences between 2009 and 2011, outside the scope of the 2003-2009 trend, which we hypothesize are partially attributable to differences in sample demographic characteristics related to changes in BRFSS methodology.

Conclusions: Overall, CVHI decreased resulting from the decreases in "ideal" blood pressure, body mass index, and cholesterol status, which may stem from low prevalence of ideal physical activity and diet status. These findings can be used to inform state-specific strategies and targets to improve cardiovascular health.

Key Words: cardiovascular health, epidemiology, states, trends, 2020 Strategic Impact Goals 


\section{INTRODUCTION}

In 2009, 83.6 million American adults had cardiovascular disease (CVD) with an overall CVD-attributable mortality rate of 235.5 per $100,000^{50}$. At an estimated total cost to the United States (U.S.) of $\$ 315.4$ billion, CVD presents a larger economic burden than any other disease $^{50}$. Despite advances in treatment and decreases in risk factors including smoking ${ }^{5}$, CVD remains the cause of 1 in 3 deaths ${ }^{50}$. Both prevalence and cost of CVD are expected to increase over the coming decades ${ }^{12}$, due to an aging population and projected increases in obesity and diabetes moderated by only limited improvements in diet and physical activity ${ }^{8,37}$. These concerns place an emphasis on primordial prevention, where public health efforts, including policy measures, target younger age groups to prevent risk factor formation, thus decreasing the likelihood of CVD and CVD-related mortality later in life ${ }^{9,36}$.

The American Heart Association's 2020 Strategic Impact Goals ${ }^{12}$ and Healthy People 2020 objectives $^{11}$ both emphasize the improvement of cardiovascular health as a priority. To this end, the American Heart Association (AHA) recently developed a comprehensive measure of cardiovascular health for use in individuals and populations. This cardiovascular health index (CVHI) incorporates biological health (total cholesterol, blood pressure, body mass index, and fasting plasma glucose) and behavioral (smoking, physical activity, and diet) factors ${ }^{12}$. The $\mathrm{CVHI}$ is presented as a total aggregate score ranging 0 to 7 and a classification of poor, intermediate, or ideal based on the status of components.

Prevalence of cardiovascular health, as measured with CVHI, has been examined in various populations globally $14,15,17,18$ and within the U.S. in both adults $25,26,33,34,84$ and adolescents $^{28}$. Ideal CVHI is associated with decreased $\mathrm{CVD}^{13,26,38}$ and decreased risk of death $^{36,85}$. Ideal CVHI during childhood has been associated with ideal levels of blood pressure, total cholesterol, and glucose later in life ${ }^{43}$. Studies have also reported that higher $\mathrm{CVHI}$ is associated with decreased unhealthy vascular changes ${ }^{19,39-42}$, decreased symptoms of depression ${ }^{47}$, higher cognitive functioning ${ }^{48}$, and decreased incident cancer ${ }^{49}$. 
Two studies have examined temporal changes in CVHI and its components in the U.S. ${ }^{37}$, 85. Both reported improvement in smoking behavior, declines in ideal body mass index (BMI) and blood glucose levels, and no change in ideal cholesterol, blood pressure, or physical activity. Whereas Yang et al reported no changes ideal diet, Huffman et al reported a slight improvement in diet in men but not women.

While geographic disparities in CVD and stroke are recognized with the southeastern U.S. having the highest all-cause and CVD specific mortality rates in the nation ${ }^{50,108-110}$, only one study has examined state-based differences in $\mathrm{CVHI}^{35}$. Currently, no studies have examined geographic differences in $\mathrm{CVHI}$ over time. The objective of this study was to investigate the change in CVHI in U.S. states from 2003-2011 using Behavioral Risk Factor Surveillance System (BRFSS) data. A secondary objective emerged during analysis based on observations of substantial differences between 2009 and 2011; we also report results of this sub-analysis.

\section{METHODS}

$\mathrm{CVHI}$ and its individual components were examined across the U.S. and then stratified by demographic characteristics and state. Time trends for each state were determined with a time variable (BRFSS study year) using Poisson regression for total $\mathrm{CVHI}$ and logistic regression for individual $\mathrm{CVHI}$ components. All models were adjusted for socioeconomic and demographic covariates.

\section{Data Source}

BRFSS is an annually administered national telephone survey collecting information in each U.S. state on health risk behaviors, chronic health conditions, and use of preventive services $^{111}$. State health departments, with support from the Center for Disease Control and Prevention, use random digit dialing to interview adults 18 years old and older who are part of the civilian, non-institutionalized population. Detailed descriptions of BRFSS study design and 
methods are available elsewhere ${ }^{111}$. Only odd years and core component questions were included in this study, a limitation necessitate by the availability of data for all CVHI components.

\section{Study Population}

All respondents of the 2003, 2005, 2007, 2009, and 2011 BRFSS surveys not living in Guam, Puerto Rico, or the Virgin Islands were examined to determine eligibility $(n=1,953,902)$ for this study. Ineligible participants included: those missing any information necessary to calculate the CVHI $(n=563,734)$; and females if pregnant or of unknown pregnancy status $(n=$ 8,643). The final, eligible study population was $1,381,525$ individuals.

\section{$\underline{\text { Calculation of CVHI }}$}

We applied previously the adapted methodology from Fang et a/35 to determine CVHI using self-report BRFSS data. CVHI consists of seven components: blood pressure, cholesterol, blood glucose, BMI, smoking behavior, physical activity, and diet. Definitions used to determine an individual's status for each component are outlined in Table 1. The nature of BRFSS questions ('yes' or 'no' for self-reported hypertension, high cholesterol and diabetes) does not allow for the determination of the "intermediate" category. For consistency, all other CVHI components were also classified as either "ideal" or "not ideal".

Total CVHI was the total number of factors categorized as "ideal" and ranged from 0 to 7. Overall CVHI was considered "ideal" if a participant was categorized as "ideal" for 6 or 7 factors ideal, "intermediate" if 3 to 5 factors were "ideal", and "poor" if 2 or fewer factors were “ideal”. BRFSS was modified between 2009 and 2011111,112, both in methodology (cellular phone numbers were added to the sampling frame) and question content (of relevance to this study both diet and physical activity questions). Our adaptation to the $\mathrm{CVHI}$ scoring methodology for 2011 is outlined in Table 1.

$\underline{\text { Independent Variables }}$ 
Based on the study question, the key independent variables were the year in which the participant completed the BRFSS survey and state, as identified by the Federal Information Processing Standards (FIPS) code. Additional covariates included age, sex, race/ethnicity (Non-Hispanic White, Non-Hispanic Black, Hispanic, and Other), and level of education (Less than High School, High School, and Some College). Income was considered as a covariate, but was not included due to the high percentage of missing observations for income in BRFSS (13.8\%). A secondary analysis found that, while income was significantly associated with CVHI, it did not alter relationships between $\mathrm{CVHI}$ and other covariates, or substantially attenuate the magnitude of associations.

\section{$\underline{\text { Statistical Analysis }}$}

Population demographic characteristics were estimated using weighted means and percentages of each covariate for each BRFSS year. Differences in demographic characteristics were tested using a Pearson chi square. Age-standardized mean CVHI and prevalence of "ideal" status for each component were determined for the entire U.S. and each state using the 2000 U.S. projected population distribution weight, which utilized the age groups 18-24 years, 25-44 years, $45-64$ years and $\geq 65$ years $^{113}$. As there was a statistically significant interaction between state and time $(p<0.0001)$, subsequent analyses were stratified by state. Poisson regression was used for analyses in which total CVHI was the dependent variable; logistic regression was used for analyses in which individual $\mathrm{CVHI}$ components were the dependent variables. Using methods similar to Yang et a/85, we assessed time trends for each state by including a time variable corresponding to the BRFSS study year. Linear trends were assessed using contrast statements which apply the Christoffel-Darboux recurrence formula for computing orthogonal polynomial contrasts ${ }^{114}$. Differences in total $\mathrm{CVHI}$ and individual $\mathrm{CVHI}$ components between 2003 and 2009 and 2009 and 2011 were calculated; the Wald test was used to assess for significant differences. For each state, we plotted the change in total CVHI versus change in the prevalence of "poor" CVHI between 2003 and 2009. 
To assess the impact of the 2009 BRFSS change in smoking behavior questions, we conducted a sensitivity analysis to determine whether differences between 2011 and 2009 smoking behavior were related to the change in question definition. Using both definitions, 2009 and 2011 smoking behavior were determined and Pearson chi square tests were used to determine significance between years.

All analyses were performed using survey procedures to account for survey weights and design. All models were adjusted by sex, age, race/ethnicity, and education. Stata 13 (StataCorp. 2013. Stata Statistical Software: Release 13. College Station, TX: StataCorp LP) was used for all statistical analyses. Maps were made using ArcGIS 10.2 (ESRI 2012. ArcGIS Desktop: Release 10.1. Redlands, CA: Environmental Systems Research Institute).

\section{RESULTS}

Demographic characteristics of the eligible and non-eligible study populations are described in Table 2. There were significant differences between eligible and non-eligible populations for all demographic variables. Non-eligible populations were younger, more likely to be male, be from a minority race/ethnicity, and have less than a college education.

Age-standardized mean CVHI for years 2003-2011 are shown in Figure 1. CVHI was $3.73 \pm 0.01$ for 2003 and declined in each subsequent year, $(3.71 \pm 0.01,3.68 \pm 0.01,3.65 \pm 0.01$ and 3.45 \pm 0.01 , respectively). Age-standardized mean CVHI and CVHI stratified by demographic characteristics are also shown in Figure 1. There were disparities in CVHI within each demographic variable, as assessed by interactions. Females had higher CVHI (in 2009) than males in 2009 (3.81 \pm 0.007 vs. $3.49 \pm 0.008$, respectively) and in every subsequent study year $(p=0.0096)$. Within race/ethnic groups, the "Other" race/ethnicity category had the highest $\mathrm{CVHI}$, followed by non-Hispanic whites, Hispanic, and non-Hispanic blacks (in 2009: $3.78 \pm 0.02,3.69 \pm 0.006,3.56 \pm 0.02$, and $3.38 \pm 0.02$, respectively; $p=0.0034)$. Within educational 
strata, those with some college had the highest $\mathrm{CVHI}$ and those with less than a high school education had the lowest (in 2009 : $3.78 \pm 0.006$ vs. $3.25 \pm 0.02$, respectively; $p<0.0001$ ).

Disparities in CVHI were also observed between individual states (interaction p value < 0.0001) and are shown in Supplemental Figure 1. In 2009, CVHI ranged from a high of $3.87 \pm 0.05$ in Colorado to a low of $3.37 \pm 0.05$ in Mississippi. States in the South Central and South Atlantic regions had the lowest $\mathrm{CVHI}$ and states in the Northeast, Pacific, and Mountain regions had the highest CVHI. Results of linear trend tests (2003-2009) for each state (data not presented but available upon request) demonstrated a significant decreasing linear trend in all but nine states (Delaware, DC, Connecticut, Massachusetts, Michigan, Nevada, Tennessee, Wisconsin, Wyoming; trend not statistically significant).

The prevalence of "ideal", "intermediate", or "poor" overall CVHI, and "ideal" or "poor" status for individual $\mathrm{CVHI}$ components are reported in Figure 2. The prevalence of "ideal" CVHI has remained constant at 5.1\%; however, the prevalence of "poor" CVHI was significantly higher in 2009 compared to 2003. Blood glucose and smoking were the components with the highest prevalence of "ideal" CVHI. Prevalence of "ideal" smoking status increased from $79.2 \%$ to 83.5\% between 2003 and 2009. Diet and physical activity were the components with the lowest prevalence of "ideal". Prevalence of "ideal" diet increased from $12.1 \%$ to $13.4 \%$ between 2003 and 2009 whereas prevalence of "ideal" status for all other components (blood pressure, cholesterol, blood glucose, physical activity) decreased. Differences outside of these trends were seen for smoking and diet status between 2009 and 2011, which correspond to 2011 BRFSS methodological changes (discussed further below).

Figure 3 summarizes state-level changes between 2003 and 2009 for each individual CVHI component. While one state (Minnesota) had an increase in prevalence of "ideal" blood pressure (Figure 3A), no state experienced a significant increase in prevalence of "ideal" cholesterol while most states had a decrease in the prevalence of "ideal" cholesterol status (Figure 3B). Further, no state experienced an increase in prevalence of "ideal" BMI though $86 \%$ 
of states experienced a decrease in the prevalence of "ideal" BMI greater than 4 percentage points (Figure 3D). All states experienced no change or an increase in prevalence of "ideal" smoking status, which ranged from a $2.1 \%$ increase in Utah to an increase of $11.9 \%$ in Alaska (Figure 3E). Six percent of states experienced increases in the prevalence of "ideal" physical activity, though $74 \%$ experienced decreases in "ideal" physical activity (Figure 3F). All states experienced an increase or no change in the prevalence of "ideal" diet, except four states which experienced decreases in "ideal" diet status (Figure 3G).

To provide information that could enable priority setting decisions for states, statespecific changes in age-standardized mean CVHI vs. the state's change in the prevalence of "poor" CVHI between 2003 and 2009 are presented in Figure 4. States are assigned into one of four quadrants which, from most to least preferable, are: Quadrant 4 (improved mean CVHI and reduced prevalence of "poor" CVHI); Quadrant 1 and Quadrant 3 (mixed results suggesting a change in the distribution of CVHI); and Quadrant 2 (decreased mean CVHI and increased prevalence of "poor" CVHI). Quadrant 4 contains only one state, the District of Columbia, there are no states in Quadrant 3 and only a few in Quadrant 1. The substantial majority of states $(88 \%)$ are in Quadrant 2, indicating that these states had both a decline in mean CVHI and an increase in the prevalence of "poor" CVHI between 2003 and 2009. From visual inspection, the four states with the largest deterioration in CVHI during the study period were Hawaii, Ohio, Oklahoma, and Arizona.

Sub-Analysis Assessing the Impact of Methodological Changes between 2009 and 2011

We observed statistically significant differences in the demographic characteristics and outcome variables between 2009 and 2011 that were outside of the scope of the trend observed between 2003 through 2009. In visual examination of Figure 1, there is a decreasing trend from 2003-2011 but a larger decrease between 2009 and 2011 than between any adjacent years. This larger-than-expected drop between 2009 and 2011 is significant for mean CVHI as well as all individual CVHI components except cholesterol and BMI (Figure 2). As reported in Figure 2, 
between 2003 and 2009, the prevalence of "poor" CVHI and prevalence of "ideal" for each CVHI component were both significantly different. As reported in Table 3, with the exception of cholesterol and BMI, these same individual CVHI components are significantly different between 2009 and 2011. Further, comparing the absolute differences in CVHI between 2003 and 2009 with 2009 and 2011, the magnitude of the one year change for total $\mathrm{CVHI}$ and three out of seven individual CVHI components (2009-2011) is larger than the six year changes (20032009).

Upon further evaluation, we observed that the eligible population in 2011 was significantly older, had a greater percentage of non-Hispanic blacks and Hispanics, and a higher percentage of individuals with a high school or less education compared to those in previous BRSS years. Sensitivity analysis for changing smoking behavior definitions showed no matter which combination of definitions used, there was significantly lower "ideal" smoking behavior between 2009 and 2011 (Table 4). The change between the years ranged from 2.3 to 6 percentage points.

\section{DISCUSSION}

This is the first study to evaluate temporal state-level trends in the U.S. Results show a linear decrease in CVHI between 2003 and 2009 in both the U.S. overall and in most individual states. We also observed differences in overall $\mathrm{CVHI}$ and its individual components between 2009 and 2011, which we partially, but only partially, attribute to methodological changes in BRFSS.

Our estimated of prevalence of "ideal" CVHI, $5.1 \%$, is higher than previous NHANES studies of $\mathrm{CVHI}$, which have reported prevalence estimates closer to $1 \% 25,85$. Differences in these prevalence estimates may be attributable to methodologic differences between BRFSS and NHANES. All BRFSS results are self-report, whereas $\mathrm{CVHI}$ can be determined using lab values in studies using NHANES. Additionally, participants with undiagnosed hypertension, 
diabetes, and hypercholesterolemia would be misclassified as "ideal" in the BRFSS adaptation of the CVHI determination. Further, self-report of height and weight are known to be biased ${ }^{100}$ and may have resulted in overestimated "ideal" BMI. Finally, diet questions used in the NHANES studies include more varied questions, while BRFSS questions are more limited set which may have resulted in an overestimation of "ideal" diet status. However, NHANES does not allow for the examination of temporal trends at the state level, which is a distinct advantage of using BRFSS.

We observed an increase in the prevalence of "poor" CVHI from $15.8 \%$ (2003) to $18.2 \%$ (2009). This represents an additional 7 million individuals with an increased risk of CVD and allcause mortality. Prevalence of "ideal" CVHI is low and did not change between 2003 and 2009. Our estimate of "poor" CVHI for 2009, 18.2\%, is higher than that reported by Fang et al, a study which also used BRFSS and which reported $11.4 \%$ prevalence of "poor" CVHI ${ }^{35}$. Different exclusion criteria may explain the higher prevalence of "poor" CVHI reported here.

We observed significant disparities in $\mathrm{CVHI}$ within demographic groups and between states. Women, those with higher levels of education, and those identifying as Other race/ethnicity had the highest levels of $\mathrm{CVHI}$. While a few states have made strides in $\mathrm{CVHI}$ improvement, 47 states are at high risk of continuing their decreasing trend in CVHI. In particular, Ohio, Arizona, Oklahoma, and Hawaii were observed to have had the largest declines in $\mathrm{CVHI}$.

Much of the decreasing trend in $\mathrm{CVHI}$ between 2003 and 2009 is likely due to decreases in "ideal" blood pressure, cholesterol, and BMI. The decreases in these factors were only slightly tempered by increases in "ideal" smoking status. The prevalence of "ideal" diet increased in many states, while the prevalence of "ideal" physical activity decreased or did not change in most states. The simultaneous improvement in diet but decrease in the prevalence of "ideal" cholesterol may be attributed to an increased overall consumption of food both fruits and vegetables as well as unhealthy options, increased diagnosis of hypercholesterolemia, or lower 
cut-off levels for the initiation of statins. There may also be a lag time where a change in diet is noted before any substantial changes in cholesterol levels are seen. In addition, the threshold for the amount of change in diet needed to produce a noticeable change in cholesterol levels may not have been met in this population. Smoking, diet, and physical activity, are not only risk factors themselves, but contribute to the development of the biological CVHI components. These should be a main target of public health efforts as well as local, state, and national policies. The continuing decline in the prevalence of "ideal" blood pressure is also a major contributor to the burden of disease and health care costs.

The overall trends in smoking, BMI, and blood glucose reported here are consistent with previously reported national trend data using NHANES ${ }^{37,85}$. Whereas here we report a decreasing trend in "ideal" blood pressure, cholesterol, and physical activity, Huffman et al and Yang et al reported no changes in these individual CVHI components. We observed increases in the prevalence of "ideal" diet, which is consistent with findings in men reported by Huffman et al. Differences in the data source, sample size, and years of data examined could explain these differences in observed trends, as Yang et al and Huffman et al examined a much larger time span using data at time points averaged over many years as a strategy to increase sample size Huffman et al predicted that, by 2020 , overall CVHI will improve by $6 \%{ }^{37}$. While this projected improvement is shy of the AHA 2020 Strategic Impact goal of a $20 \%$ improvement in cardiovascular health, the implications of our findings suggest that, with only improvements in smoking and diet status, it is unlikely that either the $6 \%$ improvement or the $20 \%$ improvement (Strategic Impact Goal) will be met.

\section{Assessing Impact of Methodological Changes between 2009 and 2011}

Changes to BRFSS questions and sampling and weighting procedures starting in 2011 have resulted in cautions from the Centers for Disease Control and Prevention regarding interpretation and comparability of 2011 data vs. previous years ${ }^{112}$. As BRFSS data is one of the only sources states have to monitor health ${ }^{100}$, we aimed to assess the differences in overall 
CVHI and its individual components between 2009 and 2011. Changes between 2009 and 2011 are larger than changes seen in the previous six year period for overall CVHI and the prevalence of all individual components except the prevalence of "ideal" BMI and cholesterol, which demonstrated no change.

It was expected that, while the magnitude of changes between previous years and 2011 would be different, the overall shape and slope of the trend would not change ${ }^{112}$. Our findings support this initial change, particularly for the prevalence of "ideal" smoking and diet status. Changes in the prevalence of "ideal" smoking status were significant even after examining changes in the BRFSS questions used to define "ideal" smoking status (Table 1). Future time points will need to be assessed to determine if the shape and slope of the trend will continue.

Between 2009-2011, the changes observed in the prevalence of "ideal" diet and physical activity status may be partially due to changes in questions for those individual CVHI components (Table 1) as well as to changes in the demographic characteristics resulting from changes in the survey sampling and weighting procedures. Specifically, cell phone numbers were included in the sampling frame for the first time, which was expected to increase respondents in lower income, lower education, and younger ages as these are demographic groups more likely to use cell phones exclusively ${ }^{112}$. While our observations are consistent with the expected changes in education, our observation of a slightly older average age in 2011 vs. 2009 (51.1 years and 50.4 years old, respectively) was different from a priori expectations. Changes to the weighting procedures in 2011 allowed for the addition of more demographic variables, including education level, marital status, and home ownership, to the weighting calculation. These changes, while increasing the accuracy of the weighting scheme, may also have contributed to the changes in the demographic characteristics of the sample and, subsequently, the differences in CVHI.

\section{Strengths and Limitations}


The key strength of this study is its use of BRFSS, which is a large, nationally representative sample, available for multiple years, and which allows for stratification and analysis at the state level. The primary limitation of this study is the self-report methodology of BRFSS which, as discussed above, may result in an overestimation of "ideal" CVHI. However, in a comparison of three major health surveys (NHANES, NHIS and BRFSS), Li et al reported that estimated prevalence rates for chronic diseases in BRFSS were comparable to that of NHANES and NHIS and those for hypertension showed only small differences between all three surveys ${ }^{115}$ Similarly, Pierannunzi et al also reported the validity and reliability of BRFSS to be comparable to other surveys, with differences limited primarily to physical measure questions due to the self-reported nature of BRFSS ${ }^{100}$. Finally, there is possible in this study resulting from the proportion of BRFSS respondents ineligible for this study due to missing data (approximately $30 \%$ ). Ineligible younger individuals would be more likely to have ideal CVHI, whereas ineligible less educated and male individuals would be more likely to have poorer CVHI.

\section{$\underline{\text { Conclusion }}$}

Understanding cardiovascular health patterns and its determinants in populations allows for primordial prevention and health-supporting approaches to be initiated before individuals or communities develop disease or risk factors. While the decrease in cardiovascular disease attributable deaths has been ascribed to both treatment advances and risk factor modification, ${ }^{5}$ it is important to consider that, with either risk factor modification or early risk factor treatment, morbidity can be decreased or compressed into the latest years ${ }^{4,116}$. In conclusion, this study provides trends in $\mathrm{CVHI}$ and its components both nationwide and for each individual U.S. state. This information can be used to inform state-specific strategies that will be most effective in improving overall cardiovascular health. Future research into the causes of changes in $\mathrm{CHVI}$ may inform policies and interventions that can improve population health. 
Table 1. BRFSS questions and definitions for classification of "ideal" for CVHI individual components

CVHI
Component
Blood

\section{Compone}

Pressure

$\begin{array}{lll}\text { Participant had previously had their cholesterol } & \text {-Blood cholesterol is a fatty substance reported in the blood. Have you ever had your blood cholesterol checked? } \\ \text { screened and never been told by a health } & \text {-Have you ever been told by a doctor or other health professional that your blood cholesterol is high? }\end{array}$

professional they had high blood pressure.

$\begin{array}{ll}\text { Cholesterol } & \text { screened and never been told by a health } \\ \text { professional they had high cholesterol. }\end{array}$

Glucose Participant had never been told by a doctor they -Have you ever been told by a doctor that you have diabetes? had diabetes.

Body Mass BMI was between 18.5 and 24.9.

Index (BMI)

Smoking

Participant had not smoked at least 100

cigarettes in their lifetime or reported smoking 100 cigarettes in their lifetime but not currently smoking.

Participant did enough moderate or vigorous physical activity to meet the recommendation $\geq 150$ minutes a week of moderate-intensity activity, $\geq 75$ minutes of vigorous-intensity activity, or an equivalent combination of physical activity.

\section{Physical}

Activity

-Have you ever been told by a doctor or other health professional that your blood cholesterol is high? About how much do you weigh without shoes? -About how tall are you without shoes?

-Have you smoked at least 100 cigarettes in your entire life?

-Do you now smoke cigarettes everyday, some days, or not at all?

-About how long has it been since you last smoked cigarettes regularly, that is, daily?

-Now, thinking about the moderate physical activities you -During the past 30 days, other than your regular job, did you do in a usual week, do you do moderate activities for at participate in any physical activities or exercise such as running, least 10 minutes at a time, such as brisk walking, bicycling, vacuuming, gardening, or anything else that caused small increases in breathing or heart rate? - How many days per week do you do these moderate activities for at least 10 minutes at a time? calisthenics, golf, gardening, or walking for exercise?

-How many times per week or per month did you take part in this activity during the past month? -On days when you do moderate activities for at least 10 -Estimated Activity Intensity for First Activity (Calculated by BRFSS) minutes at a time, how much total time per day do you -How many times per week or per month did you take part in this spend doing these activities?

-Now, thinking about the vigorous physical activities you -And when you took part in this activity, for how many minutes or
BRFSS Questions from 2003, 2005, 2007, and 2009

BRFSS Questions 2011 do in a usual week, do you do vigorous activities for at least 10 minutes at a time, such as running, aerobics, heavy yard work, or anything else that caused large hours did you usually keep at it? BRFSS) increases in breathing or heart rate?

-How many days per week do you do these vigorous activities for at least 10 minutes at a time?

-On days when you do vigorous activities for at least 10 minutes at a time, how much total time per day do you spend doing these activities?

Participant consumed 5 or more servings of -Not counting juice, how often do you eat fruit? -How often do you eat green salad? -How often do you eat potatoes not including french fries, fried potatoes, or potato chips? -How often do you eat carrots?

-Not counting carrots, potatoes, or salad, how many servings of vegetables do you usually eat?

-During the past month, not counting juice, how many times per day week, or month did you eat fruit? Count fresh, frozen, or canned fruit. fruits and vegetables per day.

-During the past month, how many times per day, week, or month
did you eat orange-colored vegetables such as sweet potatoes, pumpkin, winter squash, or carrots?

-During the past month, how many times per day, week, or month did you eat dark green vegetables for example broccoli or dark leafy greens including romaine, chard, collard greens or spinach?

-Not counting what you just told me about, during the past month, about how many times per day, week, or month did you eat OTHER vegetables? 
Table 2. Characteristics of BRFSS eligible and non-eligible study populations by year

\begin{tabular}{|c|c|c|c|c|c|c|c|c|c|c|c|}
\hline & \multicolumn{2}{|c|}{2003} & \multicolumn{2}{|c|}{2005} & \multicolumn{2}{|c|}{2007} & \multicolumn{2}{|c|}{2009} & \multicolumn{2}{|c|}{2011} & \\
\hline & Eligible & Non-Eligible & Eligible & Non-Eligible & Eligible & Non-Eligible & Eligible & Non-Eligible & Eligible & Non-Eligible & \\
\hline $\mathbf{N}$ & 176,931 & 87,753 & 244,962 & 111,150 & 307,205 & 123,707 & 310,768 & 121,839 & 341,659 & 164,808 & \\
\hline Age (Mean \pm SE) & $49.6 \pm 0.08$ & $38.1 \pm 0.10$ & $50.0 \pm 0.07$ & $37.7 \pm 0.10$ & $50.2 \pm 0.07$ & $38.5 \pm 0.10$ & $50.4 \pm 0.07$ & $39.0 \pm 0.10$ & $51.1 \pm 0.06$ & $39.1 \pm 0.08$ & $\dagger \ddagger \S$ \\
\hline Male $(n, \% *)$ & $\begin{array}{c}70,065 \\
(48.0)\end{array}$ & $\begin{array}{c}34,334 \\
(48.9)\end{array}$ & $\begin{array}{c}93,956 \\
(47.9)\end{array}$ & $\begin{array}{c}42,245 \\
(49.5)\end{array}$ & $\begin{array}{c}114,592 \\
(48.0)\end{array}$ & $\begin{array}{c}46,159 \\
(49.8)\end{array}$ & $\begin{array}{c}117,829 \\
(47.9)\end{array}$ & $\begin{array}{c}46,132 \\
(50.0)\end{array}$ & $\begin{array}{c}133,161 \\
(47.8)\end{array}$ & $\begin{array}{r}65,651 \\
(50.1)\end{array}$ & $\dagger$ \\
\hline Race/ethnicity (n, \%*) & & & & & & & & & & & $\dagger \ddagger \S$ \\
\hline Non-Hispanic White & $\begin{array}{c}147,643 \\
(75.8)\end{array}$ & $\begin{array}{c}61,589 \\
(62.6)\end{array}$ & $\begin{array}{c}205,220 \\
(76.0)\end{array}$ & $\begin{array}{c}77,754 \\
(59.8)\end{array}$ & $\begin{array}{c}257,053 \\
(74.9)\end{array}$ & $\begin{array}{c}86,279 \\
(59.4)\end{array}$ & $\begin{array}{c}258,923 \\
(74.1)\end{array}$ & $\begin{array}{c}85,006 \\
(59.1)\end{array}$ & $\begin{array}{c}276,605 \\
(72.5)\end{array}$ & $\begin{array}{c}114,463 \\
(59.5)\end{array}$ & \\
\hline Non-Hispanic Black & $\begin{array}{c}12,977 \\
(9.8)\end{array}$ & $\begin{array}{l}8,322 \\
(10.4)\end{array}$ & $\begin{array}{c}17,823 \\
(9.5)\end{array}$ & $\begin{array}{c}10,722 \\
(10.3)\end{array}$ & $\begin{array}{c}22,603 \\
(9.6)\end{array}$ & $\begin{array}{c}11,589 \\
(10.4)\end{array}$ & $\begin{array}{c}23,680 \\
(10.4)\end{array}$ & $\begin{array}{c}11,973 \\
(10.9)\end{array}$ & $\begin{array}{c}27,295 \\
(11.2)\end{array}$ & $\begin{array}{c}13,318 \\
(11.8)\end{array}$ & \\
\hline Hispanic & $\begin{array}{c}8,008 \\
(9.6)\end{array}$ & $\begin{array}{c}11,644 \\
(20.7)\end{array}$ & $\begin{array}{c}10,188 \\
(9.6)\end{array}$ & $\begin{array}{c}15,351 \\
(24.2)\end{array}$ & $\begin{array}{c}13,718 \\
(9.8)\end{array}$ & $\begin{array}{c}17,592 \\
(23.7)\end{array}$ & $\begin{array}{c}14,155 \\
(10.4)\end{array}$ & $\begin{array}{c}15,920 \\
(23.3)\end{array}$ & $\begin{array}{c}16,947 \\
(11.0)\end{array}$ & $\begin{array}{c}21,771 \\
(22.2)\end{array}$ & \\
\hline Other & $\begin{array}{c}7,317 \\
(4.8)\end{array}$ & $\begin{array}{c}5,386 \\
(6.3)\end{array}$ & $\begin{array}{c}10,100 \\
(4.9)\end{array}$ & $\begin{array}{c}6,036 \\
(5.7)\end{array}$ & $\begin{array}{c}11,781 \\
(5.8)\end{array}$ & $\begin{array}{r}6,847 \\
(6.5)\end{array}$ & $\begin{array}{c}11,785 \\
(5.1)\end{array}$ & $\begin{array}{c}7,236 \\
(6.8)\end{array}$ & $\begin{array}{c}11,899 \\
(5.3)\end{array}$ & $\begin{array}{c}9,043 \\
(6.5)\end{array}$ & \\
\hline Education (n, \%*) & & & & & & & & & & & $\dagger \neq \S$ \\
\hline Less than High School & $\begin{array}{c}16,759 \\
(9.7)\end{array}$ & $\begin{array}{c}12,438 \\
(16.8)\end{array}$ & $\begin{array}{c}21,855 \\
(9.1)\end{array}$ & $\begin{array}{c}16,347 \\
(18.4)\end{array}$ & $\begin{array}{c}26,830 \\
(8.6)\end{array}$ & $\begin{array}{c}18,034 \\
(16.9)\end{array}$ & $\begin{array}{c}24,750 \\
(8.1)\end{array}$ & $\begin{array}{c}16,323 \\
(15.7)\end{array}$ & $\begin{array}{c}26,244 \\
(12.4)\end{array}$ & $\begin{array}{c}20,179 \\
(20.0)\end{array}$ & \\
\hline High School & $\begin{array}{c}52,020 \\
(29.0)\end{array}$ & $\begin{array}{c}28,613 \\
(32.9)\end{array}$ & $\begin{array}{c}72,821 \\
(28.3)\end{array}$ & $\begin{array}{c}37,009 \\
(33.0)\end{array}$ & $\begin{array}{c}90,982 \\
(27.0)\end{array}$ & $\begin{array}{c}40,651 \\
(32.2)\end{array}$ & $\begin{array}{c}90,098 \\
(26.5)\end{array}$ & $\begin{array}{c}65,303 \\
(31.2)\end{array}$ & $\begin{array}{c}98,142 \\
(28.4)\end{array}$ & $\begin{array}{c}51,245 \\
(30.5)\end{array}$ & \\
\hline Some College & $\begin{array}{c}107,932 \\
(61.3)\end{array}$ & $\begin{array}{r}46,277 \\
(50.3)\end{array}$ & $\begin{array}{c}149,968 \\
(62.6)\end{array}$ & $\begin{array}{c}57,204 \\
(48.7)\end{array}$ & $\begin{array}{c}188,997 \\
(64.5)\end{array}$ & $\begin{array}{c}64,151 \\
(50.9)\end{array}$ & $\begin{array}{c}195,540 \\
(65.5)\end{array}$ & $\begin{array}{c}65,303 \\
(53.1)\end{array}$ & $\begin{array}{c}216,775 \\
(59.3)\end{array}$ & $\begin{array}{c}91,953 \\
(49.6)\end{array}$ & \\
\hline
\end{tabular}

Participants were non-eligible if missing any responses needed to calculate CVHI; females with a positive or unknown pregnancy status; and those living in Puerto Rico, Guam, or US Virgin Islands.

*\% are weighted frequencies using survey procedures

† indicates significance at the $p=0.05$ level for the comparison of eligible versus non-eligible across years

$\neq$ indicates significance at the $p=0.05$ level for the comparison of eligible across years

$\S$ indicates significance at the $p=0.05$ level for the comparison of non-eligible across $2003-2009$ 
Table 3. Summary of differences in overall CVHI and CVHI individual components, 2009 vs. 2011

\begin{tabular}{|c|c|c|c|c|c|c|c|c|}
\hline \multirow[b]{3}{*}{ Mean Overall CVHI } & \multicolumn{4}{|c|}{ United States Overall } & \multirow{2}{*}{\multicolumn{4}{|c|}{ Difference 2003 to 2009Difference 2009 to 2011}} \\
\hline & Differen & 2003 to 20 & ifferen & 2009 to 2011 & & & & \\
\hline & -0.08 & $<0.0001$ & -0.20 & $<0.0001$ & -0.08 & $\begin{array}{c}74.5 \\
(38 / 51)\end{array}$ & -0.21 & $\begin{array}{c}98.0 \\
(50 / 51)\end{array}$ \\
\hline \% "Poor" CVHI & 2.4 & $<0.0001$ & 4.5 & $<0.0001$ & 2.6 & $\begin{array}{c}84.3 \\
(43 / 51)\end{array}$ & 4.6 & $\begin{array}{c}92.3 \\
(47 / 51)\end{array}$ \\
\hline \% "Ideal" CVHI & 0.0 & 0.12 & -2.1 & $<0.0001$ & 0.004 & $\begin{array}{c}9.8 \\
(5 / 51) \\
\end{array}$ & -2.1 & $\begin{array}{c}90.2 \\
(46 / 51) \\
\end{array}$ \\
\hline \% "Ideal" Blood Pressure & -3.0 & $<0.0001$ & -2.1 & $<0.0001$ & -3.4 & $\begin{array}{c}80.4 \\
(41 / 51)\end{array}$ & -2.1 & $\begin{array}{c}39.2 \\
(20 / 51)\end{array}$ \\
\hline \% "Ideal” Cholesterol & -4.1 & $<0.0001$ & 0.3 & 0.83 & -4.0 & $\begin{array}{c}78.4 \\
(40 / 51)\end{array}$ & 0.08 & $\begin{array}{c}17.6 \\
(9 / 51)\end{array}$ \\
\hline \% "Ideal" Blood Glucose & -1.3 & $<0.0001$ & -0.8 & 0.0002 & -1.2 & $\begin{array}{c}43.1 \\
(22 / 51)\end{array}$ & -1.1 & $\begin{array}{c}19.6 \\
(10 / 51)\end{array}$ \\
\hline \% "Ideal” BMI & -3.7 & $<0.0001$ & -0.7 & 0.18 & -4.0 & $\begin{array}{c}84.3 \\
(43 / 51)\end{array}$ & -0.9 & $\begin{array}{c}5.9 \\
(3 / 51)\end{array}$ \\
\hline \% "Ideal" Smoking Behavior & 4.4 & $<0.0001$ & -6.0 & $<0.0001$ & 4.6 & $\begin{array}{c}74.5 \\
(38 / 51) \\
\end{array}$ & -6.7 & $\begin{array}{c}90.2 \\
(46 / 51)\end{array}$ \\
\hline \% "Ideal” Physical Activity & -1.3 & $<0.0001$ & -5.9 & $<0.0001$ & -1.1 & $\begin{array}{c}45.1 \\
(23 / 51)\end{array}$ & -5.7 & $\begin{array}{c}98.0 \\
(50 / 51)\end{array}$ \\
\hline \% “Ideal” Diet & 1.3 & $<0.0001$ & -4.7 & $<0.0001$ & 1.0 & $\begin{array}{c}31.4 \\
(16 / 51)\end{array}$ & -4.3 & $\begin{array}{c}94.1 \\
(48 / 51)\end{array}$ \\
\hline
\end{tabular}

* Percentage of states that have a significant difference between the two years 
Table 4. Sensitivity analysis comparing changes in smoking behavior definitions over the change in BRFSS sampling and weighting, $2009-2011$

\begin{tabular}{lcc}
\hline & $\begin{array}{c}\text { Percent of Population with “Ideal” } \\
\text { Smoking Behavior }\end{array}$ & 2009 versus 2011 \\
\hline $\mathbf{2 0 0 9}$ results using 2003-9 definition & 83.5 & $<0.0001$ \\
$\mathbf{2 0 1 1}$ results using 2011 definition & 77.5 & \\
& & $<0.0001$ \\
$\mathbf{2 0 0 9}$ results using 2003-9 definition & 83.5 & \\
$\mathbf{2 0 1 1}$ results using 2003-9 definition & 81.2 & $<0.0001$ \\
$\mathbf{2 0 0 9}$ results using 2011 definition & 81.3 & \\
$\mathbf{2 0 1 1}$ results using 2011 definition & 77.5 &
\end{tabular}


Figure 1. Age-standardized mean CVHI for 2003 to 2011. Panel A: Overall CVHI; Panel B: Overall CVHI stratified by gender; Panel C: Overall CVHI stratified by race/ethnicity; Panel D: Overall CVHI stratified by education level
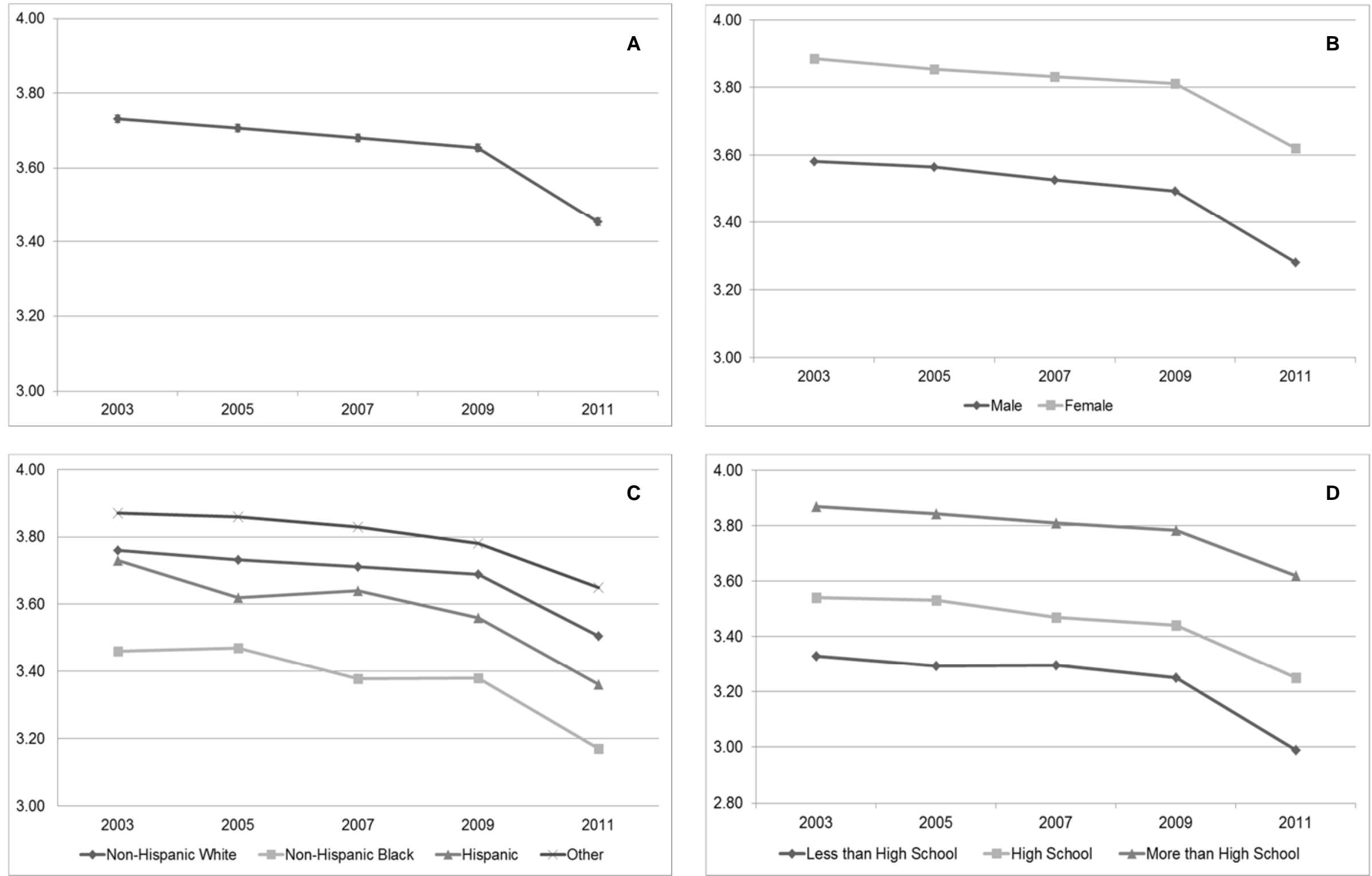
Figure 2. Age-adjusted prevalence estimates for "poor", "intermediate", and "ideal" overall CVHI and prevalence of "poor" and "ideal" for each of the seven CVHI individual components from 2003 to 2011.

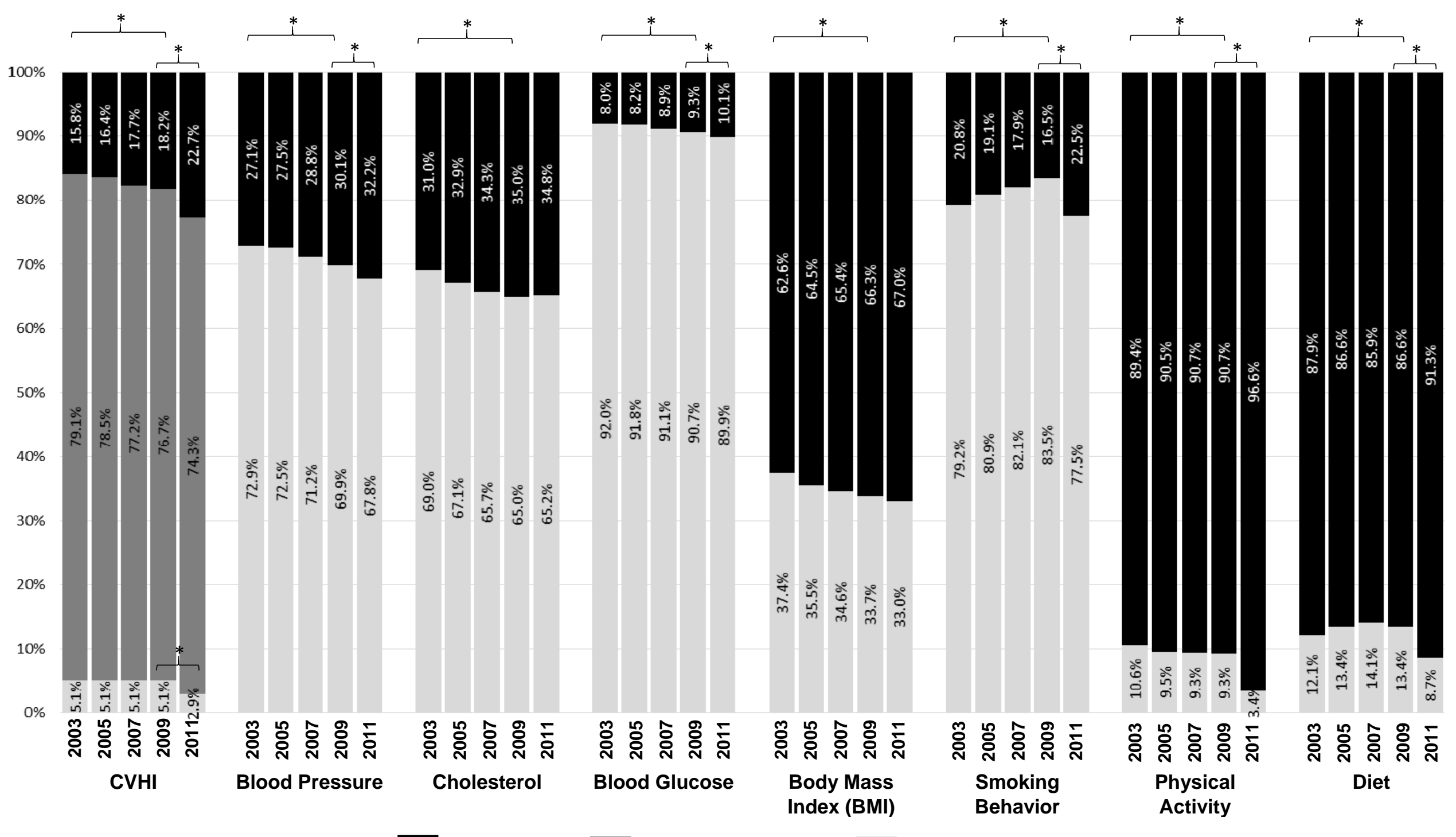

Percent Poor

Percent Intermediate

Percent Ideal

* Indicates $p<0.05$ for Pearson chi square test between 2009 and 2011 or 2003 and 2009 
Figure 3. Absolute change in the prevalence of "ideal" status for each CVHI individual component, 2003-2009 (calculated as \% ideal in 2009 - \% ideal in 2003); (A) blood pressure, (B) cholesterol, (C) blood glucose, (D) body mass index, $(E)$ smoking behavior, $(F)$ physical activity, and $(G)$ diet
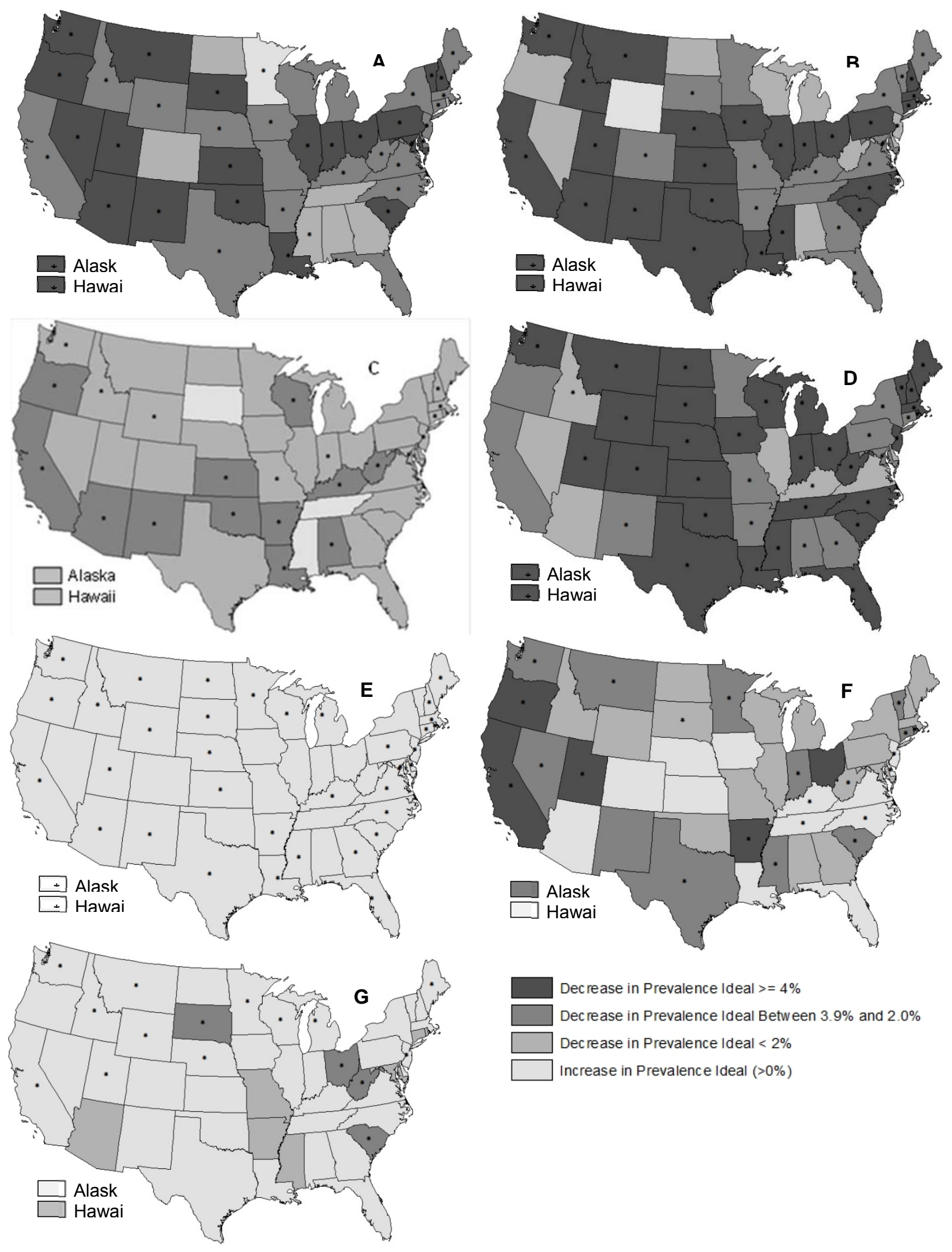

Dec rease in Prevalence $\mid$ deal $>=4 \%$

Dec rease in Prevalence Ideal Between $3.9 \%$ and $2.0 \%$ Decrease in Prevalence $\mid$ deal $<2 \%$ Increase in Prevalence Ideal $(>0 \%)$

* Indicates $p<0.05$ for Pearson chi square comparing 2003 and 2009 values. 
Figure 4. Change in state age-standardized mean CVHI, 2003-2009, vs. change in state prevalence of "poor" CVHI, 2003-2009

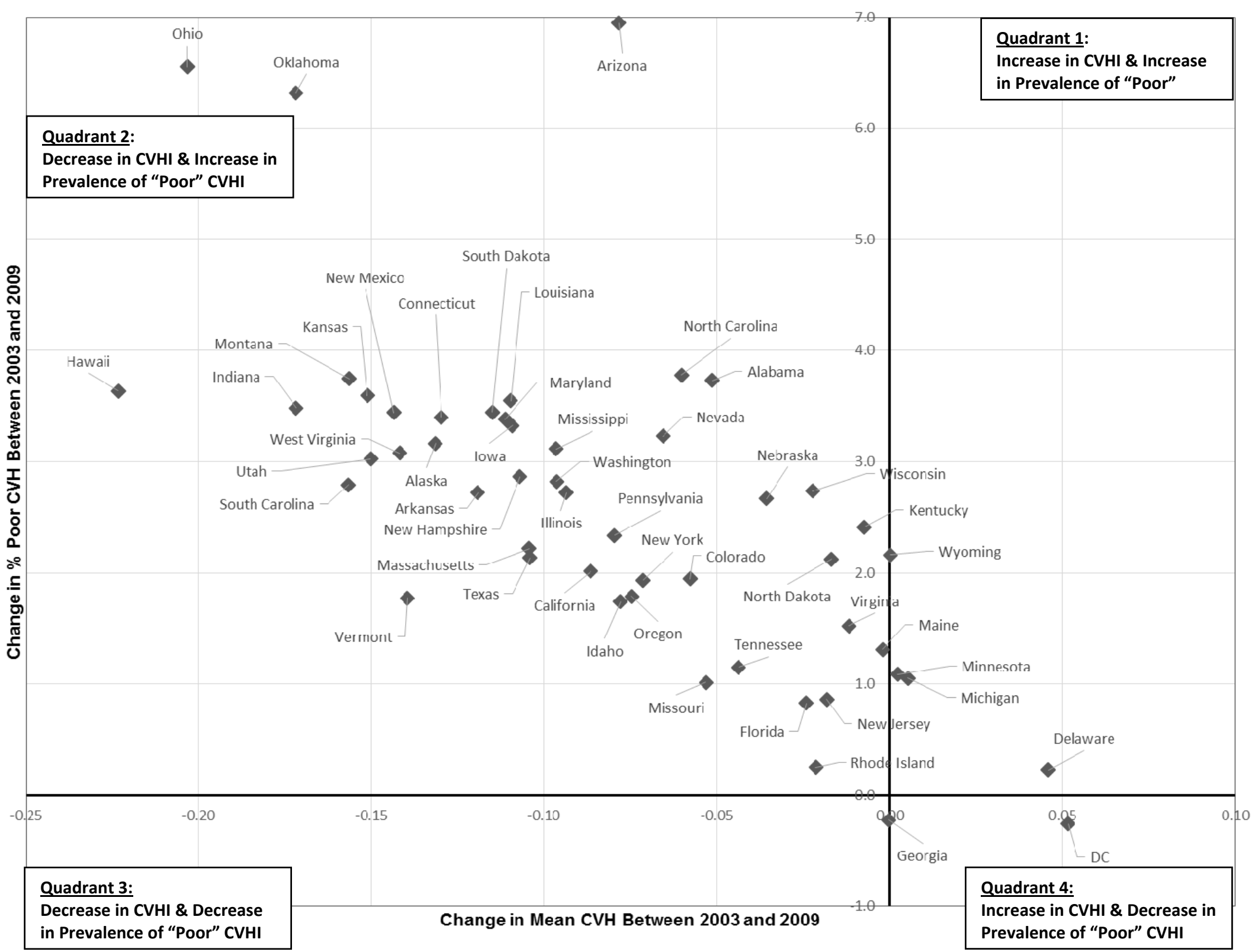




\section{Chapter 5}

FULL TITLE: Health care resource availability and cardiovascular health in the United States

SHORT TITLE: Health care resources and cardiovascular health

Authors and Affiliations: Courtney S. Pilkerton, BA ${ }^{1,2,3}$, Sarah S. Singh, MD, $\mathrm{MPH}^{2,3}$, Thomas K. Bias, $\mathrm{PhD}^{2,4,5}$, and Stephanie J. Frisbee, $\mathrm{PhD}^{2,3,4}$

${ }^{1}$ School of Medicine, West Virginia University, Morgantown, WV

${ }^{2}$ School of Public Health, West Virginia University, Morgantown, WV

${ }^{3}$ Center for Cardiovascular and Respiratory Sciences, West Virginia University Robert C. Byrd Health Sciences Center, Morgantown, WV

${ }^{4}$ West Virginia Clinical and Translational Science Institute (WV-CTSI), West Virginia University, Morgantown, WV

${ }^{5}$ Health Research Center, West Virginia University Robert C. Byrd Health Sciences Center, Morgantown, WV

\section{Corresponding Author:}

Stephanie J. Frisbee, PhD

West Virginia University

Robert C. Byrd Health Sciences Center

Center for Cardiovascular \& Respiratory Sciences

1 Medical Center Drive - PO Box 1905

Morgantown WV 26505-1905

304-293-6552 / sfrisbee@hsc.wvu.edu

Journal Subject Codes: 8, 112, 113, 121, 135, 190

Word Count (Abstract): 218

Word Count (Full Manuscript): 6860 


\section{ABSTRACT}

Background: Cardiovascular disease remains the leading cause of death in the U.S. Reducing the population burden of cardiovascular disease will require an increased focus on understanding how to promote and support cardiovascular health. Our objective was to examine the association between health care resource availability and cardiovascular health. We assessed this association in both individuals and populations.

Methods and Results: Cardiovascular health, defined using the American Heart Association Index (CVHI), was examined using the 2011 Behavioral Risk Factor Surveillance data $(\mathrm{n}=$ $308,895)$. Linear regression analysis was performed to examine associations between health care resources and $\mathrm{CVHI}$ in communities. Poisson regression analysis was performed to examine the association between health care resources and $\mathrm{CVHI}$ in individuals. The average CVHI was $3.3 \pm 0.005$ and is poorer in the Southeast and Appalachian regions of the United States. Primary care physicians and physician assistants were positively associated with both individual and community-level $\mathrm{CVHI}$, while cardiovascular disease specialists were negatively associated with CVHI. Individuals benefiting most from increased primary care provider supply were: middle aged; female, had Non-Hispanic Other race/ethnicity; those with household income $<\$ 25,000 /$ year; living in a non-urban community with insurance coverage.

Conclusions: Our results support the importance of primary care provider supply for overall CVHI. Future research should examine which resources and policies could impact the supply of primary care providers.

Key Words: cardiovascular health, epidemiology, primary care, 2020 Strategic Impact Goals 


\section{INTRODUCTION}

Although mortality attributable to cardiovascular disease (CVD) continues to decline, CVD remains the cause of one in three deaths in the United States (U.S.) $)^{2}$ and it has been projected that, by 2030 , more than $40 \%$ of the U.S. population will be living with CVD. Further, the associated direct medical costs are predicted to triple, and the indirect costs of CVD to increase by $61 \%$ (both from 2010 levels) ${ }^{8}$. In attempts to ameliorate the individual and societal burden of CVD, improving cardiovascular health has been prioritized as a national public health goal. A key American Heart Association 2020 Strategic Impact Goal is to decrease the number of deaths due to CVD by $20 \%$ and to improve the cardiovascular health of Americans by $20 \%{ }^{12}$. Additionally, Healthy People 2020 objectives also aim to increase cardiovascular health in the U.S. population (HDS-1) $)^{11}$.

To support and advance these priorities, the American Heart Association recently developed a comprehensive index which allows for the measurement of cardiovascular health $(\mathrm{CVH})$ in both individuals and populations ${ }^{12}$. This cardiovascular health index (CVHI) includes both health factors (total cholesterol, blood pressure, body mass index, and blood glucose) as well as health behaviors (smoking, physical activity, and diet). Less than five percent of the U.S. population has "ideal" $\mathrm{CVHI}^{25,35}$ and, with growing concern for the ability to meet the stated public health goals, ${ }^{37}$ the need for population-based approaches to meet these goals is underscored. Such approaches will require an understanding of $\mathrm{CVH}$ in individuals and communities, the individual and community-level factors that affect $\mathrm{CVH}$, and the tools, such as public policies ${ }^{79,87,117}$, that can improve population $\mathrm{CVH}$.

Health care resources, particularly a medical home, are key to maintaining and improving health. This priority is reflected in the Healthy People 2020 objective (AHS-5) to increase the proportion of persons who have a specific source of ongoing care ${ }^{11}$. A medical home, defined as a regular place and/or provider of care, has been associated with better health 
status $^{60}$, more equitable care ${ }^{61}$, and increased use of preventive services ${ }^{62-64}$. Two essential aspects of medical homes are the provider supply and the physical facility ${ }^{65}$.

Increased physician supply has been found to be associated with better outcomes across a wide variety of medical conditions and procedures ${ }^{66}$ and increases in total provider supply were found to lead to improved health outcomes ${ }^{67}$. More specifically, increases in primary care physician (PCP) supply is associated with increased prevalence of positive health outcomes $^{60,61,118}$, including self-reported general health ${ }^{119}$, higher U.S. state health rankings ${ }^{120}$, and decreased mortality ${ }^{121}$. One study determined that a 1 per 10,000 population increase in PCPs decreased all-cause mortality $5.3 \%$ per year ${ }^{122}$. As there is a documented shortage of health care providers particularly in rural areas ${ }^{123,124}$, it has been proposed that increasing the availably of physician assistants (PA) and nurse practitioners (NP) may compensate for PCP shortages $^{68}$. Further, several studies have suggested that PAs and NPs provide a similar quality of services and may contribute to cost-containment ${ }^{69}$, particularly in rural areas ${ }^{125-127}$.

Community health centers, such as Rural Health Centers (RHC) and Federally Qualified Health Centers (FQHC) funded by the Health Research and Services Administration (HRSA), aim to provide the desired centralized, stable source of care to underserved communities and vulnerable populations ${ }^{70,128}$. Uninsured and Medicaid patients visiting community health centers are more likely to have a regular source of care, have seen a provider in the past year, and to receive preventive screenings when compared with patients at other sites of care ${ }^{129}$. Studies indicate community health centers provide more equitable care and increased number of services for vulnerable populations when compared with other primary care sites $^{72,73}$.

The purpose of the present study was to examine the association between health care resource availability (provider supply and physical facilities) and CVH as defined by the CVHI. Our primary hypothesis was that higher $\mathrm{CVHI}$ is associated with provider supply and physical facilities; in particular those with a preventive or primary care focus. We assessed this 
association in both individuals and populations. Necessary adjustment for the insurance status of both individuals and communities was considered, but was not the focus of this study.

\section{METHODS}

The relationship between $\mathrm{CVHI}$ and the availability of community health care resources was examined in the U.S. To examine the association between health care resources and $\mathrm{CVHI}$ in communities, linear regression analysis was performed, adjusting for multiple community- level socioeconomic and demographic covariates. To examine the association between health care resources and $\mathrm{CVHI}$ in individuals, Poisson regression analysis was performed, adjusting for multiple community and individual-level socioeconomic and demographic covariates.

\section{Data Source}

The Behavioral Risk Factor Surveillance System (BRFSS) is an annually administered national telephone survey in each U.S. state and the District of Columbia and collects information on health risk behaviors, chronic health conditions, and use of preventive services ${ }^{56}$. Random digit dialing is used to interview adults at least 18 years of age who are part of the civilian, non-institutionalized population. Detailed descriptions of BRFSS study design and methods are described elsewhere ${ }^{56}$. Due to question availability for all AHA CVHI components, 2011 BRFSS data was used in this study.

\section{Study Population}

All participants of the 2011 BRFSS survey were examined to determine eligibility $(n=$ $507,402)$. Participants were excluded if they were missing any question required to determine one of the seven CVHI components $(n=157,908)$ or if missing a county Federal Information Processing Standards (FIPS) code $(n=37,163)$. Females were also ineligible if pregnant or if pregnancy status was unknown at the time of survey $(n=3,693)$. The final eligible population included 308,895 individuals (60.9\% of all 2011 respondents). Communities were defined as a 
health service area (HSA), a county or cluster of counties which are reasonably independent regarding hospital care. HSAs were determined using county FIPS code and the National Cancer Institute's Surveillance, Epidemiology, and End Results Program (SEER) ${ }^{83}$. HSAs with fewer than 15 respondents $(n=120)$ were excluded; 833 HSAs $(87.5 \%)$ were include in the final analysis.

\section{Cardiovascular Health}

CVHI in individuals was determined using an approach previously adapted for BRFS ${ }^{6}$ and is summarized here in Table 1. For individuals, CVHI was calculated as a count of components meeting "ideal" criteria and could range from 0 to 7 . For HSAs, CVHI was calculated as the age-standardized mean of all eligible BRFSS participants in that HSA. $\underline{\text { Health Care Resources }}$

Information to assess health care resource availability was obtained from the Area Health Resource File (AHRF) ${ }^{89}$, an annual compilation of health care resources and socioeconomic data from $>50$ sources that is compiled and published by HRSA. To determine estimates of resource availability in HSAs, the absolute number of each resource for all counties in an HSA was summed and then divided by the total population of the HSA. Health care resource availability was determined by: number of PCPs, PAs, NPs, and CVD specialists; and number of hospital beds, FQHCs or RHCs, and hospitals with a primary care department. PCPs were defined as non-federal medical doctors and doctors of osteopathy, under age 75, not hospital residents, whose major professional activity was classified as patient care, and selfdesignated practice specialty was general practice, general family medicine, general internal medicine, or general pediatrics. CVD specialists were defined as non-federal medical doctors whose self-designated specialty was cardiovascular disease.

\section{$\underline{\text { Covariates }}$}

Socioeconomic and demographic characteristics of each county were obtained from the $\mathrm{AHRF}^{89}$ and aggregated to the HSA as discussed above. HSA-level socioeconomic and 
demographic covariates were (for categorical variables, expressed as a percent of the total HSA population): male; non-Hispanic black; Hispanic; median household income; 4-year college graduates; health insurance status; urban status, aged 65+; poverty. Covariate data were from 2010 or 2011 (availability varied slightly). Individual-level demographic characteristics were obtained from BRFSS and included: age; sex; race/ethnicity (non-Hispanic white, non-Hispanic black, Hispanic, and Other); education level (less than high school, high school, some college); income (under $\$ 25,000, \$ 25,000$ - $\$ 49,999, \$ 50,000$ - $\$ 74,999, \$ 75,000$ or more); and insurance status (none, some coverage).

$\underline{\text { Statistical Analysis }}$

For HSAs, age-standardized mean CVHI was determined using 2000 U.S. projected population (distribution 8$)^{92}$ and using survey procedures to account for BRFSS survey weights and design. The 2000 standard population distribution used age groups 18-24 years, 25-44 years, 45-64 years and 65 years and older. A map of mean CVHI by HSA was made using ArcGIS 10.1 (ESRI 2012. ArcGIS Desktop: Release 10.1. Redlands, CA: Environmental Systems Research Institute). Population demographic characteristics were estimated using weighted means and percentages of each covariate. Univariate and adjusted linear regression analysis was performed to determine the association between HSA health care resources and CVHI. Univariate and adjusted Poisson regression analysis was performed to determine the association between HSA health care resources and individual-level $\mathrm{CVHI}$, with adjustment for both HSA and individual-level covariates. Poisson regression coefficients are interpreted as mean ratios: the mean $\mathrm{CVHI}$ of a group divided by the mean $\mathrm{CVHI}$ of the referent group.

Interactions between PCPs and both individual and HSA-level socioeconomic and demographic factors were assessed. For significant interactions, the margins command was used to determine predicted individual $\mathrm{CVHI}$ by number of PCPs for covariate group levels. All statistical analyses were performed with Stata 13 (StataCorp. 2013. Stata Statistical Software: Release 13. College Station, TX: StataCorp LP). 


\section{RESULTS}

Characteristics of the communities and individuals included in the study population are presented in Table 2. The average HSA had 63 PCPs per 100,000 population and 25 PAs per 100,000 population. HSAs were mostly urban $(74.8 \%)$, and averaged $21 \%$ college graduates, $14 \%$ with no health insurance, and $15 \% \geq 65$ years old. Both individual and HSA mean CVHI was 3.3. Compared to included HSAs, excluded HSAs were more likely to have a smaller nonHispanic black and Hispanic population, a smaller proportion of college graduates, a slightly larger proportion living in poverty, and were substantially more rural (data not shown). The geographical distribution of age-standardized HSA-level CVHI is shown in Figure 1. HSAs with insufficient data were more frequently in the Midwest and upper plains.

Individuals were more likely to be female (52.5\%), non-Hispanic white (72.4\%), have at least some college education (59.4\%), and have some health insurance coverage (88.3\%). Compared to eligible individuals, non-eligible individuals were younger, male, and less educated (data not shown).

Results from linear regression analysis assessing the association between available health care resources and HSA-level CVHI are shown in Table 3. In univariate analysis, all health resource variables were associated with $\mathrm{CVHI}$ except NPs and hospitals with primary care departments. After adjustment for HSA socioeconomic and demographic factors, PCPs, PAs, and CVD specialist supply remained associated with CVHI: PCPs and PAs were positively associated with CVHI, while CVD specialists were negatively associated with CVHI.

Standardized coefficients were examined to assess the comparative impact of health care resources and traditional socioeconomic and demographic factors on HSA-level CVHI. College education was more important than any health care resource or other HSA-level factor: a one standard deviation increase in the percent of an HSA with a college education was associated with a 0.10-point increase in age-standardized HSA-level CVHI. The number of 
PCPs was the most important health resource associated with HSA-level CVHI; a one standard deviation increase in the number of PCPs per 100,000 population was associated with a 0.06 point increase in HSA-level CVHI.

Results from Poisson regression analysis assessing the association between available health care resources and individual-level $\mathrm{CVHI}$ are shown in Table 4. In univariate analysis, all health resource variables are associated with CVHI except NPs. After adjustment for individual and HSA socioeconomic and demographic factors, PCPs, PAs, CVD specialist supply, and hospital beds remain associated with individual CVHI: PCPs and PAs were positively associated with CVHI, while CVD specialists and hospital beds were negatively associated with CVHI.

In individual-level models, we observed statistically significant interactions between HSA-level PCP supply and several individual and HSA socioeconomic and demographic characteristics, including sex $(p=0.01)$, race/ethnicity $(p=0.04)$, income $(p=0.001)$, and age $(p<0.001)$. Figure 2 presents the predicted individual $\mathrm{CVHI}$ for these interactions. As PCP supply increased, those aged 31-65 years old had increasing CVHI (Figure 2A), while those 1830 years had decreasing $\mathrm{CVHI}$ and those $>65$ years had no change in $\mathrm{CVHI}$. At all income levels, PCP supply was associated with higher $\mathrm{CVHI}$, though those with a household income $<\$ 25,000$ benefitted most (Figure 2B). Increased PCP supply was associated with higher CVHI for all race/ethnicities except non-Hispanic black (Figure 2C). "Other" race/ethnicity appeared to benefit the most from increased PCP supply. Both men and women had higher CVHI with increased PCP supply, but women appeared to benefit more from an increased supply of PCPs (Figure 2D).

We also we observed statistically significant interactions between PCP supply and HSAlevel socioeconomic and demographic characteristics including population density $(p=0.04)$ and the proportion without health insurance $(p=0.002)$. At all levels of HSA health insurance coverage, increased PCP supply was associated with higher individual CVHI (Figure 2E) and 
individuals in communities with the lowest level of health insurance coverage benefited the most. Individuals in both urban and non-urban communities experienced higher CVHI with increased PCP supply (Figure 2F), with individuals in non-urban communities benefiting more than individuals in urban communities.

Finally, in community-level (HSA) models, we observed a near statistically significant interaction ( $p=0.07$ ) between HSA-level PCP and population density. Similar to the results seen

for individuals, both urban and non-urban communities had higher $\mathrm{CVHI}$ as PCP supply increased (Figure 3) and non-urban communities benefited slightly more than urban communities.

\section{DISCUSSION}

To our knowledge, this is the first study to assess the relationship between health care resource availability and cardiovascular health. In both individuals and communities, the key health care resources associated with CVHI were PCPs and PAs.

Health Care Resource Availability and Individual-Level CVHI

In individuals, our observation that PCP and PA supply was positively associated with $\mathrm{CVHI}$ is consistent with other studies reporting that PCPs were associated with better health outcomes and that PAs may provide care similar to physicians ${ }^{127}$. However, we did not observe an association between NPs and $\mathrm{CVHI}$, though other studies have suggested that NPs may also provide care similar to PCPs ${ }^{69,125,130}$. Our observations, at least regarding the beneficial effect of PCP and PA supply, are consistent with previously suggested mechanisms for the impact of primary care on health outcomes: (1) improved access to primary and also specialty care, as PCPs are often gatekeepers to further care, (2) better quality of care, (3) greater focus on preventive care, and (4) early detection and management of health complications before advanced treatment is necessary ${ }^{60}$. 
Our observation that CVD specialist supply was negatively associated with CVHI is consistent with Starfield et $a^{61}$ who reported specialists to be associated with increases in mortality. Further, in a cross sectional study, this observation is not unexpected as specialists are geographically concentrated in areas higher population and resources ${ }^{67}$. Future studies attempting to explore the mechanism between specialist care and health should consider quality of care, geographic patterns in practice, and relationships between PCP and specialist provider supply as these complex relationships have been discussed by others, including Cooper et a/67 who reported that increased supply of specialists and PCPs was associated with higher care quality, and Ricketts et al ${ }^{131}$ who observed regional patterns in the association between the supply of specialists and health outcomes.

Both health care resource supply, community socioeconomic and demographic factors, and individual factors were all significantly associated with individual-level CVHI, though individual factors (sex, income, and education level) had the greatest influence (5-to-17-fold higher effect size) on individual-level CVHI. This is not unexpected, as individual factors are much more proximal to individual health than are community factors. Further, these results are consistent with a deep literature discussing the positive association between education and health 24, 132, 133. Interestingly, an individual's insurance status was not associated with CVHI, which is consistent with Sox et al ${ }^{134}$ who reported a regular physician was more important than insurance status.

Health Care Resources and Community-Level Cardiovascular Health

For both communities and individuals, education had, by a substantial margin, the largest impact on CVHI. However, in contrast to individuals, in communities PCP had the second-largest impact on $\mathrm{CVHI}$. The relative effect sizes of community health care resources and demographic factors in community-level analysis are much closer than in individual-level analysis. These findings are consistent with other studies reporting that community factors and/or PCP supply were associated with mortality ${ }^{135,136}$. For individuals and communities, the 
supply of health care facilities (hospital beds etc.) had only a very small (hospital beds for individuals) or no association (communities) with CVHI.

\section{Modification of Association between Cardiovascular Health and Primary Care Provider Supply}

Very few studies have examined how individual and community demographic factors may modify the association between $\mathrm{CVHI}$ and health care resource availability. Our results reported here suggest that individuals who derived the largest marginal benefit from increased PCP supply were: middle age, females, non-Hispanic Other race/ethnicity; and had a household income $<\$ 25,000 /$ year and lived in a non-urban community with low insurance coverage. The increased benefit for individuals living in communities with low insurance coverage may be due to the presence of RHCs and FQHCS, which we confirmed in a brief sub-analysis to be present in significantly higher numbers in these communities, and is consistent with studies suggesting community health centers are particularly helpful to vulnerable populations ${ }^{129}$. Groups benefitting the least from increased provider supply were young adults and non-Hispanic blacks. In fact, our results suggested that $\mathrm{CVHI}$ in young adults decreased with PCP supply, possibly because, in this age group, health care visits may be more associated with a health crisis or acute illness rather than preventive care and so more likely to be associated with a diagnosis (leading to lower $\mathrm{CVHI}$ ), whereas in other age groups health care visits may be more balanced between preventive and acute care. Our observation that non-Hispanic blacks do not benefit from increased PCP supply suggests other barriers to care for this population.

$\underline{\text { Implications and Suggested Strategies for Improving Cardiovascular Health }}$

Results reported here suggest that a focus on improving $\mathrm{CVHI}$ in individuals would require targeting individual factors, some of which are non-modifiable (sex and age).

Improvements in education and income of individuals would improve individual CVHI more than any other factors assessed. The continued importance of education for both individual and community health cannot be overlooked. Policies and programs to support higher education is likely to result in improved individual and population health. Non-Hispanic black individuals 
continue to have lower health status than other race/ethnicities and also derive less benefit from health care resource availability.

The similarity in the importance of health care resources to both individual and community $\mathrm{CVHI}$ suggests that approaches to increase the supply of primary care providers would beneficially affect health at all levels. Our results lend quantitative support to policies and program priorities aimed at increasing access to preventive care for individuals and in communities $^{11,79,117}$ to increase overall $\mathrm{CVHI}$ and reduce disparities in $\mathrm{CVHI}$ between age, income, and gender groups.

The continued projected decline in the number of medical school graduates selecting primary care specialties presents a real and substantial challenge to increasing PCP supply, especially in rural and underserved communities ${ }^{137-139}$, and, by extension of our results reported here, improving $\mathrm{CVHI}$ in both individuals and communities. The anti-primary care specialization trend is a concern not only for PCPs, but also PAs and NPs: currently, only $43 \%$ of PAs and $52 \%$ of NPs choose primary care specialties ${ }^{139}$. Future research must examine which resources and policies can impact the supply of primary care providers.

Strengths and Limitations

The use of BRFSS, a large, nationally representative sample, which allows for stratification and analysis at the state level is a key strength of this study. The key limitation of this study is the self-report methodology of BRFSS which may result in an overestimation of $\mathrm{CVHI}$. There is also possible bias as there were a significant percentage of participants with missing data for at least one CVHI component. Communities excluded due to suppressed or missing FIPS code in BRFSS were rural with higher Hispanic populations and therefore this analysis may not be generalizable to those populations.

\section{$\underline{\text { Conclusion }}$}

This study provides an assessment of the specific health care resources that are associated with higher CVHI. This information can be used to inform policies and targets for 
population health improvement. Further research is needed to determine which policies and factors can be used to increase PCP supply and influence where they practice. 


\section{Acknowledgements:}

The authors wish to thank Dr. Matthew J. Gurka from the West Virginia University School of Public Health for his very helpful technical (statistical) advice during this study.

\section{Funding Sources:}

Board. Research reported in this study was supported, in part, by the West Virginia Clinical and Translational Research Institute (WV-CTSI), which is supported by the National Institute of General Medical Sciences of the National Institute of Health under award U54GM104942. The content is solely the responsibility of the authors and does not necessarily represent the official views of the National Institutes of Health.

\section{Disclosures:}

This study was approved as non-human subjects research by the West Virginia University Institutional Review 
Table 1. Summary of BRFSS questions and definitions for classification of "ideal" CVHI in individuals

\begin{tabular}{|c|c|c|c|}
\hline & $\begin{array}{l}\text { American Heart Association } \\
\text { Definition of "Ideal"12 }\end{array}$ & $\begin{array}{c}\text { Adaptation of "Ideal" to be Used for } \\
\text { Individuals }\end{array}$ & 2011 BRFSS Questions Used to Determine "Ideal" Status \\
\hline Cholesterol & $<200 \mathrm{mg} / \mathrm{dL}$ untreated & $\begin{array}{l}\text { Previously screened and never been told had } \\
\text { high cholesterol }\end{array}$ & $\begin{array}{l}\text {-Have you ever been told by a doctor, nurse, or other health professional that } \\
\text { you have high blood pressure? }\end{array}$ \\
\hline Blood Pressure & $<120 /<80 \mathrm{~mm} \mathrm{Hg}$ untreated & Never been told had high blood pressure & $\begin{array}{l}\text {-Blood cholesterol is a fatty substance reported in the blood. Have you ever } \\
\text { had your blood cholesterol checked? } \\
\text {-Have you ever been told by a doctor or other health professional that your } \\
\text { blood cholesterol is high? }\end{array}$ \\
\hline BMI & $<25 \mathrm{~kg} / \mathrm{m}^{2}$ & $18.5-24.9 \mathrm{~kg} / \mathrm{m}^{2}$ & $\begin{array}{l}\text {-About how much do you weigh without shoes? } \\
\text {-About how tall are you without shoes? }\end{array}$ \\
\hline Smoking & Never or quit $\geq 12$ months ago & $\begin{array}{l}\text { Had not smoked at least } 100 \text { cigarettes in their } \\
\text { lifetime or reported smoking } 100 \text { cigarettes in } \\
\text { their lifetime but not currently smoking }\end{array}$ & $\begin{array}{l}\text {-Have you smoked at least } 100 \text { cigarettes in your entire life? } \\
\text {-Do you now smoke cigarettes every day, some days, or not at all? } \\
\text {-About how long has it been since you last smoked cigarettes regularly, that is, } \\
\text { daily? }\end{array}$ \\
\hline Blood Sugar & $<100 \mathrm{mg} / \mathrm{dL}$ untreated & Never been told had diabetes & -Have you ever been told by a doctor that you have diabetes? \\
\hline Diet & $\begin{array}{l}4-5 \text { diet components meeting } \\
\text { national standards (fruits and } \\
\text { vegetables, fish, fiber-rich } \\
\text { whole grains, sodium, sugar- } \\
\text { sweetened beverages) }\end{array}$ & $\geq 5$ servings of fruits and vegetables/day & $\begin{array}{l}\text {-During the past month, not counting juice, how many times per day, week, or } \\
\text { month did you eat fruit? Count fresh, frozen, or canned fruit. } \\
\text {-During the past month, how many times per day, week, or month did you eat } \\
\text { orange-colored vegetables such as sweet potatoes, pumpkin, winter squash, or } \\
\text { carrots? } \\
\text {-During the past month, how many times per day, week, or month did you eat } \\
\text { dark green vegetables for example broccoli or dark leafy greens including } \\
\text { romaine, chard, collard greens or spinach? } \\
\text {-Not counting what you just told me about, during the past month, about how } \\
\text { many times per day, week, or month did you eat OTHER vegetables? }\end{array}$ \\
\hline Physical Activity & $\begin{array}{l}\geq 150 \mathrm{~min} / \mathrm{wk} \text { moderate } \\
\text { intensity OR } \geq 75 \mathrm{~min} / \mathrm{wk} \\
\text { vigorous intensity OR } \\
\text { combination }\end{array}$ & $\begin{array}{l}\geq 150 \mathrm{~min} / \text { wk moderate intensity } \mathrm{OR} \geq 75 \\
\text { min/wk vigorous intensity OR combination }\end{array}$ & $\begin{array}{l}\text {-During the past } 30 \text { days, other than your regular job, did you participate in any } \\
\text { physical activities or exercise such as running, calisthenics, golf, gardening, or } \\
\text { walking for exercise? } \\
\text {-How many times per week or per month did you take part in this activity during } \\
\text { the past month? } \\
\text {-And when you took part in this activity, for how many minutes or hours did you } \\
\text { usually keep at it? } \\
\text {-Estimated Activity Intensity for First Activity (Calculated by BRFSS) } \\
\text {-How many times per week or per month did you take part in this activity during } \\
\text { the past month? } \\
\text {-And when you took part in this activity, for how many minutes or hours did you } \\
\text { usually keep at it? } \\
\text {-Estimated Activity Intensity for Second Activity (Calculated by BRFSS) }\end{array}$ \\
\hline
\end{tabular}


Table 2. Characteristics of individual and community (HSA) study population.

\begin{tabular}{|c|c|}
\hline \multicolumn{2}{|c|}{ Community (HSA) Health Care Resources (per 100000 population) } \\
\hline $\begin{array}{l}\text { Primary Care Physicians } \\
\text { Physician Assistants } \\
\text { Nurse Practitioners } \\
\text { Cardiovascular Disease Specialists } \\
\text { Hospital Beds } \\
\text { Number of FQHCs or RHCs } \\
\text { Hospitals with a Primary Care Department }\end{array}$ & $\begin{array}{c}63.4 \pm 20.8 \\
24.6 \pm 16.0 \\
40.1 \pm 18.7 \\
4.1 \pm 4.0 \\
334.0 \pm 193.5 \\
6.6 \pm 7.0 \\
1.0 \pm 1.4\end{array}$ \\
\hline \multicolumn{2}{|l|}{ Community (HSA) Demographic Characteristics } \\
\hline $\begin{array}{l}\text { \% Non-Hispanic Black } \\
\% \text { Hispanic } \\
\% \text { College Graduates } \\
\% \text { Male } \\
\% \text { Poverty } \\
\text { Median Household Income }(\$) \\
\% \text { No Health Insurance } \\
\% 65 \text { Years and Older } \\
\text { Population Density }\end{array}$ & $\begin{array}{c}9.7 \pm 13.0 \\
9.4 \pm 12.7 \\
21.4 \pm 7.9 \\
49.6 \pm 1.3 \\
16.7 \pm 5.1 \\
44,082 \pm 9,958 \\
14.4 \pm 4.2 \\
15.1 \pm 3.5 \\
\\
623(74.8) \\
210(25.2) \\
\end{array}$ \\
\hline Community Cardiovascular Health Index & $3.34 \pm 0.3$ \\
\hline \multicolumn{2}{|l|}{ Individual Demographic Characteristics } \\
\hline $\begin{array}{l}\text { Age (years) } \\
\text { Sex }\end{array}$ & $\begin{array}{c}51.4 \pm 0.06 \\
189,044(52.5) \\
119,753(47.5)\end{array}$ \\
\hline $\begin{array}{r}\text { Non-Hispanic White } \\
\text { Non-Hispanic Black } \\
\text { Hispanic } \\
\text { Other }\end{array}$ & $\begin{array}{c}249,022(72.4) \\
25,905(11.3) \\
15,736(11.0) \\
10,111(5.3)\end{array}$ \\
\hline $\begin{array}{r}\text { Less than High School } \\
\text { High School } \\
\text { Some College }\end{array}$ & $\begin{array}{c}23,284(12.2) \\
86,991(28.4) \\
198,083(59.4)\end{array}$ \\
\hline $\begin{array}{r}\text { Under } \$ 25,000 \\
\$ 25,000-\$ 49,999 \\
\$ 50,000-\$ 74,999 \\
\$ 75,000 \text { or More }\end{array}$ & $\begin{array}{l}75,356(26.6) \\
72,534(25.2) \\
44,871(16.3) \\
79,975(31.8)\end{array}$ \\
\hline $\begin{array}{r}\text { Some Coverage } \\
\text { None }\end{array}$ & $\begin{array}{c}283,666(88.3) \\
24,636(11.7) \\
\end{array}$ \\
\hline Individual Cardiovascular Health Index & $3.30 \pm 0.005$ \\
\hline
\end{tabular}

* Mean \pm Standard Deviation presented for continuous variables and $n$ (frequency) presented for categorical variables. Frequencies weighted for individuals.

Abbreviations: HSA: Health Service Area; FQHC: Federally Qualified Health Center; RHC: Rural Health Center 
Table 3. Results from linear regression analysis assessing the association between community (HSA) health care resources and community CVHI, unadjusted and adjusted for community (HSA) socioeconomic and demographic factors

\begin{tabular}{|c|c|c|c|c|c|c|c|c|}
\hline Covariate & \multicolumn{2}{|c|}{ Univariate } & & \multicolumn{2}{|c|}{ Adjusted } & \multirow[t]{2}{*}{ Standardized } & \multicolumn{2}{|l|}{ Standard Deviation } \\
\hline \multicolumn{8}{|c|}{ Community (HSA) Health Care Resources (per 100000 population) } & \\
\hline Primary Care Physicians & 0.06 & $0.05-0.07$ & * & 0.03 & $0.01-0.04$ & 0.06 & 20.82 & * \\
\hline Physician Assistants & 0.05 & $0.03-0.06$ & * & 0.01 & $0.003-0.03$ & 0.02 & 16.05 & * \\
\hline Nurse Practitioners & 0.005 & $-0.006-0.02$ & & -0.01 & $-0.02-0.002$ & -0.02 & 18.69 & \\
\hline Cardiovascular Disease Specialists & 0.12 & $0.07-0.18$ & * & -0.08 & $-0.15--0.02$ & -0.03 & 3.96 & * \\
\hline Hospital Beds ${ }^{\dagger}$ & -0.01 & $-0.02--0.001$ & * & -0.003 & $-0.01-0.007$ & -0.006 & 193.52 & \\
\hline Number of FQHCs and RHCs ${ }^{\ddagger}$ & -0.009 & $-0.01--0.0006$ & * & -0.002 & $-0.005-0.0007$ & -0.01 & 6.98 & \\
\hline Hospitals with Primary Care Department ${ }^{\ddagger}$ & -0.003 & $-0.02-0.01$ & & -0.006 & $-0.02-0.008$ & -0.008 & 1.39 & \\
\hline \multicolumn{9}{|c|}{ Community (HSA) Demographic Characteristics } \\
\hline$\%$ Non-Hispanic Black & -0.05 & $-0.07--0.04$ & * & -0.006 & $-0.02-0.01$ & -0.008 & 12.99 & \\
\hline$\%$ Hispanic & 0.03 & $0.01-0.04$ & * & 0.03 & $0.009-0.05$ & 0.04 & 12.73 & * \\
\hline$\%$ College Graduates & 0.19 & $0.17-0.22$ & * & 0.12 & $0.09-0.16$ & 0.10 & 7.93 & * \\
\hline$\%$ Male & 0.22 & $0.06-0.37$ & * & 0.15 & $-0.002-0.30$ & 0.02 & 1.29 & \\
\hline$\%$ Poverty & -0.25 & $-0.28--0.21$ & * & -0.08 & $-0.15--0.01$ & -0.04 & 5.08 & * \\
\hline Median Household Income (per \$1000) & 0.01 & $0.01-0.02$ & * & -0.00005 & $-0.004-0.004$ & 0.0005 & 9.96 & \\
\hline$\%$ No Health Insurance & -0.16 & $-0.21--0.11$ & * & -0.05 & $-0.12-0.008$ & -0.02 & 4.19 & \\
\hline$\% 65$ Years and Older & -0.14 & $-0.20--0.07$ & * & -0.03 & $-0.10-0.04$ & -0.009 & 3.15 & \\
\hline Urban & 0.00 & & & 0.00 & & & & \\
\hline Not Urban & 0.05 & $0.003-0.10$ & * & -0.34 & $-0.82-0.11$ & -0.02 & 0.43 & \\
\hline
\end{tabular}

* Indicates significance at the alpha 0.05 level

Coefficients presented as a 10-unit change in the covariate except for ${ }^{\dagger}$ which indicates a 100 -unit change and ${ }^{\ddagger}$ which indicates a 1 -unit change

Abbreviations: HSA: Health Service Area; CVHI: cardiovascular health index; FQHC: Federally Qualified Health Center; RHC: Rural Health Center 
Table 4. Results from Poisson regression analysis assessing the association (mean ratios) community (HSA) health care resources and individual-level CVHI, unadjusted and adjusted for community and (HSA) individual socioeconomic and demographic factors

\begin{tabular}{|c|c|c|c|c|}
\hline Covariate & Univariate & & Adjusted & \\
\hline \multicolumn{5}{|c|}{ Community (HSA) Health Care Resources (per 100000 population) } \\
\hline Primary Care Physicians & $1.02(1.01-1.02)$ & * & $1.01(1.00-1.01)$ & \\
\hline Physician Assistants & $1.01(1.00-1.01)$ & * & $1.00(1.00-1.01)$ & * \\
\hline Nurse Practitioners & $1.00(1.00-1.00)$ & & $1.00(1.00-1.00)$ & \\
\hline Cardiovascular Disease Specialists & $1.04(1.04-1.05)$ & * & $0.98(0.97-0.99)$ & * \\
\hline Hospital Beds ${ }^{\dagger}$ & $0.98(0.98-0.99)$ & * & $1.00(0.99-1.00)^{\S}$ & * \\
\hline Number of FQHCs and $\mathrm{RHCs}^{\ddagger}$ & $0.99(0.99-1.00)$ & * & $1.00(1.00-1.00)$ & \\
\hline Hospitals with Primary Care Department ${ }^{\ddagger}$ & $0.98(0.98-0.98)$ & * & $1.00(0.99-1.00)$ & \\
\hline \multicolumn{5}{|c|}{ Community (HSA) Demographic Characteristics } \\
\hline$\%$ Non-Hispanic Black & $0.99(0.99-0.99)$ & * & $1.00(1.00-1.00)$ & \\
\hline$\%$ Hispanic & $1.01(1.01-1.02)$ & * & $1.01(1.01-1.02)$ & * \\
\hline$\%$ College Graduates & $1.06(1.05-1.06)$ & * & $1.03(1.02-1.04)$ & * \\
\hline$\%$ Male & $1.02(0.99-1.05)$ & & $1.04(1.00-1.08)$ & * \\
\hline$\%$ Poverty & $0.93(0.93-0.94)$ & * & $1.01(0.99-1.02)$ & \\
\hline Median Household Income (per \$1000) & $1.00(1.00-1.00)$ & * & $1.00(1.00-1.00)$ & \\
\hline$\%$ No Health Insurance & $0.98(0.98-0.99)$ & * & $0.98(0.97-0.99)$ & * \\
\hline $\begin{array}{l}\% 65 \text { Years and Older } \\
\text { Population Density }\end{array}$ & $0.93(0.92-0.94)$ & * & $1.03(1.01-1.04)$ & * \\
\hline Urban & 1.00 & & 1.00 & \\
\hline Not Urban & $1.06(1.05-1.07)$ & * & $0.99(0.98-1.00)$ & \\
\hline \multicolumn{5}{|l|}{ Individual Demographic Characteristics } \\
\hline Age (per 10 years) & $0.94(0.93-0.94)$ & * & $0.94(0.94-0.94)$ & * \\
\hline \multicolumn{5}{|l|}{ Sex } \\
\hline Male & 1.00 & & 1.00 & \\
\hline Female & $1.10(1.09-1.11)$ & * & $1.12(1.12-1.13)$ & * \\
\hline \multicolumn{5}{|l|}{ Race/Ethnicity } \\
\hline Non-Hispanic White & 1.00 & & 1.00 & \\
\hline Non-Hispanic Black & $0.92(0.91-0.93)$ & * & $0.93(0.92-0.94)$ & * \\
\hline Hispanic & $1.01(0.99-1.02)$ & & $1.00(0.99-1.01)$ & \\
\hline Other & $1.09(1.07-1.10)$ & * & $1.01(1.00-1.03)$ & * \\
\hline \multicolumn{5}{|l|}{ Education } \\
\hline Less than High School & 1.00 & & 1.00 & \\
\hline High School & $1.10(1.09-1.12)$ & * & $1.05(1.04-1.06)$ & * \\
\hline Some College & $1.25(1.24-1.27)$ & * & $1.12(1.10-1.13)$ & * \\
\hline \multicolumn{5}{|l|}{ Income } \\
\hline Under $\$ 25,000$ & 1.00 & & 1.00 & \\
\hline$\$ 25,000-\$ 49,999$ & $1.10(1.09-1.11)$ & * & $1.08(1.07-1.09)$ & \\
\hline$\$ 50,000-\$ 74,999$ & $1.16(1.15-1.17)$ & * & $1.11(1.10-1.12)$ & * \\
\hline$\$ 75,000$ or More & $1.26(1.25-1.27)$ & * & $1.17(1.16-1.18)$ & \\
\hline \multicolumn{5}{|l|}{ Insurance Status } \\
\hline Some Coverage & 1.00 & & 1.00 & \\
\hline None & $0.98(0.97-0.99)$ & * & $1.00(0.99-1.01)$ & \\
\hline
\end{tabular}

* Indicates significance at the alpha 0.05 level

Coefficients presented as a 10-unit change in the covariate except for ${ }^{\dagger}$ which indicates a 100-unit change and

${ }^{\ddagger}$ which indicates a 1-unit change

${ }^{\S}$ Result presented after rounding (before rounding coefficient was 0.99995 (0.99993-0.99998))

Abbreviations: HSA: Health Service Area; CVHI: cardiovascular health index; FQHC: Federally Qualified Health Center; RHC: Rural Health Center 
Figure 1. Mean age-standardized CVHI for United States health service area, 2011 (BFRSS data)

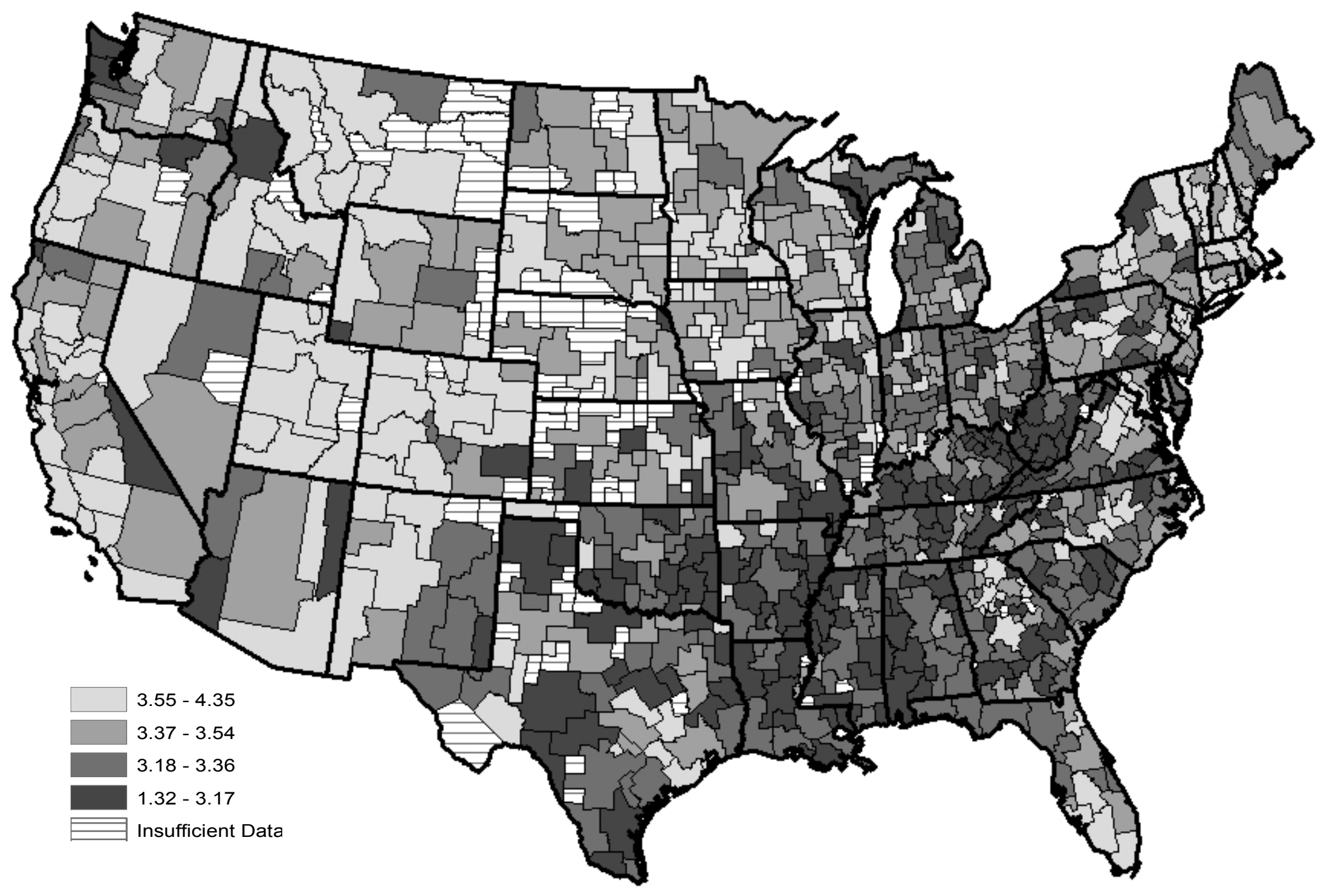

Abbreviations: CVHI: cardiovascular health index; BRFSS: Behavioral Risk Factor Surveillance Survey 

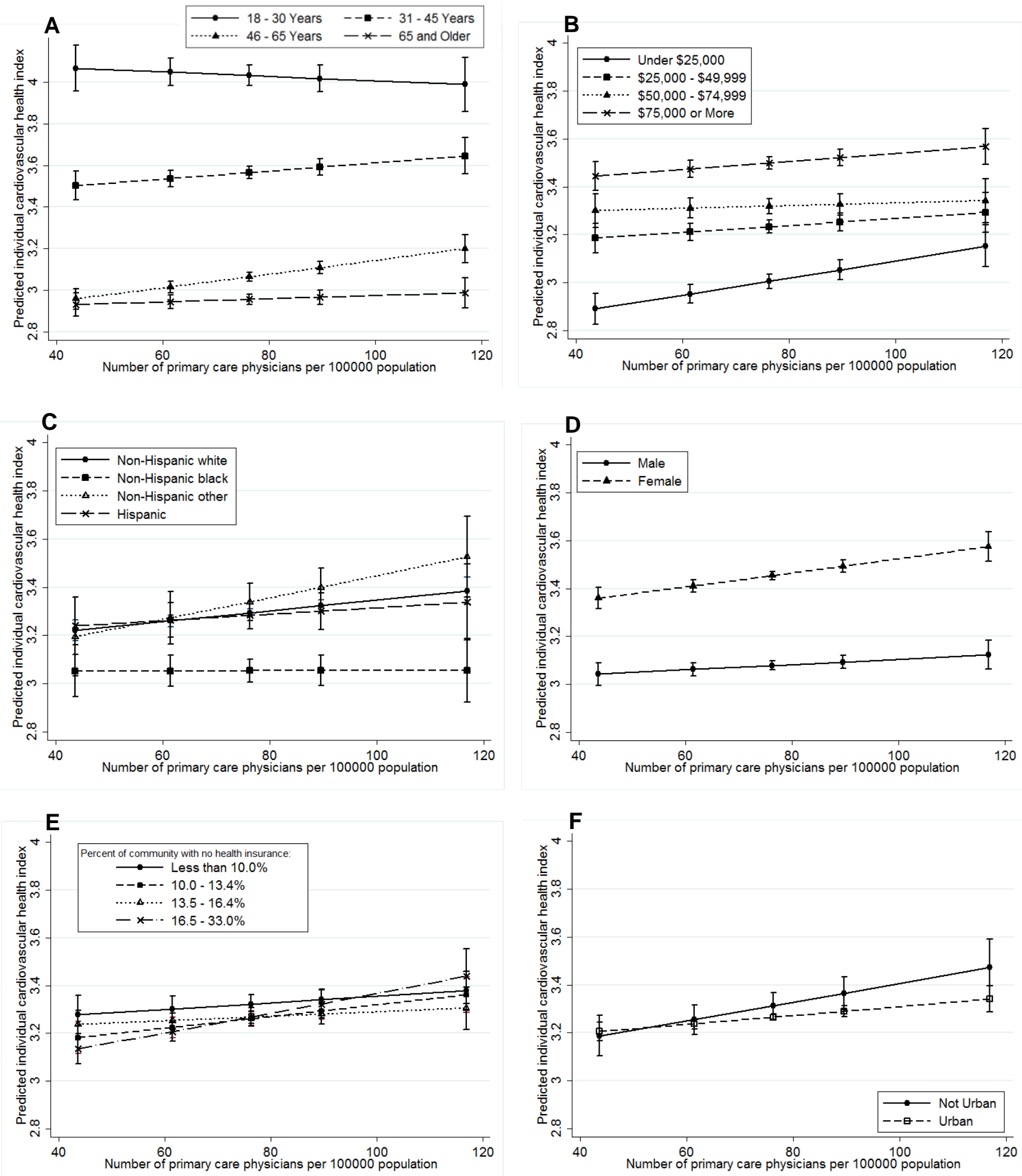

Figure 2. Results from regression analysis demonstrating differential association (interaction) between the number of PCPs per 100,000 population and individual-level predicted CVHI based upon individual and community (HSA) factors: (A) individual age; (B) individual income; (C) individual race/ethnicity; (D) individual sex; $(E)$ community insurance coverage; and $(F)$ community population density

Abbreviations: PCPS: primary care providers; CVHI: cardiovascular health index; HSA: Health Service Area 
Figure 3. Results from regression analysis demonstrating differential association (interaction) between the number of PCPs per 100,000 population and community (HSA)-level predicted $\mathrm{CVHI}$ based upon community (HSA) population density

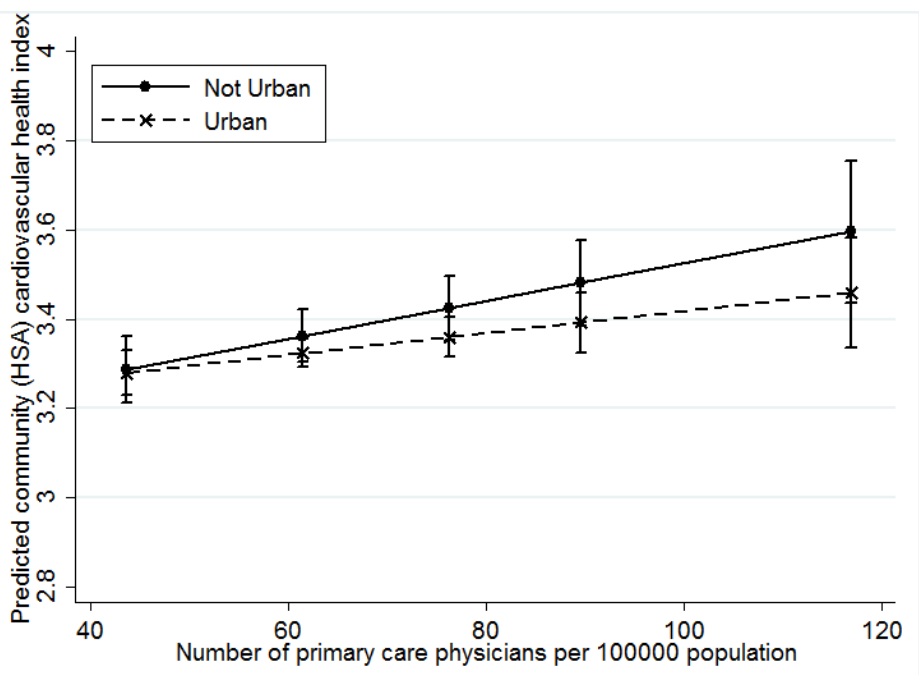

Abbreviations: PCPs: primary care providers; CVHI: cardiovascular health index; HSA: Health

Service Area 


\section{Chapter 6}

FULL TITLE: Association between state-level health care resource policies and cardiovascular health in the United States

SHORT TITLE: Health care resource policy and cardiovascular health

AUTHORS \& AFFILIATIONS: Courtney Pilkerton, B.A. ${ }^{1,2,3}$, Sarah S. Singh, M.D., MPH ${ }^{2,3}$, Thomas K. Bias, $\mathrm{PhD}^{3,4}$, and Stephanie J. Frisbee, $\mathrm{PhD}^{3,4}$

${ }^{1}$ West Virginia University School of Medicine

${ }^{2}$ West Virginia University School of Public Health, Department of Epidemiology

${ }^{3}$ West Virginia University Robert C. Byrd Health Sciences Center, Center for Cardiovascular and Respiratory Sciences

4West Virginia University School of Public Health, Department of Health Policy, Management \& Leadership

\section{CORRESPONDING AUTHOR:}

Stephanie J. Frisbee, PhD

West Virginia University

Robert C. Byrd Health Sciences Center

Center for Cardiovascular \& Respiratory Sciences

1 Medical Center Drive - PO Box 1905

Morgantown WV 26505-1905

304-293-6552 / sfrisbee@hsc.wvu.edu 


\section{ABSTRACT}

Introduction: Despite advances in treatment and decreases in risk factors, cardiovascular disease remains the cause of 1 in 3 deaths in the United States. A thorough understanding of health determinants requires inclusion of factors at multiple levels of proximity to individuals. The objective of this study was to identify the health care resource policies that promote cardiovascular health.

Methods: 2011 Behavioral Risk Factor Surveillance System survey data were used to calculate American Heart Association's cardiovascular health index (CVHI) for individuals. Health care resource policy variables assessed were Medicaid to Medicare reimbursement ratio, loan repayment programs for primary care providers, physician barrier to licensure index, nurse practitioner autonomy index, and physician assistant autonomous relationship index. Poisson regression was used to determine the association between health care resource policies and CVHI.

Results: All policy categories were associated with CVHI in unadjusted models with the Medicaid to Medicare reimbursement ratio, physician barrier to licensure index, and nurse practitioner autonomy index remaining associated with $\mathrm{CVHI}$ after adjustment for individual and county factors. Increasing Medicaid to Medicare reimbursement ratio was associated with lower $\mathrm{CVHI}$ while increasing physician barrier to licensure index and nurse practitioner autonomy index was associated with higher CVHI.

Conclusion: Policies with the potential to increase the autonomy of primary care providers or decrease barriers in their ability to practice were associated with higher $\mathrm{CVHI}$ even after controlling for provider supply. Further research is needed to explore the mechanism for how these policies impact cardiovascular health. 


\section{INTRODUCTION}

Although mortality attributable to cardiovascular disease continues to decline, CVD remains the cause of one in three deaths in the United States (U.S.) ${ }^{2}$ and it has been projected that, by 2030, more than $40 \%$ of the U.S. population will be living with CVD. Further, the associated direct medical costs are predicted to triple, and the indirect costs of CVD to increase by $61 \%$ (both from 2010 levels) ${ }^{8}$. In attempts to ameliorate the individual and societal burden of cardiovascular disease, improving cardiovascular health has been prioritized as a national public health goal. Health policy has proven itself effective in achieving many of the past successes in public health ${ }^{75,140}$. Further, Frieden's health impact model proposes that it is the policies that address issues on a societal or population level that have the most potential for improving population health as they require less effort on the part of the individual ${ }^{76}$.

However, even with these past successes, public health approaches in the past decade have been focused on programs aimed at changing individual behaviors and not on policies that attempt to alter the physical and social environment in which individuals (and populations) live ${ }^{141}$. More recently, public health groups have begun to advocate to re-balance these individual-level behavioral approaches with population-level policy approaches as a means to more efficiently and effectively improve population health ${ }^{12}$. In a panel discussion of the challenges in tackling chronic diseases, it was highlighted that a key challenge related to policy interventions is the need to determine which policies work best and how best to implement these policies ${ }^{77}$. There is a need for practice-based evidence ${ }^{142,143}$ to show that the implementation of policies suggested by scientific evidence has an impact on health outcomes.

Several recent studies have examined the associations between health outcomes and policy environments suggesting increased number and strictness of firearm policy is associated with fewer firearm fatalities ${ }^{144}$, stronger alcohol policy environment is associated with decreased binge drinking prevalence ${ }^{145}$, increased tobacco policy is associated with improved smoking 
behavior $^{81,146}$, increased strength of competitive food policies is associated with lower adolescent weight ${ }^{147}$, increased food service and nutrition policies are associated with less youth obesity ${ }^{148}$, policies to reduce sodium in processed foods are associated with lower blood pressure ${ }^{80,149}$. Previous work we have conducted suggests primary care provider supply, whether primary care physicians or physician assistants, is associated with cardiovascular health. Therefore it follows that policies with potential influence on primary care provider supply may impact cardiovascular health as well. Expected compensation has been suggested as one factor important in student decisions to pursue specialty care over primary care. As Medicare and Medicaid make up a large portion of the payer pool, the payment policies of these programs have been suggested to influence provider distribution ${ }^{119,150}$. Loan repayment programs are another attempt at influencing the primary versus specialty ratio, but have shown inconsistent associations with provider supply ${ }^{151-153}$. For physicians, it has been suggested that licensure is the main mechanism of control over provider supply with barriers to licensure resulting in decreased supply ${ }^{154}$. Factors associated with physician assistant and nurse practitioner retention and recruitment are autonomy, broad scope of practice, and authority to prescribe ${ }^{69}$, 126. The purpose of the present study was to examine the association between state-level health care resource policy and the cardiovascular health index $(\mathrm{CVHI})$. Our primary hypothesis is that higher cardiovascular health index is associated with policies that support increased supply of health care providers with a preventive or primary care focus.

\section{METHODS}

\section{Study Population}

All participants of the 2011 BRFSS survey were examined to determine eligibility $(n=507,402)$. The Behavioral Risk Factor Surveillance System (BRFSS) is an annually administered national 
telephone survey in each U.S. state and the District of Columbia. Detailed description of BRFSS study design and methods are described elsewhere ${ }^{56,111}$. BRFSS data from 2011 was abstracted for cardiovascular health index (CVHI) component questions and individual socioeconomic and demographic characteristics. Participants were excluded if they were missing any question required to determine one of the seven CVHI components $(n=157,908)$ or if missing a county Federal Information Processing Standards (FIPS) code $(n=37,163)$. Females were also ineligible if pregnant or pregnancy status unknown at the time of survey $(n=$ 3,693). The final population of eligible individuals was 308,895 .

\section{Cardiovascular Health}

BRFSS questions and definitions used to determine ideal for each of the American Heart Association's CVHI ${ }^{12}$ components were defined using previous work by Fang et $\mathrm{al}^{35}$.

Cholesterol, blood pressure, and diabetes were considered ideal if they had never been told had high cholesterol. Body mass index for an individual was considered ideal if between 18.5 and

24.9. Smoking behavior was considered ideal if individual had not smoked at least 100 cigarettes in their lifetime or not currently smoking. Diet was considered ideal if individual had $\geq$ to 5 servings of fruits and vegetables per day. Physical activity was considered ideal if individual participated in $\geq 150 \mathrm{~min} /$ week moderate intensity $\mathrm{OR} \geq 75 \mathrm{~min} /$ week vigorous intensity OR equivalent combination. CVHI was calculated as a sum of components meeting ideal criteria, and could range from 0 to 7.

\section{Health Resource Policy}

A summary of the state policies included in this study and how they are defined is presented in Table 1. Five policy variables were included for assessment; Medicaid to Medicare 
reimbursement ratio, loan repayment programs for primary care providers, physician barrier to licensure index, nurse practitioner (NP) autonomy index, and physician assistant (PA) autonomous relationship index. Data on state Medicaid to Medicare reimbursement ratios was abstracted from the Henry J. Kaiser Family Foundation ${ }^{155}$. Data on state based loan repayment programs for primary care providers was abstracted from the Association of American Medical Colleges database ${ }^{156}$. The physician barrier to licensure index was made up of three components, controlled substance prescribing registration, availability of locum tenens licensure, and licensure fees. Increasing index score indicates decreased barriers to licensure. Data on licensure fees was abstracted from the Federation of State Medical Boards ${ }^{157}$. Data on controlled substance prescribing registration and availability of locum tenens licensure was abstracted from Barton Associates, a national locum tenens physician, PA, and NP staffing and recruiting firm ${ }^{158}$. The NP autonomy index was made up of three components, practice autonomy, primary care consideration, and prescribing autonomy. Increasing index score indicates more autonomous practice. Data for the NP autonomy index was abstracted from Barton Associates ${ }^{159}$. The PA autonomous relationship index was made up of six components $^{160}$, license consideration, scope of services, practice supervision, prescribing supervision, co-signature requirements, and PA to physician ratio limit. Increasing index indicates a more autonomous relationship between PAs and their supervising physician. Data for the PA autonomous relationship index was abstracted from Barton Associates ${ }^{161}$

Three additional components were considered for physician barrier to licensure index, required years post-graduate training, time limit for completing licensure exams, and attempts at licensure examination allowed, but were not included due to lack of variation across states. Four additional components were considered for the NP index, ability to order physical therapy or sign death certificates, handicap parking permits, or worker' compensation claims, but were not included as they did not reflect preventive care aspects of provider responsibilities. Policies 
targeted at expanding community health workers were considered, but not included due to inconsistent definitions of community health worker between states. State policies on certificate of need, aimed at decreasing overlap of services and excess medical facilities, were considered, but not included as in previous work we found facility availability was not associated with cardiovascular health.

\section{Covariates}

Socioeconomic and demographic characteristics of each county were abstracted from the Area Health Resource File (AHRF) ${ }^{89}$. AHRF is an annual compilation of health care resources and socioeconomic data collected from over 50 sources by the Health Resources and Services Administration. Individual socioeconomic and demographic characteristics included age, sex, race/ethnicity (non-Hispanic white, non-Hispanic black, Hispanic, and other), education level (less than high school, high school, some college), income (under $\$ 25,000, \$ 25,000-\$ 49,999$, $\$ 50,000$ - $\$ 74,999, \$ 75,000$ or more), and health insurance status. County socioeconomic and demographic characteristics included sex (percent of the population male), percent nonHispanic black, percent Hispanic, median household income, percent four-year college graduates, percent without health insurance, percent unemployment, percent of the population over 65 years old, population density, and percent poverty. County primary care physician supply and PA supply were also included.

\section{Statistical Analysis}

Study population characteristics were estimated using weighted means and percentages of each covariate. Poisson regression analysis was performed to determine the association between health resource policy and individual-level CVHI. Poisson regression coefficients are 
interpreted as mean ratios; the mean $\mathrm{CVHI}$ of a group over the mean $\mathrm{CVHI}$ of the referent group. Interactions between state health care provider policies and county socioeconomic status and provider supply were assessed. For significant interactions, the margins command was used to determine predicted individual-level $\mathrm{CVHI}$ by county socioeconomic status for state health care provider levels. Interactions between health care resource policy and provider supply were not significant. All statistical analyses were performed with Stata 13 (StataCorp. 2013. Stata Statistical Software: Release 13. College Station, TX: StataCorp LP) and were run using survey procedures to account for survey design and sampling methods.

\section{RESULTS}

Socioeconomic and demographic characteristics of the study population are presented in Table 2. Counties in which study participants lived had an average population that was $49.2 \%$ male, $12.1 \%$ Non-Hispanic black, and $15.3 \%$ Hispanic. On average, $15.8 \%$ of a county's population was classified as living in poverty, $13.2 \%$ were age 65 or older, $17.3 \%$ had no health insurance, and $27.8 \%$ of adults over 25 years of age were four-year college graduates. The average county had a median household income of $\$ 52,260$. On average, a county had 74 primary care physicians per 100000 people and 26 PAs per 100000 people. The average individual was 51 years old. The study population was $52.2 \%$ female, $72.2 \%$ Non-Hispanic white, $59.5 \%$ had some college, and $31.6 \%$ had an annual household income of $\$ 75,000$ or more. The average CVHI was $3.31 \pm 0.005$, with $2.6 \% \pm 0.001$ of the population having ideal CVHI (6 or 7 ideal components) and $26.6 \% \pm 0.002$ having poor CVHI (0-2 ideal components).

The percent of the population having ideal, intermediate, and poor $\mathrm{CVHI}$ by policy category is presented in Table 3. There were significant differences in the distribution of ideal, intermediate, and poor $\mathrm{CVHI}$ as the NP autonomy index and the PA autonomous relationship 
index increased. The presence of policies increasing PA's and NP's flexibility and autonomy are associated with an increase in the prevalence of ideal CVHI and a lower prevalence of poor CVHI.

Results from the Poisson regression analysis for the association between health resource policy and individual $\mathrm{CVHI}$ are presented in Tables 4 (policy indices as continuous variables) and 5 (policy indices as indicator variables). All policy categories were associated with $\mathrm{CVHI}$ in unadjusted models with the Medicaid to Medicare reimbursement ratio, physician barrier to licensure index, and NP autonomy index remaining associated with $\mathrm{CVHI}$ after adjustment for individual and county factors (Table 4). Increasing Medicaid to Medicare reimbursement ratio was associated with lower CVHI. Increasing physician barrier to licensure index and NP autonomy index was associated with higher CVHI. When policy indices were put in the model as indicator variables (Table 5) loan repayment programs, and increased number of physician barriers to licensure and increased number components of the PA autonomous relationship index were associated with higher $\mathrm{CVHI}$. Increased number of components of the NP autonomy index was associated with lower CVHI.

Predicted $\mathrm{CVHI}$ analysis for interactions between county percent living at or below poverty line and health care resource policy variables is presented in Figure 1. Individuals living in states with the highest Medicaid to Medicare reimbursement ratio do not change CVHI when living in counties with higher poverty (Figure 1A). Interaction between county poverty and loan repayment programs was not significant (Figure 1B). Although interactions between policy indices and county poverty were significant patterns were difficult to discern. 


\section{DISCUSSION}

To our knowledge, this is the first study to assess the relationship between policies that are meant to impact provider supply and CVHI. Policies that aim to increase the autonomy of primary care providers or decrease barriers in their ability to practice were associated with higher $\mathrm{CVHI}$. These findings are consistent with literature suggesting primary care provider supply and influences of provider supply can impact health outcomes. Consistent with existing literature, policies with the potential to increase the autonomy of primary care providers or decrease barriers in their ability to practice were associated with higher $\mathrm{CVHI}{ }^{69,126}$. Although not significant, there was a trend for increasing number of components of the PA autonomous relationship index being associated with higher $\mathrm{CVHI}$. It is possible there are specific policies included in the index that are more important than others and examining components individually may be more appropriate. It is also possible there are community variables that mediate this relationship as it was no longer significant only after adjusting for community factors. Other studies have shown inconsistent associations with provider supply and loan repayment programs ${ }^{151-153}$ and we did not see an association between loan repayment programs and cardiovascular health.

A higher Medicaid to Medicare reimbursement ratio means consistently higher reimbursement payments to providers and with higher payments, studies suggest more providers would want to work in these states ${ }^{119,150}$. Inconsistent with existing literature, our finding suggests increasing Medicaid to Medicare reimbursement ratio was associated with lower $\mathrm{CVHI}$. As there are many considerations that go into a state's reimbursement ratio this variable may be a proxy for other state or community level variables like economic structure or political culture for which we did not adjust.

Even though examining $\mathrm{CVHI}$ at the individual level, there was a small but significant impact on $\mathrm{CVHI}$ by health care resource policy. However, our analyses raised more questions than they 
answered. It is unclear how policies are impacting cardiovascular health as our hypothesis that it was through provider supply does not appear to be true as adjusting did not change the association between $\mathrm{CVHI}$ and policy. Further research needs to examine potential mechanisms and what other factors might be mediating this relationship. There was also significant modification of the relationship between cardiovascular health and health resource policy by county poverty, but it is not clear what the meaning of these interactions is and further analysis is needed to determine why some policies appear to be more important in areas with higher prevalence of those living at or below the poverty line.

The self-report nature of BRFSS questions as well as questions for cholesterol, blood pressure, and diabetes that require participants to have seen a health provider may lead to an overestimation of ideal health. There is also possible bias as there was a significant percentage of participants with missing data for at least one CVHI component. As a cross-sectional study, no causal inferences can be made. The strength of this study is the large nationally representative sample that allows for data to be connected to community level information. One limitation of this study is the self-report nature which may overestimate ideal health. There is also possible bias as there was a significant percentage of participants with missing data for at least one CVHI component. Younger individuals would be more likely to have ideal CVHI, but less educated and male individuals would be more likely to have poorer CVHI. Communities excluded due to suppressed or missing FIPS code in BRFSS were rural with higher Hispanic populations and therefore this analysis may not be generalizable to those populations.

Policies with the potential to increase the autonomy of primary care providers or decrease barriers in their ability to practice were associated with higher CVHI. Further research is needed to explore the mechanism for how these policies impact cardiovascular health and their interactions with other factors. This information would allow policy makers and public health 
officials to create a policy strategies and priorities that maximize the limited resources states and communities have to improve cardiovascular health. 
Table 1. Summary of how polices included in study are defined.

\begin{tabular}{|c|c|c|c|}
\hline Policy/Policy Index & Component & Definition/Characterization & Literature Support \\
\hline $\begin{array}{l}\text { Medicaid to Medicare } \\
\text { Reimbursement Ratio } \\
\text { (continuous) }\end{array}$ & & $\begin{array}{l}\text { State's physician fees relative to Medicare fees in each state that } \\
\text { has a fee-for-service component to Medicaid }\end{array}$ & 119,150 \\
\hline $\begin{array}{l}\text { Loan Repayment } \\
\text { Programs } \\
\text { (yes/no) }\end{array}$ & & State has at least one state specific loan repayment program & $151-153$ \\
\hline $\begin{array}{l}\text { Physician Barrier to } \\
\text { Licensure Index } \\
(0-3)\end{array}$ & $\begin{array}{l}\text { Prescribing } \\
\text { Locum Tenens } \\
\text { License Fees }\end{array}$ & $\begin{array}{l}\text { No required separate controlled substance registration for physicians } \\
\text { Locum tenens licensure possible } \\
\text { Below median in physician licensing fees }\end{array}$ & 154 \\
\hline $\begin{array}{l}\text { Nurse Practitioner } \\
\text { Autonomous } \\
\text { Relationship Index } \\
(0-3)\end{array}$ & $\begin{array}{l}\text { Autonomy } \\
\text { Primary Care } \\
\text { Prescribing }\end{array}$ & $\begin{array}{l}\text { Allows independent practice } \\
\text { Considers nurse practitioners primary care providers } \\
\text { Allows independent prescribing }\end{array}$ & 69,162 \\
\hline $\begin{array}{l}\text { Physician Assistant } \\
\text { Autonomous } \\
\text { Relationship Index } \\
(0-6)\end{array}$ & $\begin{array}{l}\text { Supervision } \\
\text { Prescribing } \\
\text { Co-signature } \\
\text { Number Limit }\end{array}$ & $\begin{array}{l}\text { Use of "licensure" term in policy } \\
\text { Allows services provided to be determined between supervising } \\
\text { physician and physician assistant } \\
\text { Level of supervision decided by supervising physician } \\
\text { Prescribing scope determined by supervising physician } \\
\text { Allows co-signature requirement to be decided by supervising } \\
\text { physician } \\
\text { No limit on the number of physician assistants that can work under } \\
\text { one physician }\end{array}$ & $68,126,162,163$ \\
\hline
\end{tabular}


Table 2. Characteristics of study population, BRFSS 2011.

\begin{tabular}{|c|c|}
\hline \multicolumn{2}{|l|}{ County Provider Supply } \\
\hline \multirow{2}{*}{$\begin{array}{l}\text { Primary Care Physicians per } 100000 \text { population } \\
\text { Physician Assistants per } 100000 \text { population }\end{array}$} & $74.0 \pm 0.09$ \\
\hline & $25.9 \pm 0.06$ \\
\hline \multicolumn{2}{|l|}{ County Demographic Characteristics } \\
\hline \multirow{10}{*}{$\begin{array}{l}\text { Percent } 65 \text { Years and Older } \\
\text { Percent Male } \\
\text { Percent Non-Hispanic Black } \\
\text { Percent Hispanic } \\
\text { Percent College Graduates } \\
\text { Median Household Income }(\$) \\
\text { Percent Poverty } \\
\text { Percent Unemployment } \\
\text { Percent No Health Insurance } \\
\text { Population Density }\end{array}$} & $13.2 \pm 0.01$ \\
\hline & $49.2 \pm 0.004$ \\
\hline & $12.1 \pm 0.04$ \\
\hline & $15.3 \pm 0.06$ \\
\hline & $27.8 \pm 0.03$ \\
\hline & $52260 \pm 46$ \\
\hline & $15.8 \pm 0.02$ \\
\hline & $9.1 \pm 0.01$ \\
\hline & $17.3 \pm 0.02$ \\
\hline & \\
\hline \multirow{2}{*}{$\begin{array}{r}\text { Urban } \\
\text { Not Urban }\end{array}$} & $229,160(79.9 \%)$ \\
\hline & $112,499(20.1 \%)$ \\
\hline \multicolumn{2}{|l|}{ Individual Demographic Characteristics } \\
\hline \multirow{2}{*}{$\begin{array}{l}\text { Age (years) } \\
\text { Sex }\end{array}$} & $51.1 \pm 0.06$ \\
\hline & \\
\hline Female & $208,498(52.2 \%)$ \\
\hline Male & $133,161(47.8 \%)$ \\
\hline \multicolumn{2}{|l|}{ Race/Ethnicity } \\
\hline Non-Hispanic White & $276,605(72.5 \%)$ \\
\hline Non-Hispanic Black & $27,295(11.2 \%)$ \\
\hline Hispanic & $16,947(11.0 \%)$ \\
\hline Other & $11,899(5.3 \%)$ \\
\hline \multicolumn{2}{|l|}{ Education } \\
\hline Less than High School & $26,244(12.4 \%)$ \\
\hline High School & $98,142(28.4 \%)$ \\
\hline Some College & $216,775(59.3 \%)$ \\
\hline \multicolumn{2}{|l|}{ Income } \\
\hline Under $\$ 25,000$ & $84,455(26.9 \%)$ \\
\hline$\$ 25,000-\$ 49,999$ & $81,161(25.4 \%)$ \\
\hline$\$ 50,000-\$ 74,999$ & $49,572(16.3 \%)$ \\
\hline$\$ 75,000$ or More & $86,073(31.3 \%)$ \\
\hline \multicolumn{2}{|l|}{ Health Insurance Status } \\
\hline $\begin{array}{l}\text { Has Health Insurance } \\
\text { No Health Insurance }\end{array}$ & $\begin{array}{c}313,302(88.1 \%) \\
27,771(11.9 \%)\end{array}$ \\
\hline \multicolumn{2}{|l|}{ Cardiovascular Health } \\
\hline \multirow{4}{*}{$\begin{array}{l}\text { Mean Individual Cardiovascular Health Index } \\
\text { Percent with Poor Cardiovascular Health Index } \\
\text { Percent with Intermediate Cardiovascular Health Index } \\
\text { Percent with Ideal Cardiovascular Health Index }\end{array}$} & $3.31 \pm 0.004$ \\
\hline & $26.8 \pm 0.002$ \\
\hline & $70.7 \pm 0.002$ \\
\hline & $2.5 \pm 0.001$ \\
\hline
\end{tabular}

Percent with Ideal Cardiovascular Health Index $2.5 \pm 0.001$

BRFSS - Behavioral Risk Factor Surveillance System

Mean \pm standard deviation is presented for continuous variables and $n$ (weighted frequency) is presented for categorical variables. 
Table 3. Cardiovascular health status of study population by state health resource policy status.

\begin{tabular}{|c|c|c|c|c|}
\hline Policy/Policy Index & Ideal CVHI & $\begin{array}{l}\text { Intermediate } \\
\text { CVHI }\end{array}$ & Poor CVHI & \\
\hline $\begin{array}{l}\text { Medicaid to Medicare } \\
\text { Reimbursement Ratio }\end{array}$ & $0.60 \pm 0.003$ & $0.61 \pm 0.001$ & $0.62 \pm 0.001$ & \\
\hline \multicolumn{5}{|l|}{ Loan Repayment Programs } \\
\hline Yes & $6,839(2.5)$ & $244,991(70.9)$ & $105,736(26.6)$ & \\
\hline No & $3,012(2.5)$ & $96,671(70.4)$ & $40,717(27.1)$ & \\
\hline \multicolumn{5}{|l|}{$\begin{array}{l}\text { Physician Barrier to Licensure } \\
\text { Index }\end{array}$} \\
\hline $\begin{array}{ll}2 & 0\end{array}$ & $2,517(0.8)$ & 83,566 (72.9) & $35,281(26.3)$ & \\
\hline 1 & $3,562(0.8)$ & $111,146(71.6)$ & $46,473(27.7)$ & \\
\hline 2 & $3,217(0.7)$ & $128,089(72.3)$ & $56,505(27.0)$ & \\
\hline 3 & $555(0.7)$ & $18,861(72.2)$ & $8,194(27.1)$ & \\
\hline \multicolumn{4}{|l|}{$\begin{array}{l}\text { Nurse Practitioner Autonomy } \\
\text { Index }\end{array}$} & * \\
\hline (1) & $7,596(1.2)$ & $12,834(65.3)$ & 207 (33.5) & \\
\hline 1 & $53,002(2.5)$ & $113,068(70.5)$ & $2,833(27.0)$ & \\
\hline 2 & $35,159(2.4)$ & $78,855(70.0)$ & $2,255(27.6)$ & \\
\hline 3 & $50,696(3.0)$ & $136,905(72.4)$ & $4,556(24.6)$ & \\
\hline \multicolumn{4}{|l|}{$\begin{array}{l}\text { Physician Assistant Autonomous } \\
\text { Relationship Index }\end{array}$} & * \\
\hline 0 & 0 & 0 & 0 & \\
\hline 1 & $108(1.0)$ & $8,054(65.3)$ & $4,809(33.7)$ & \\
\hline 2 & $437(1.4)$ & $26,637(66.5)$ & $15,048(32.1)$ & \\
\hline 3 & $1,257(2.1)$ & $49,687(69.4)$ & $24,313(28.5)$ & \\
\hline 4 & $2,342(2.7)$ & $82,411(72.0)$ & $33,358(25.3)$ & \\
\hline 5 & 4,472 (2.8) & $140,511(71.2)$ & $56,430(25.9)$ & \\
\hline 6 & 1,235 (3.2) & $34,362(74.5)$ & $12,495(22.2)$ & \\
\hline
\end{tabular}

* Indicates $p$ value $<0.05$ for the comparison of policy categories across CVHI classification (Chi Square) 
Table 4. Poisson regression analysis for the relationship between health resource policy and cardiovascular health.

\begin{tabular}{|c|c|c|c|c|}
\hline \multirow[b]{2}{*}{ Policy } & \multicolumn{4}{|c|}{ Mean Ratio (95\% Confidence Interval) } \\
\hline & Model $1^{\dagger}$ & Model $2^{\ddagger}$ & Model $3 \S$ & Model 4" \\
\hline Medicaid to Medicare Reimbursement Ratio & $0.93(0.91,0.94)^{*}$ & $0.93(0.92,0.95)^{\star}$ & $0.97(0.95,0.99)^{*}$ & $0.97(0.95,0.99)^{*}$ \\
\hline Loan Repayment Programs & $1.01(1.00,1.01)^{*}$ & $1.00(1.00,1.01)$ & $1.00(1.00,1.01)$ & $1.00(1.00,1.01)$ \\
\hline Physician Barrier to Licensure Index & $1.00(1.00,1.01)^{*}$ & $1.01(1.01,1.01)^{*}$ & $1.01(1.01,1.01)^{*}$ & $1.01(1.01,1.01)^{*}$ \\
\hline Nurse Practitioner Autonomy Index & $1.01(1.01,1.01)^{*}$ & $1.01(1.00,1.01)^{*}$ & $1.01(1.00,1.01)^{*}$ & $1.01(1.00,1.01)^{*}$ \\
\hline $\begin{array}{l}\text { Physician Assistant Autonomous Relationship } \\
\text { Index }\end{array}$ & $1.02(1.02,1.02)^{*}$ & $1.01(1.01,1.01)^{*}$ & $1.00(1.00,1.00)$ & $1.00(1.00,1.00)$ \\
\hline
\end{tabular}

Index

* Indicates $p$ value $<0.05$

† Model 1 is the unadjusted analysis

¥ Model 2 is adjusted for individual characteristics including age, sex, race/ethnicity, education level, income level, and health insurance status

$\S$ Model 3 is further adjusted for county characteristics including $\% 65$ years and older, $\%$ male, $\%$ non-Hispanic black, \% Hispanic,

$\%$ college graduates, median household income, \% poverty, \% unemployment, \% no health insurance, and population density

II Model 4 is further adjusted for county primary care physician supply and county physician assistant supply 
Table 5. Poisson regression analysis for the relationship between health resource policy and cardiovascular health with policy indices as indicator variables.

\begin{tabular}{|c|c|c|c|c|c|}
\hline \multirow[b]{2}{*}{ Policy } & & \multicolumn{4}{|c|}{ Mean Ratio (95\% Confidence Interval) } \\
\hline & & Model $1^{\dagger}$ & Model $2^{\ddagger}$ & Model $3 \S$ & Model 4" \\
\hline $\begin{array}{l}\text { Medicaid to Medicare Reimbursement } \\
\text { Ratio }\end{array}$ & & $0.93(0.92,0.95)^{*}$ & $0.94(0.93,0.96)^{*}$ & $0.99(0.97,1.01)$ & $0.99(0.97,1.01)$ \\
\hline Loan Repayment Programs & & $1.01(1.01,1.02)^{*}$ & $1.01(1.00,1.01)^{*}$ & $1.01(1.00,1.01)^{*}$ & $1.01(1.00,1.01)^{*}$ \\
\hline Physician Barrier to Licensure Index & $\begin{array}{l}0 \\
1 \\
2 \\
3\end{array}$ & $\begin{array}{c}1 \text { (referent) } \\
1.02(1.01,1.03)^{*} \\
1.01(1.00,1.01) \\
1.01(1.00,1.03)\end{array}$ & $\begin{array}{c}1 \text { (referent) } \\
1.03(1.02,1.03)^{*} \\
1.02(1.01,1.03)^{*} \\
1.03(1.01,1.04)^{*}\end{array}$ & $\begin{array}{c}1 \text { (referent) } \\
1.03(1.02,1.03)^{*} \\
1.02(1.01,1.03)^{*} \\
1.03(1.02,1.05)^{*}\end{array}$ & $\begin{array}{c}1 \text { (referent) } \\
1.03(1.02,1.03)^{*} \\
1.02(1.01,1.03)^{*} \\
1.03(1.02,1.05)^{*}\end{array}$ \\
\hline Nurse Practitioner Autonomy Index & $\begin{array}{l}0 \\
1 \\
2 \\
3\end{array}$ & $\begin{array}{c}1 \text { (referent) } \\
1.00(0.98,1.01) \\
0.98(0.97,0.99)^{*} \\
1.02(1.00,1.03)^{*}\end{array}$ & $\begin{array}{c}1 \text { (referent) } \\
0.98(0.96,0.99)^{*} \\
0.97(0.96,0.98)^{*} \\
1.00(0.98,1.01)\end{array}$ & $\begin{array}{c}1 \text { (referent) } \\
0.98(0.97,1.00)^{*} \\
0.98(0.96,0.99)^{*} \\
1.00(0.98,1.01)\end{array}$ & $\begin{array}{c}1 \text { (referent) } \\
0.98(0.96,1.00)^{*} \\
0.98(0.96,0.99)^{*} \\
1.00(0.98,1.01)\end{array}$ \\
\hline $\begin{array}{l}\text { Physician Assistant Autonomous } \\
\text { Relationship Index }\end{array}$ & $\begin{array}{l}1 \\
2 \\
3 \\
4 \\
5 \\
6\end{array}$ & $\begin{array}{c}1 \text { (referent) } \\
1.03(1.02,1.05)^{*} \\
1.07(1.05,1.08)^{*} \\
1.11(1.09,1.13)^{*} \\
1.10(1.08,1.11)^{*} \\
1.14(1.13,1.16)^{*}\end{array}$ & $\begin{array}{c}1 \text { (referent) } \\
1.03(1.02,1.05)^{*} \\
1.06(1.05,1.08)^{*} \\
1.08(1.07,1.10)^{*} \\
1.08(1.06,1.09)^{*} \\
1.11(1.09,1.13)^{*}\end{array}$ & $\begin{array}{c}1 \text { (referent) } \\
1.03(1.01,1.04)^{*} \\
1.05(1.03,1.06)^{*} \\
1.04(1.03,1.06)^{*} \\
1.04(1.03,1.06)^{*} \\
1.05(1.03,1.07)^{*}\end{array}$ & $\begin{array}{c}1 \text { (referent) } \\
1.03(1.01,1.04)^{*} \\
1.05(1.03,1.06)^{*} \\
1.04(1.03,1.06)^{*} \\
1.04(1.03,1.06)^{*} \\
1.05(1.03,1.07)^{*}\end{array}$ \\
\hline
\end{tabular}

* Indicates $p$ value $<0.05$

$\uparrow$ Model 1 is the unadjusted analysis

$\ddagger$ Model 2 is adjusted for individual characteristics including age, sex, race/ethnicity, education level, income level, and health insurance status

$\S$ Model 3 is further adjusted for county characteristics including \% 65 years and older, \% male, \% non-Hispanic black, \% Hispanic,

$\%$ college graduates, median household income, \% poverty, \% unemployment, \% no health insurance, and population density

II Model 4 is further adjusted for county primary care physician supply and county physician assistant supply 

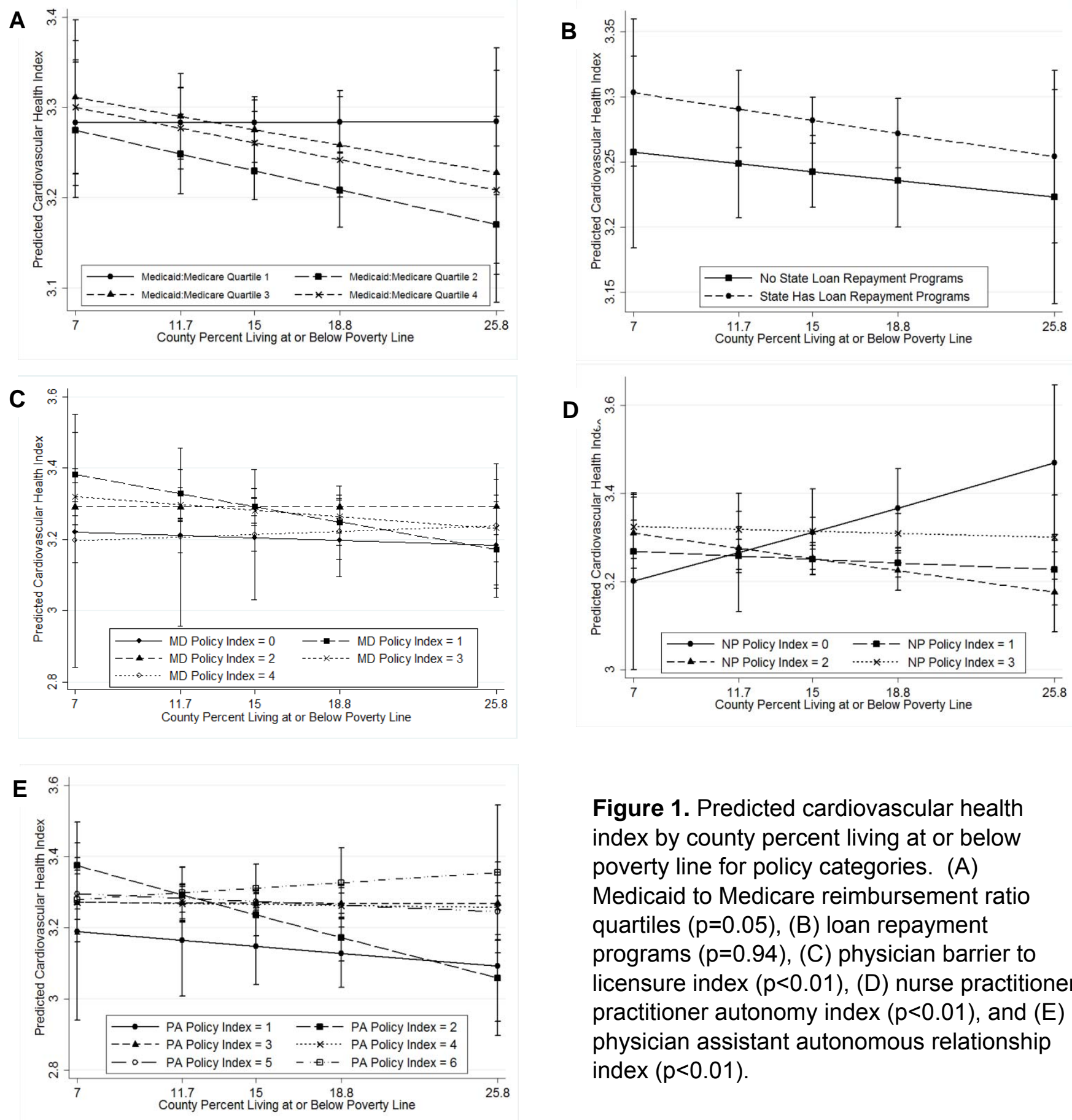

Figure 1. Predicted cardiovascular health index by county percent living at or below poverty line for policy categories. (A) Medicaid to Medicare reimbursement ratio quartiles $(p=0.05)$, (B) loan repayment programs $(p=0.94),(C)$ physician barrier to licensure index $(p<0.01)$, (D) nurse practitioner practitioner autonomy index $(p<0.01)$, and $(E)$ physician assistant autonomous relationship index $(p<0.01)$. 


\section{Chapter 7}

\section{Discussion}

\subsection{Summary of Key Findings}

This project examined individual, community, organizational, and policy factors associated with cardiovascular health using nationally representative data from the Behavioral Risk Factor Surveillance Survey (BRFSS) and the Area Health Resource File (AHRF). We confirmed our central hypothesis that higher cardiovascular health was associated with primary care provider supply and those polices with potential to influence provider supply.

In the first study, county population attainment of Healthy People 2010 objectives of cardiovascular health components (blood pressure, cholesterol, blood glucose, BMI, smoking behavior, diet, and exercise) was very low. Smoking behavior had the highest level of attainment at $25 \%$. CVHI was poorest in the Southeast and Appalachian regions. The impact of higher county prevalence of college education on CVHI was substantially greater than all other sociodemographic factors examined.

In the second study, we found both individual characteristics and county demographics were associated with CVHI. Educational attainment, whether at the individual level or county level, again had a comparatively large influence on $\mathrm{CVHI}$ when compared with other factors. While individual factors had the greatest impact on individual $\mathrm{CVHI}$, community characteristics were able to modify the relationship between individual characteristics and CVHI. The poorest individuals benefited from living in higher income areas while higher income individuals benefited when in lower income areas. Higher density of an individual's race/ethnicity in their community was associated with higher $\mathrm{CVHI}$.

In the third study, $\mathrm{CVHI}$ decreased from $3.73 \pm 0.01$ in 2003 to $3.45 \pm 0.01$ in 2011 . The majority of states experienced decreases in mean $\mathrm{CVHI}$ and an increase in the prevalence of poor CVHI in their population between 2003 and 2009. Among CVHI components, the highest 
prevalence of ideal was seen for blood glucose followed by smoking, whereas the lowest was seen for physical activity and diet. Women, those with higher levels of education, and those identifying as other race/ethnicity had the highest levels of CVHI. Forty-seven states were at high risk of continuing their decreasing trend in CVHI. In particular, Ohio, Arizona, Oklahoma, and Hawaii had the largest declines in $\mathrm{CVHI}$. Much of the decreasing trend in $\mathrm{CVHI}$ between 2003 and 2009 is likely due to decreases in ideal blood pressure, cholesterol, and BMI. Changes between 2009 and 2011 were larger than changes seen in the previous six year period for overall $\mathrm{CVHI}$ and most of its components highlighting the effects of the methodologic and sampling changes in BRFSS in 2011.

In the fourth study, primary care physician and physician assistant supply were positively associated with $\mathrm{CVHI}$ in both community and individual-level analysis. Higher numbers of cardiovascular disease specialists was negatively associated with $\mathrm{CVHI}$. While primary care provider supply was significantly associated with individual-level CVHI, individual factors such as sex, income, and education level had the greatest influence on individual-level CVHI. Those individuals deriving the largest marginal benefit from increased primary care provider supply were middle aged, non-Hispanic other race/ethnicity, female, lived in a non-urban community, had a household income less than $\$ 25,000$ per year, and lived in a community with low insurance coverage.

In the fifth study, policies with the potential to increase the autonomy of primary care physicians and nurse practitioners or decrease barriers in their ability to practice were associated with higher CVHI even after controlling for provider supply. Increasing Medicaid to Medicare reimbursement ratio was associated with lower $\mathrm{CVHI}$. Although not significant the trend for increasing number of components of the PA autonomous relationship index was towards higher $\mathrm{CVHI}$. There was significant modification of the relationship between $\mathrm{CVHI}$ and health resource policy by county poverty, but patterns were difficult to understand. 


\subsection{Significance and Implications}

The contribution of this research is a more thorough understanding of the influences of and interactions between multiple levels of factors associated with cardiovascular health. Motivated by the conceptual framework of the social ecological model, we moved outside the focus of most studies, which has been on factors proximal to the individual. This project adds to the understanding of the determinants of individual cardiovascular health by examining factors at the organizational, community, and policy levels. The centrality of college education whether at the individual or community level was consistently identified as an important influence on cardiovascular health. At the organizational level, primary care provider supply was associated with cardiovascular health even when hospitals and clinics were not. We also identified state policies that can impact individual cardiovascular health. While important in their identification as determinants of cardiovascular health, we also explored the interactions between factors at different levels providing a more complete picture of the complexity and importance of the context in which individuals live. These interactions suggest feedback loops that, similar to the cycle of poverty, create differential advantage to certain populations and potentially increase disparities over time.

These contributions are significant because they allow policymakers and public health officials to make more informed decisions about the environments and types of policies that when in place may improve cardiovascular health. Once such environments are established it is hoped the projected public health and economic burden of cardiovascular disease in the U.S. will be reduced. At the population level, an increase in cardiovascular health of one percent moves approximately three million individuals from poor cardiovascular health to intermediate cardiovascular health. Higher cardiovascular health has been associated with decreased 


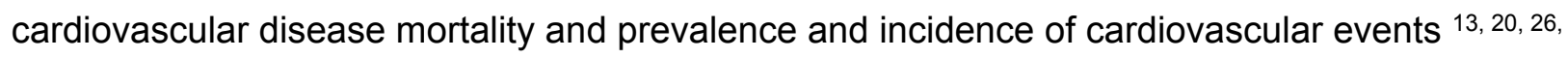
36,38 .

\subsection{Strengths and Limitations}

The strength of this study is the large nationally representative sample available for multiple years by using BRFSS data. BRFSS also allowed for data to be examined at the state and county level. The use of BRFSS has several limitations including issues with sampling methods and question design. Previous to 2011 only landlines were called and those with cell phones only would not be able to be sampled and may bias results in those years. BRFSS data is also self-report and known to consistently overestimate ideal cardiovascular health ${ }^{25,35}$. Li et al, compared three major health surveys, NHANES, NHIS and BRFSS, finding the prevalence rates for chronic diseases in BRFSS to be comparable to that of NHANES and NHIS ${ }^{115}$. Pierannunzi et al also found validity and reliability of BRFSS to be comparable to other surveys with differences mainly in physical measure questions due to the self-reported nature of the survey ${ }^{100}$.

The amount of missing data or suppressed data in BRFSS, particularly with county FIPs codes is another limitation. However, BRFSS is the best available national database allowing the connection of an individual to their state and county of residence. There is also potential bias as a significant percentage of participants had missing data for at least one CVHI component. Younger individuals would be more likely to have ideal CVHI, but less educated and male individuals would be more likely to have poorer CVHI.

Ideally each component of the cardiovascular health index would have three levels and not two, but due to the way questions in BRFSS have been structured only a bivariate response is possible for some components (blood pressure, cholesterol, and blood sugar). Also, diet questions in BRFSS only cover fruit and vegetable consumption and no other diet components. 
There is also a concern about time lag in any discussion of policy and we were unable to control for length of time since a policy had been enacted and implemented. In all analyses, except time trend, data are cross sectional and therefore conclusions about causality cannot be made.

\subsection{Future Research}

Despite advances in treatment and decreases in risk factors, cardiovascular disease remains the cause of 1 in 3 deaths in the U.S. ${ }^{2,5}$ and less than $5 \%$ of U.S adults have ideal cardiovascular health ${ }^{50}$. It is expected the prevalence of cardiovascular disease will increase by $10 \%$, direct medical costs will triple by 2030 , and cardiovascular health will only improve $6 \%$ by 2020 , far less than the goal of $20 \%$ improvement ${ }^{8,37}$.

Findings from this project suggest the need to better understand the mechanisms of health resource policy's impact on cardiovascular health in order to create a policy strategy that can maximize the limited resources states and communities have to improve cardiovascular health. Results from the fifth study and preliminary mediation analysis suggest a more complex structure of how provider supply and other community factors mediate the relationship between policy and cardiovascular health than we hypothesized. Future studies should build off this work and use more sophisticated/advanced analyses, like structural equation modeling, to better understand these relationships. Another component necessary for the determination of the most efficient policy strategies is cost. In prioritization of policies and programs that should be implemented it would be imperative to consider the improvements in cardiovascular health likely in relation to the costs of implementing those policies and programs.

A core component in each study in this project was the examination of interactions between the various levels of factors and how they can moderate the impacts of other factors on cardiovascular health. Future effort should examine the suggestion that these interactions create feedback loops that may potentially increase disparities over time. The effect of health care resource supply and policies may not only be overall influences on cardiovascular health 
but may also change the interactions between other factors. Providers and policies may have the potential to close gaps in cardiovascular health present due to cycles of disadvantage. Both study one which examined a county-level outcome and study three which compared results from both individual-level and county-level analyses attempted to understand the similarities and differences between determinants of population and individual health. While our findings suggested for cardiovascular health, education and primary care provider supply were important at both levels this may not always be true. There is a vast literature discussing not only the importance of population level solutions, but stressing the additional factors such as culture and institutional structure that make population level outcomes more than just the sum or average of individual outcomes ${ }^{164,165}$. Future efforts should continue to consider that these models may not always have similar determinants and/or interactions between factors. Aspects of this project have also identified challenges for future research due to the ecologic nature of natural policy experiments that require the use of national cross-sectional data. Changing survey methodologies and inconsistent question availability are continuing challenges, highlighted in the results from the third study. This project provides baseline cardiovascular health information by state that future research should utilize to monitor trends and effects of policy changes over time. Another concern is the decreasing availability of geographical information in national data sets. Although BRFSS data from 2013 would have been the most recent available and provided a second time point in which to begin to examine trends since the 2011 BRFSS methodologic changes, the database from 2013 has suppressed county identifying codes. This project highlights the multilevel nature of determinants of health and their interactions and future projects that look to include this information will be unable to connect community factors to individual data without these codes. 


\section{REFERENCES}

1. Bronfenbrenner U. Ecological systems theory. Jessica Kingsley Publishers; 1992.

2. Mozaffarian D, Benjamin EJ, Go AS, Arnett DK, Blaha MJ, Cushman M, de Ferranti S, Després J-P, Fullerton HJ, Howard VJ. Executive summary: Heart disease and stroke statistics-2015 update a report from the american heart association. Circulation. 2015;131:434-441

3. Ford ES, Capewell S. Proportion of the decline in cardiovascular mortality disease due to prevention versus treatment: Public health versus clinical care. Annual review of public health. 2011;32:5-22

4. Jones DS, Greene JA. The contributions of prevention and treatment to the decline in cardiovascular mortality: Lessons from a forty-year debate. Health Affairs. 2012;31:2250-2258

5. Ford ES, Ajani UA, Croft JB, Critchley JA, Labarthe DR, Kottke TE, Giles WH, Capewell S. Explaining the decrease in us deaths from coronary disease, 1980-2000. New England Journal of Medicine. 2007;356:2388-2398

6. Ford ES, Capewell S. Coronary heart disease mortality among young adults in the us from 1980 through 2002: Concealed leveling of mortality rates. Journal of the American College of Cardiology. 2007;50:2128-2132

7. Roth GA, Forouzanfar MH, Moran AE, Barber R, Nguyen G, Feigin VL, Naghavi M, Mensah GA, Murray CJ. Demographic and epidemiologic drivers of global cardiovascular mortality. New England Journal of Medicine. 2015;372:1333-1341

8. Heidenreich PA, Trogdon JG, Khavjou OA, Butler J, Dracup K, Ezekowitz MD, Finkelstein EA, Hong $\mathrm{Y}$, Johnston SC, Khera A. Forecasting the future of cardiovascular disease in the united states a policy statement from the american heart association. Circulation. 2011;123:933-944

9. Lloyd-Jones DM, Leip EP, Larson MG, D'Agostino RB, Beiser A, Wilson PW, Wolf PA, Levy D. Prediction of lifetime risk for cardiovascular disease by risk factor burden at 50 years of age. Circulation. 2006;113:791-798

10. Wilkins JT, Ning H, Berry J, Zhao L, Dyer AR, Lloyd-Jones DM. Lifetime risk and years lived free of total cardiovascular disease. JAMA : the journal of the American Medical Association. 2012;308:1795-1801

11. U.S. Department of Health and Human Services. Healthy people 2020 heart disease and stroke objectives. 2013

12. Lloyd-Jones DM, Hong Y, Labarthe D, Mozaffarian D, Appel LJ, Van Horn L, Greenlund K, Daniels $S$, Nichol G, Tomaselli GF. Defining and setting national goals for cardiovascular health promotion and disease reduction the american heart association's strategic impact goal through 2020 and beyond. Circulation. 2010;121:586-613

13. Wu S, Huang Z, Yang X, Zhou Y, Wang A, Chen L, Zhao H, Ruan C, Wu Y, Xin A. Prevalence of ideal cardiovascular health and its relationship with the 4-year cardiovascular events in a northern chinese industrial city. Circulation: Cardiovascular Quality and Outcomes. 2012;5:487-493

14. Zeng Q, Dong S-Y, Song Z-Y, Zheng Y-S, Wu H-Y, Mao L-N. Ideal cardiovascular health in chinese urban population. International Journal of Cardiology. 2012;167:2311-2317

15. Wu H-Y, Sun Z-H, Cao D-P, Wu L-X, Zeng Q. Cardiovascular health status in chinese adults in urban areas: Analysis of the chinese health examination database 2010. International journal of cardiology. 2012;168:760-764

16. Bi Y, Jiang Y, He J, Xu Y, Wang L, Xu M, Zhang M, Li Y, Wang T, Dai M. Status of cardiovascular health in chinese adults. Journal of the American College of Cardiology. 2015;65:1013-1025

17. Lee H-J, Suh B, Yoo T-G, Lee H, Shin DW. Trends in cardiovascular health metrics among korean adults. Korean Journal of Family Medicine. 2013;34:403-412 
18. Del Brutto OH, Mera RM, Montalván M, Del Brutto VJ, Zambrano M, Santamaría M, Tettamanti D. Cardiovascular health status and metabolic syndrome in ecuadorian natives/mestizos aged 40 years or more with and without stroke and ischemic heart disease-an atahualpa project casecontrol nested study. Journal of Stroke and Cerebrovascular Diseases. 2013;23:643-648

19. Oikonen M, Laitinen TT, Magnussen CG, Steinberger J, Sinaiko AR, Dwyer T, Venn A, Smith KJ, Hutri-Kähönen N, Pahkala K. Ideal cardiovascular health in young adult populations from the united states, finland, and australia and its association with cimt: The international childhood cardiovascular cohort consortium. Journal of the American Heart Association. 2013;2:e00244

20. Wilsgaard T, Loehr LR, Mathiesen EB, Løchen M-L, Bønaa KH, Njølstad I, Heiss G. Cardiovascular health and the modifiable burden of incident myocardial infarction: The troms $\varnothing$ study. $B M C$ public health. 2015;15:221

21. O'Flynn AM, McHugh SM, Madden JM, Harrington JM, Perry IJ, Kearney PM. Applying the ideal cardiovascular health metrics to couples: A cross-sectional study in primary care. Clinical cardiology. 2015

22. Gupta B, Gupta R, Sharma KK, Gupta A, Mahanta TG, Deedwania PC. Low prevalence of ahadefined ideal cardiovascular health factors among urban men and women in india. Global Heart. 2015

23. Graciani A, León-Muñoz LM, Guallar-Castillón P, Rodríguez-Artalejo F, Banegas JR. Cardiovascular health in a southern mediterranean european country a nationwide populationbased study. Circulation: Cardiovascular Quality and Outcomes. 2013;6:90-98

24. Janković S, Stojisavljević D, Janković J, Erić M, Marinković J. Association of socioeconomic status measured by education, and cardiovascular health: A population-based cross-sectional study. BMJ open. 2014;4:e005222

25. Shay CM, Ning H, Allen NB, Carnethon MR, Chiuve SE, Greenlund KJ, Daviglus ML, Lloyd-Jones DM. Status of cardiovascular health in us adults clinical perspective. Circulation. 2012;125:45-56

26. Folsom AR, Yatsuya H, Nettleton JA, Lutsey PL, Cushman M, Rosamond WD. Community prevalence of ideal cardiovascular health, by the american heart association definition, and relationship with cardiovascular disease incidence. Journal of the American College of Cardiology. 2011;57:1690-1696

27. Ford ES. Ideal cardiovascular health start young, finish strong. Circulation. 2012;125:1955-1957

28. Shay CM, Ning H, Daniels SR, Rooks CR, Gidding SS, Lloyd-Jones DM. Status of cardiovascular health in us adolescents clinical perspective prevalence estimates from the national health and nutrition examination surveys (nhanes) 2005-2010. Circulation. 2013;127:1369-1376

29. Ning H, Labarthe DR, Shay CM, Daniels SR, Hou L, Van Horn L, Lloyd-Jones DM. Status of cardiovascular health in us children up to 11 years of age the national health and nutrition examination surveys 2003-2010. Circulation: Cardiovascular Quality and Outcomes. 2015;8:164171

30. Fretts AM, Howard BV, McKnight B, Duncan GE, Beresford SA, Mete M, Zhang Y, Siscovick DS. Life's simple 7 and incidence of diabetes among american indians: The strong heart family study. Diabetes care. 2014;37:2240-2245

31. Short VL. Racial differences in ideal cardiovascular health metrics among mississippi adults, 2009 mississippi behavioral risk factor surveillance system. Preventing chronic disease. 2013;10

32. Djoussé L, Petrone AB, Blackshear C, Griswold M, Harman JL, Clark CR, Talegawkar S, Hickson DA, Gaziano JM, Dubbert PM. Prevalence and changes over time of ideal cardiovascular health metrics among african-americans: The jackson heart study. Preventive medicine. 2015;74:111116 
33. Kim JI, Sillah A, Boucher JL, Sidebottom AC, Knickelbine T. Prevalence of the american heart association's "ideal cardiovascular health" metrics in a rural, cross-sectional, community-based study: The heart of new ulm project. Journal of the American Heart Association. 2013;2:e000058

34. Bostean G, Roberts CK, Crespi CM, Prelip M, Peters A, Belin TR, McCarthy WJ. Cardiovascular health: Associations with race-ethnicity, nativity, and education in a diverse, population-based sample of californians. Annals of epidemiology. 2013;23:388-394

35. Fang J, Yang $Q$, Hong $Y$, Loustalot $F$. Status of cardiovascular health among adult americans in the 50 states and the district of columbia, 2009. Journal of the American Heart Association. 2012;1:e005371

36. Ford ES, Greenlund KJ, Hong Y. Ideal cardiovascular health and mortality from all causes and diseases of the circulatory system among adults in the united states. Circulation. 2012;125:987995

37. Huffman MD, Capewell S, Ning H, Shay CM, Ford ES, Lloyd-Jones DM. Cardiovascular health behavior and health factor changes (1988-2008) and projections to 2020: Results from the national health and nutrition examination surveys (nhanes). Circulation. 2012;125:2595-2602

38. Dong C, Rundek T, Wright CB, Anwar Z, Elkind MS, Sacco RL. Ideal cardiovascular health predicts lower risks of myocardial infarction, stroke, and vascular death across whites, blacks, and hispanicsclinical perspective the northern manhattan study. Circulation. 2012;125:2975-2984

39. Alman AC, Maahs DM, Rewers MJ, Snell-Bergeon JK. Ideal cardiovascular health and the prevalence and progression of coronary artery calcification in adults with and without type 1 diabetes. Diabetes care. 2013:DC_130997

40. Ogagarue ER, Lutsey PL, Klein R, Klein BE, Folsom AR. Association of ideal cardiovascular health metrics and retinal microvascular findings: The atherosclerosis risk in communities study. Journal of the American Heart Association. 2013;2:e000430

41. Pahkala K, Hietalampi H, Laitinen TT, Viikari JS, Rönnemaa T, Niinikoski H, Lagström H, Talvia S, Jula A, Heinonen OJ. Ideal cardiovascular health in adolescence effect of lifestyle intervention and association with vascular intima-media thickness and elasticity (the special turku coronary risk factor intervention project for children [strip] study). Circulation. 2013;127:2088-2096

42. Zhang Q, Zhang S, Wang C, Gao X, Zhou Y, Zhou H, Wang A, Wu J, Bian L, Wu S. Ideal cardiovascular health metrics on the prevalence of asymptomatic intracranial artery stenosis: $A$ cross-sectional study. PloS one. 2013;8:e58923

43. Laitinen TT, Pahkala K, Magnussen CG, Viikari JS, Oikonen M, Taittonen L, Mikkilä V, Jokinen E, Hutri-Kähönen N, Laitinen T. Ideal cardiovascular health in childhood and cardiometabolic outcomes in adulthoodclinical perspective the cardiovascular risk in young finns study. Circulation. 2012;125:1971-1978

44. Laitinen TT, Pahkala K, Magnussen CG, Oikonen M, Viikari JS, Sabin MA, Daniels SR, Heinonen OJ, Taittonen L, Hartiala O. Lifetime measures of ideal cardiovascular health and their association with subclinical atherosclerosis: The cardiovascular risk in young finns study. International journal of cardiology. 2015;185:186-191

45. Daviglus ML, Liu K, Pirzada A, Yan LL, Garside DB, Feinglass J, Guralnik JM, Greenland P, Stamler J. Favorable cardiovascular risk profile in middle age and health-related quality of life in older age. Archives of internal medicine. 2003;163:2460-2468

46. Daviglus ML, Liu K, Pirzada A, Yan LL, Garside DB, Greenland P, Manheim LM, Dyer AR, Wang R, Lubitz J. Cardiovascular risk profile earlier in life and medicare costs in the last year of life. Archives of internal medicine. 2005;165:1028-1034

47. España-Romero V, Artero EG, Lee D-c, Sui X, Baruth M, Ruiz JR, Pate RR, Blair SN. A prospective study of ideal cardiovascular health and depressive symptoms. Psychosomatics. 2013;54:525535 
48. Reis JP, Loria CM, Launer LJ, Sidney S, Liu K, Jacobs DR, Zhu N, Lloyd-Jones DM, He K, Yaffe K. Cardiovascular health through young adulthood and cognitive functioning in midlife. Annals of neurology. 2013;73:170-179

49. Rasmussen-Torvik LJ, Shay CM, Abramson JG, Friedrich CA, Nettleton JA, Prizment AE, Folsom AR. Ideal cardiovascular health is inversely associated with incident cancerclinical perspective the atherosclerosis risk in communities study. Circulation. 2013;127:1270-1275

50. Go AS, Mozaffarian D, Roger VL, Benjamin EJ, Berry JD, Blaha MJ, Dai S, Ford ES, Fox CS, Franco S. Heart disease and stroke statistics--2014 update: A report from the american heart association. Circulation. 2014;129:e28

51. Winkleby MA, Jatulis DE, Frank E, Fortmann SP. Socioeconomic status and health: How education, income, and occupation contribute to risk factors for cardiovascular disease. American journal of public health. 1992;82:816-820

52. Braveman PA, Cubbin C, Egerter S, Williams DR, Pamuk E. Socioeconomic disparities in health in the united states: What the patterns tell us. American Journal of Public Health. 2010;100:S186S196

53. Unger E, Diez-Roux AV, Lloyd-Jones DM, Mujahid MS, Nettleton JA, Bertoni A, Badon SE, Ning H, Allen NB. Association of neighborhood characteristics with cardiovascular health in the multiethnic study of atherosclerosis. Circulation: Cardiovascular Quality and Outcomes. 2014;7:524531

54. Link BG, Phelan J. Social conditions as fundamental causes of disease. Journal of health and social behavior. 1995:80-94

55. Chaix B. Geographic life environments and coronary heart disease: A literature review, theoretical contributions, methodological updates, and a research agenda. Annual review of public health. 2009;30:81-105

56. Centers for Disease Control and Prevention. Behavioral risk factor surveillance system annual survey data. 2014

57. United States Department of Health and Human Services Health Resources and Services Administration. Area health resource files. 2014

58. Brownson RC, Bright FS. Chronic disease control in public health practice: Looking back and moving forward. Public health reports. 2004;119:230

59. Brownson RC, Haire-Joshu D, Luke DA. Shaping the context of health: A review of environmental and policy approaches in the prevention of chronic diseases. Annu.Rev.Public Health. 2006;27:341-370

60. Starfield B, Shi L, Macinko J. Contribution of primary care to health systems and health. Milbank quarterly. 2005;83:457-502

61. Starfield B, Shi L, Grover A, Macinko J. The effects of specialist supply on populations' health: Assessing the evidence. Cancer. 2005;103:23.18

62. Jasek JP. Having a primary care provider and receipt of recommended preventive care among men in new york city. American journal of men's health. 2011;5:225-235

63. Bindman AB, Grumbach K, Osmond D, Vranizan K, Stewart AL. Primary care and receipt of preventive services. Journal of general internal medicine. 1996;11:269-276

64. Blewett LA, Johnson PJ, Lee B, Scal PB. When a usual source of care and usual provider matter: Adult prevention and screening services. Journal of general internal medicine. 2008;23:13541360

65. Baker Jr EL, Potter MA, Jones DL, Mercer SL, Cioffi JP, Green LW, Halverson PK, Lichtveld MY, Fleming DW. The public health infrastructure and our nation's health 1. Annu. Rev. Public Health. 2005;26:303-318 
66. Halm EA, Lee C, Chassin MR. Is volume related to outcome in health care? A systematic review and methodologic critique of the literature. Annals of internal medicine. 2002;137:511-520

67. Cooper RA. States with more physicians have better-quality health care. Health Affairs. 2009;28:w91-w102

68. Moote M, Krsek C, Kleinpell R, Todd B. Physician assistant and nurse practitioner utilization in academic medical centers. American Journal of Medical Quality. 2011;26:452-460

69. Bauer JC. Nurse practitioners as an underutilized resource for health reform: Evidence-based demonstrations of cost-effectiveness. Journal of the American Academy of Nurse Practitioners. 2010;22:228-231

70. Taylor J. The fundamentals of community health centers. 2004

71. U.S. Department of Commerce Economics and Statistics Administration U.S. Census Bureau. American community survey 5 year 2006 - 2010. 2014

72. Shi L, Lebrun LA, Hung L-M, Zhu J, Tsai J. Us primary care delivery after the health center growth initiative: Comparison of health centers, hospital outpatient departments, and physicians' offices. The Journal of ambulatory care management. 2012;35:60-74

73. Laiteerapong N, Kirby J, Gao Y, Yu TC, Sharma R, Nocon R, Lee SM, Chin MH, Nathan AG, NgoMetzger $Q$. Health care utilization and receipt of preventive care for patients seen at federally funded health centers compared to other sites of primary care. Health services research. 2014;49:1498-1518

74. Control CfD, Prevention. Ten great public health achievements--united states, 2001-2010. MMWR. Morbidity and mortality weekly report. 2011;60:619

75. CDC. Ten great public health achievements-united states, 1900-1999. MMWR Morb Mortal Wkly Rep. 1999;48

76. Frieden TR. A framework for public health action: The health impact pyramid. Journal Information. 2010;100

77. Daar AS, Singer PA, Persad DL, Pramming SK, Matthews DR, Beaglehole R, Bernstein A, Borysiewicz LK, Colagiuri S, Ganguly N. Grand challenges in chronic non-communicable diseases. Nature. 2007;450:494-496

78. Go AS, Mozaffarian D, Roger VL, Benjamin EJ, Berry JD, Borden WB, Bravata DM, Dai S, Ford ES, Fox CS. Heart disease and stroke statistics -2013 update a report from the american heart association. Circulation. 2013;127:e6-e245

79. Weintraub WS, Daniels SR, Burke LE, Franklin BA, Goff DC, Hayman LL, Lloyd-Jones D, Pandey DK, Sanchez EJ, Schram AP. Value of primordial and primary prevention for cardiovascular disease a policy statement from the american heart association. Circulation. 2011;124:967-990

80. He FJ, Pombo-Rodrigues S, MacGregor GA. Salt reduction in england from 2003 to 2011: Its relationship to blood pressure, stroke and ischaemic heart disease mortality. BMJ open. 2014;4:e004549

81. Liu A, Castillo MG, Capewell S, Lucy J, O'Flaherty M. Reduction in myocardial infarction admissions in liverpool after the smoking ban: Potential socioeconomic implications for policymaking. BMJ open. 2013;3:e003307

82. Hardy ST, Loehr LR, Butler KP, Chang PP, Folsom AR, Heiss G, MacLehose RF, Matsushita K, Avery $\mathrm{CL}$. Absract mp77: Projected impact of shifting population distributions of blood pressure on rates of coronary heart disease, heart failure and stroke: The atherosclerosis risk in communities study. American Heart Association and American Stroke Association Cardiovascular Disease, Epidemiology and Prevention, Nutrition, Physical Activity, and Metabolism 2014 Scientific Sessions. 2014

83. National Cancer Institute SEER. Surveillance, epidemiology, and end result program: Health service areas (hsa). 2008 
84. Bambs C, Kip KE, Dinga A, Mulukutla SR, Aiyer AN, Reis SE. Low prevalence of "ideal cardiovascular health" in a community-based population the heart strategies concentrating on risk evaluation (heart score) study. Circulation. 2011;123:850-857

85. Yang $Q$, Cogswell ME, Flanders WD, Hong $Y$, Zhang Z, Loustalot F, Gillespie C, Merritt R, Hu FB. Trends in cardiovascular health metrics and associations with all-cause and cvd mortality among us adults. JAMA: The Journal of the American Medical Association. 2012;307:1273-1283

86. Huffman MD, Lloyd-Jones DM, Ning H, Labarthe DR, Castillo MG, O'Flaherty M, Ford ES, Capewell S. Quantifying options for reducing coronary heart disease mortality by 2020. Circulation. 2013;127:2477-2484

87. Mozaffarian D, Afshin A, Benowitz NL, Bittner V, Daniels SR, Franch HA, Jacobs DR, Kraus WE, Kris-Etherton PM, Krummel DA. Population approaches to improve diet, physical activity, and smoking habits a scientific statement from the american heart association. Circulation. 2012;126:1514-1563

88. U.S. Department of Health and Human Services. Healthy people 2010. 2010

89. U.S. Department of Health and Human Services Health Resources and Services Administration. Area health resources file. 2013

90. United States Department of Agriculture Economic Research Service. Rural-urban continuum codes. 2013

91. Bee A. Household income inequality within us counties: 2006-2010. Washington, DC: US Census Bureau. 2012

92. Klein RJ, Schoenborn CA. Age adjustment using the 2000 projected us population. 2001

93. Emberson J, Whincup P, Morris R, Walker M, Ebrahim S. Evaluating the impact of population and high-risk strategies for the primary prevention of cardiovascular disease. European heart journal. 2004;25:484-491

94. Foraker RE, Olivo-Marston SE, Allen NB. Lifestyle and primordial prevention of cardiovascular disease: Challenges and opportunities. Current Cardiovascular Risk Reports. 2012;6:520-527

95. Shishehbor MH, Litaker D, Pothier CE, Lauer MS. Association of socioeconomic status with functional capacity, heart rate recovery, and all-cause mortality. JAMA : the journal of the American Medical Association. 2006;295:784-792

96. Groot W, Maassen van den Brink $\mathrm{H}$. The health effects of education. Economics of Education Review. 2007;26:186-200

97. Franzini L, Spears W. Contributions of social context to inequalities in years of life lost to heart disease in texas, USA. Social science \& medicine. 2003;57:1847-1861

98. Monheit AC. Education policy is health policy. Inquiry. 2007;44:233-237

99. Low MD, Low BJ, Baumler ER, Huynh PT. Can education policy be health policy? Implications of research on the social determinants of health. Journal of Health Politics, Policy and Law. 2005;30:1131-1162

100. Pierannunzi C, Hu SS, Balluz L. A systematic review of publications assessing reliability and validity of the behavioral risk factor surveillance system (brfss), 2004-2011. BMC medical research methodology. 2013;13:49

101. Galea S, Tracy M, Hoggatt KJ, DiMaggio C, Karpati A. Estimated deaths attributable to social factors in the united states. Am J Public Health. 2011;101:1456-1465

102. Diez-Roux AV, Nieto FJ, Muntaner C, Tyroler HA, Comstock GW, Shahar E, Cooper LS, Watson RL, Szklo M. Neighborhood environments and coronary heart disease: A multilevel analysis. American journal of epidemiology. 1997;146:48-63

103. Singh GK, Siahpush M, Azuine RE, Williams SD. Increasing area deprivation and socioeconomic inequalities in heart disease, stroke, and cardiovascular disease mortality among working age populations, united states, 1969-2011. International Journal. 2015;3:119-133 
104. Pickett KE, Wilkinson RG. People like us: Ethnic group density effects on health. Ethnicity \& health. 2008;13:321-334

105. Kershaw KN, Osypuk TL, Do DP, De Chavez PJ, Roux AVD. Neighborhood-level racial/ethnic residential segregation and incident cardiovascular disease: The multi-ethnic study of atherosclerosis. Circulation. 2014:CIRCULATIONAHA. 114.011345

106. Egolf B, Lasker J, Wolf S, Potvin L. The roseto effect: A 50-year comparison of mortality rates. American Journal of Public Health. 1992;82:1089-1092

107. Moore CJ, Cunningham SA. Social position, psychological stress, and obesity: A systematic review. Journal of the Academy of Nutrition and Dietetics. 2012;112:518-526

108. Labarthe DR. Epidemiology and prevention of cardiovascular diseases: A global challenge. Jones \& Bartlett Learning; 2011.

109. Cooper R, Cutler J, Desvigne-Nickens P, Fortmann SP, Friedman L, Havlik R, Hogelin G, Marler J, McGovern P, Morosco G. Trends and disparities in coronary heart disease, stroke, and other cardiovascular diseases in the united states: Findings of the national conference on cardiovascular disease prevention. Circulation. 2000;102:3137-3147

110. Mensah GA, Mokdad AH, Ford ES, Greenlund KJ, Croft JB. State of disparities in cardiovascular health in the united states. Circulation. 2005;111:1233-1241

111. Centers for Disease Control and Prevention. Behavioral risk factor surveillance system survey data and documentation. 2014

112. Control CfD, Prevention. Methodologic changes in the behavioral risk factor surveillance system in 2011 and potential effects on prevalence estimates. MMWR. Morbidity and mortality weekly report. 2012;61:410

113. Klein RJ, Schoenborn CA, Statistics NCfH. Healthy people 2010 statistical notes: Age adjustment using the 2000 projected us population. 2001;20:1-12

114. StataCorp. Stata 13 base reference manual: Contrast. College Station, TX: Stata Press; 2013.

115. Li C, Balluz LS, Ford ES, Okoro CA, Zhao G, Pierannunzi C. A comparison of prevalence estimates for selected health indicators and chronic diseases or conditions from the behavioral risk factor surveillance system, the national health interview survey, and the national health and nutrition examination survey, 2007-2008. Preventive medicine. 2012;54:381-387

116. Fries JF, Bruce B, Chakravarty E. Compression of morbidity 1980-2011: A focused review of paradigms and progress. Journal of aging research. 2011;2011:1-10

117. Pearson TA, Palaniappan LP, Artinian NT, Carnethon MR, Criqui MH, Daniels SR, Fonarow GC, Fortmann SP, Franklin BA, Galloway JM. American heart association guide for improving cardiovascular health at the community level, 2013 update a scientific statement for public health practitioners, healthcare providers, and health policy makers. Circulation. 2013;127:17301753

118. Goodman DC, Grumbach K. Does having more physicians lead to better health system performance? JAMA: the journal of the American Medical Association. 2008;299:335-337

119. Gravelle H, Morris S, Sutton M. Are family physicians good for you? Endogenous doctor supply and individual health. Health services research. 2008;43:1128-1144

120. Bigbee JL. Relationships between nurse-and physician-to-population ratios and state health rankings. Public Health Nursing. 2008;25:244-252

121. Shi L. The relationship between primary care and life chances. Journal of health care for the poor and underserved. 1992;3:321-335

122. Macinko J, Starfield B, Shi L. Quantifying the health benefits of primary care physician supply in the united states. International Journal of Health Services. 2007;37:111-126 
123. Gamm L, Castillo G, Pittman S. Access to quality health services in rural areas-primary care: A literature review. LD Gamm, LL Hutchinson, BJ Dabney, BJ and AM Dorsey (Eds.), Rural healthy people. 2010

124. Salsberg ES, Forte GJ. Trends in the physician workforce, 1980-2000. Health Affairs. 2002;21:165-173

125. Dierick-van Daele A, Metsemakers JF, Derckx EW, Spreeuwenberg C, Vrijhoef HJ. Nurse practitioners substituting for general practitioners: Randomized controlled trial. Journal of advanced Nursing. 2009;65:391-401

126. Henry LR, Hooker RS, Yates KL. The role of physician assistants in rural health care: A systematic review of the literature. The Journal of Rural Health. 2011;27:220-229

127. Everett CM, Schumacher JR, Wright A, Smith MA. Physician assistants and nurse practitioners as a usual source of care. The Journal of Rural Health. 2009;25:407-414

128. U.S. Department of Health and Human Services Health Resources Administration. What is a health center? 2014

129. Shi L, Stevens GD. The role of community health centers in delivering primary care to the underserved: Experiences of the uninsured and medicaid insured. The Journal of ambulatory care management. 2007;30:159-170

130. Mundinger MO, Kane RL, Lenz ER, Totten AM, Tsai W-Y, Cleary PD, Friedewald WT, Siu AL, Shelanski ML. Primary care outcomes in patients treated by nurse practitioners or physicians. JAMA: the journal of the American Medical Association. 2000;283:59-68

131. Ricketts TC, Holmes GM. Mortality and physician supply: Does region hold the key to the paradox? Health services research. 2007;42:2233-2251

132. Baker DP, Leon J, Smith Greenaway EG, Collins J, Movit M. The education effect on population health: A reassessment. Population and development review. 2011;37:307-332

133. Albert C, Davia MA. Education is a key determinant of health in europe: A comparative analysis of 11 countries. Health promotion international. 2011;26:163-170

134. Sox CM, Swartz K, Burstin HR, Brennan TA. Insurance or a regular physician: Which is the most powerful predictor of health care? American Journal of Public Health. 1998;88:364-370

135. Farmer FL, Stokes CS, Fiser RH, Papini DP. Poverty, primary care and age-specific mortality*. The Journal of Rural Health. 1991;7:153-169

136. Shi L, Macinko J, Starfield B, Wulu J, Regan J, Politzer R. The relationship between primary care, income inequality, and mortality in us states, 1980-1995. The Journal of the American Board of Family Practice. 2003;16:412-422

137. McCarthy M. Us production of new primary care doctors falls far short of need, study finds. BMJ: British Medical Journal. 2013;346

138. Kruse J. Income ratio and medical student specialty choice: The primary importance of the ratio of mean primary care physician income to mean consulting specialist income. Family medicine. 2013;45:281

139. Petterson SM, Phillips Jr RL, Bazemore AW, Teevan BB, Koinis GT. Relying on nps and pas does not avoid the need for policy solutions for primary care. American family physician. 2013;88:230

140. CDC. Ten great public health achievements--united states, 2001-2010. MMWR. Morbidity and mortality weekly report. 2011;60:619

141. Schmid TL, Pratt M, Howze E. Policy as intervention: Environmental and policy approaches to the prevention of cardiovascular disease. American Journal of Public Health. 1995;85:1207-1211

142. Green LW, Ottoson J, GarcÃ-a Cs, Robert H. Diffusion theory and knowledge dissemination, utilization, and integration in public health. Annual Review of Public Health. 2009;30:151

143. Chriqui JF, O'Connor JC, Chaloupka FJ. What gets measured, gets changed: Evaluating law and policy for maximum impact. The Journal of Law, Medicine \& Ethics. 2011;39:21-26 
144. Fleegler Ew LLKMMCHDMR. Firearm legislation and firearm-related fatalities in the united states. 2013:1-9

145. Naimi TS, Blanchette J, Nelson TF, Nguyen T, Oussayef N, Heeren TC, Gruenewald P, Mosher J, Xuan Z. A new scale of the us alcohol policy environment and its relationship to binge drinking. American journal of preventive medicine. 2014;46:10-16

146. Gilpin EA, Stillman FA, Hartman AM, Gibson JT, Pierce JP. Index for us state tobacco control initial outcomes. American journal of epidemiology. 2000;152:727-738

147. Taber DR, Chriqui JF, Perna FM, Powell LM, Chaloupka FJ. Weight status among adolescents in states that govern competitive food nutrition content. Pediatrics. 2012;130:437-444

148. Nanney MS, Nelson T, Wall M, Haddad T, Kubik M, Laska MN, Story M. State school nutrition and physical activity policy environments and youth obesity. American journal of preventive medicine. 2010;38:9-16

149. Bibbins-Domingo K, Chertow GM, Coxson PG, Moran A, Lightwood JM, Pletcher MJ, Goldman L. Projected effect of dietary salt reductions on future cardiovascular disease. New England Journal of Medicine. 2010;362:590-599

150. Dummit LA. Primary care physician supply, physician compensation, and medicare fees: What is the connection. Issue Brief Natl Health Policy Forum. 2008;827:1-13

151. Wilson N, Couper I, De Vries E, Reid S, Fish T, Marais B. A critical review of interventions to redress the inequitable distribution of healthcare professionals to rural and remote areas. Rural \& Remote Health. 2009;9

152. Bärnighausen T, Bloom DE. Financial incentives for return of service in underserved areas: A systematic review. BMC health services research. 2009;9:86

153. Buykx P, Humphreys J, Wakerman J, Pashen D. Systematic review of effective retention incentives for health workers in rural and remote areas: Towards evidence-based policy. Australian Journal of Rural Health. 2010;18:102-109

154. Rayack E. Medical licensure. Law and Human Behavior. 1983;7:147-156

155. The Henry J. Kaiser Family Foundation. State health facts: Medicaid-to-medicare fee index. 2012

156. Association of American Medical Colleges. Loan repayment/forgiveness and scholarship programs. 2014

157. Federation of State Medical Boards. State-specific requirements for initial medical licensure. 2015

158. Barton Associates. State physician licensing guide. 2015

159. Barton Associates. Np scope of practice laws. 2014

160. American Academy of Physician Assistants. State law issues: The six key elements of a modern physician assistant practice act. 2011

161. Barton Associates. Pa scope of practice law guide. 2014

162. University of Wisconsin's Population Health I. County health rankings and roadmaps: A healthier nation county by county. 2013;2013

163. Hooker RS, Cawley JF. Physician assistants in american medicine. Churchill Livingstone St. Louis; 2003.

164. Mayhew BH. Structuralism versus individualism: Part 1, shadowboxing in the dark. Social Forces. 1980;59:335-375

165. Rose G. Sick individuals and sick populations. International journal of epidemiology. 2001;30:427-432 